University of Texas at El Paso

\title{
DigitalCommons@UTEP
}

Open Access Theses \& Dissertations

2014-01-01

\section{Hydrogen Generation from Ammonia Borane and Water through the Combustion Reactions with Mechanically Alloyed Al/Mg Powder}

Daniel Rodriguez

University of Texas at El Paso, darodriguez8@miners.utep.edu

Follow this and additional works at: https://digitalcommons.utep.edu/open_etd

Part of the Chemical Engineering Commons, Materials Science and Engineering Commons, Mechanical Engineering Commons, and the Mechanics of Materials Commons

\section{Recommended Citation}

Rodriguez, Daniel, "Hydrogen Generation from Ammonia Borane and Water through the Combustion Reactions with Mechanically Alloyed Al/Mg Powder" (2014). Open Access Theses \& Dissertations. 1338.

https://digitalcommons.utep.edu/open_etd/1338 
HYDROGEN GENERATION FROM AMMONIA BORANE AND WATER THROUGH THE Combustion Reactions with Mechanically Alloyed Al/Mg Powder

\section{DANIEL RODRIGUEZ}

Department of Mechanical Engineering

\section{APPROVED:}

Evgeny Shafirovich, Ph.D., Chair

Yirong Lin, Ph.D.

David A. Roberson, Ph.D.

Charles Ambler, Ph.D.

Dean of the Graduate School 
Copyright (C)

by

Daniel Rodriguez

2014 


\section{Dedication}

I dedicate this thesis to my family for cherishing me with love and affections and their beloved partnership for success in my life. 


\title{
HYDROGEN GENERATION FROM AMMONIA BORANE AND WATER THROUGH THE COMBUSTION REACTIONS WITH MECHANICALLY ALLOYED AL/MG POWDER
}

\author{
by \\ DANIEL RODRIGUEZ
}

\begin{abstract}
THESIS
Presented to the Faculty of the Graduate School of The University of Texas at El Paso

in Partial Fulfillment

of the Requirements

for the Degree of

MASTER OF SCIENCE

Department of Mechanical Engineering

THE UNIVERSITY OF TEXAS AT EL PASO
\end{abstract}

August 2014 


\section{Acknowledgements}

I would like to express my gratitude to my advisor, Dr. Evgeny Shafirovich, whose expertise, understanding, and patience, added considerably to my graduate experience. I appreciate his vast knowledge and skills in many areas, and his assistance in writing reports. I thank him for offering me this great opportunity. I also want to thank Dr. Edward Dreizin and his team at the New Jersey Institute of Technology for providing the reactive materials that made possible this research.

I understand that this research would not have been possible without the financial assistance of the U.S Department of Defense, Grant W911NF-12-1-0056 (Grants Officer's Representative (GOR): Dr. Ralph Anthenien, Co-GOR: Dr. Clifford Bedford). Also, equipment obtained through Grant W911NF14-1-0034 (the same Program Managers) was partly used in this research.

I would like to thank my co-workers Marco Machado, Ashvin Kumar Narayana Swamy, Armando Delgado, and Mohammad Shafiul Alam for always being friendly and helpful. Last but not least, I would also like to thank my family for the support they provided me through my entire life. 


\begin{abstract}
Finding and developing a safe and effective method for hydrogen storage is integral to its use as an alternative source of energy. The goal of the studies described in this thesis was to investigate the feasibility of developing combustible hydrogen-generating compositions based on ammonia borane and novel energetic materials such as nanocomposite and mechanically alloyed reactive materials, recently obtained by Prof. Edward Dreizin's team at the New Jersey Institute of Technology (NJIT). Such compositions could be stored for long time and release hydrogen on demand, upon ignition. The first phase of the research included thermodynamic calculations for combustion of ammonia borane with various reactive materials obtained at NJIT. The second phase involved experiments with compositions that appeared to be promising based on thermodynamic calculations. An experimental setup with laser ignition of mixtures was developed for these experiments. As a result of these tests, further work was focused on mixtures of ammonia borane, gelled water, and mechanically alloyed $\mathrm{Al} / \mathrm{Mg}$ powder. The last part of the research revealed the reaction mechanisms during combustion of these mixtures. For this purpose, isotopic tests, involving use of heavy water and mass-spectroscopy of gaseous combustion products, were conducted. The results of the present work indicate that combustible mixtures of ammonia borane, water, and mechanically alloyed $\mathrm{Al} / \mathrm{Mg}$ powder are promising for the development of hydrogen generators that release large amounts of hydrogen upon ignition.
\end{abstract}




\section{Table of Contents}

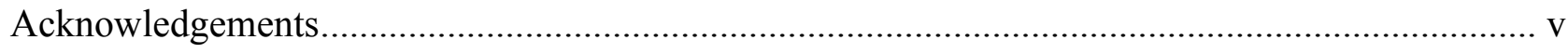

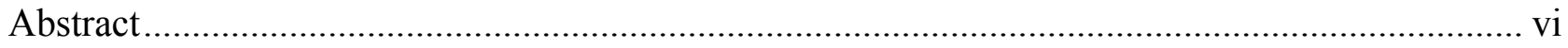

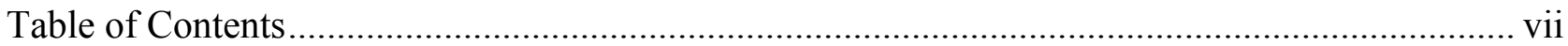

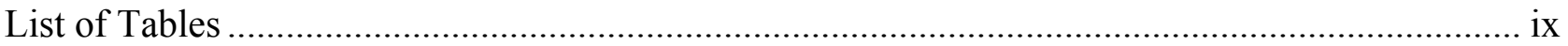

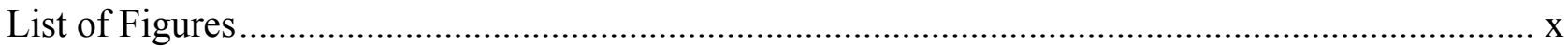

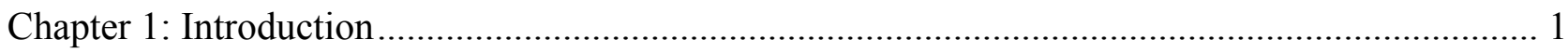

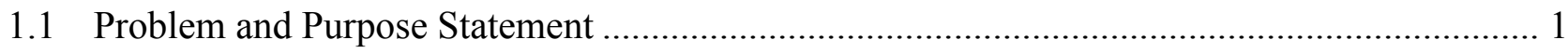

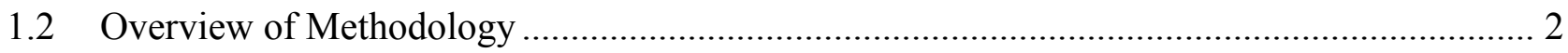

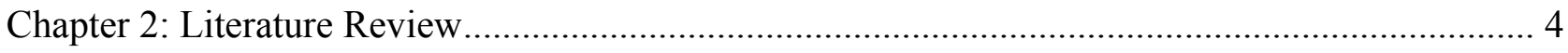

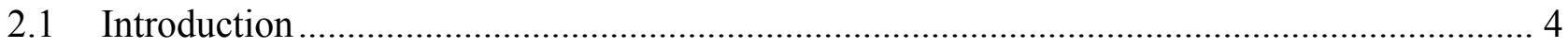

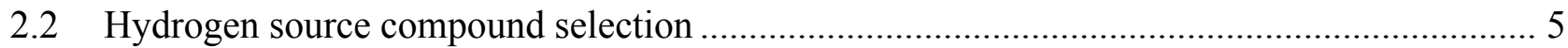

2.3 Methods for releasing hydrogen from ammonia borane ........................................ 10

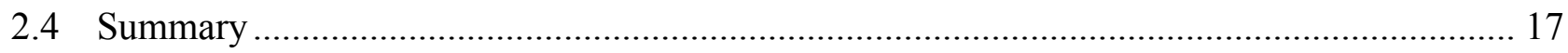

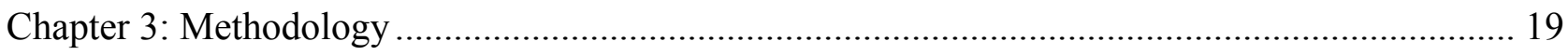

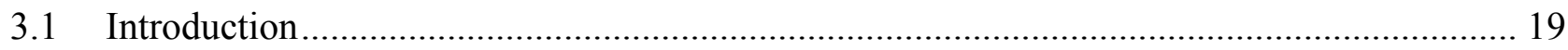

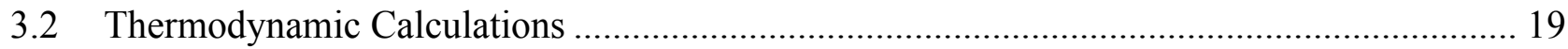

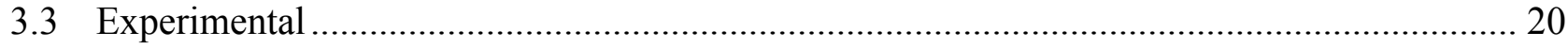

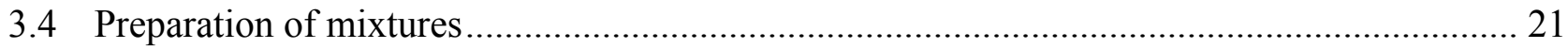

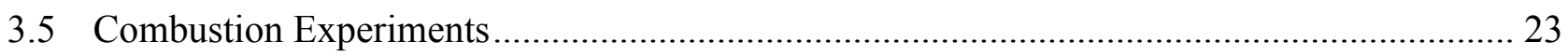

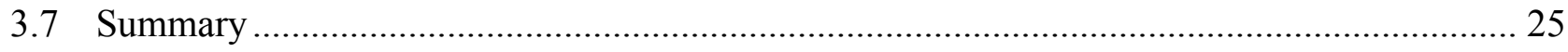

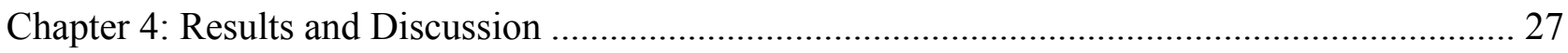

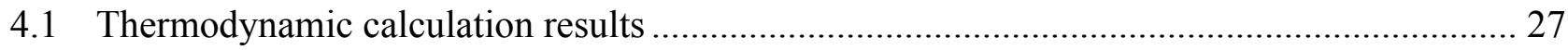

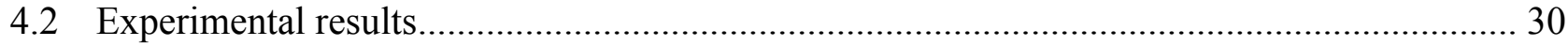

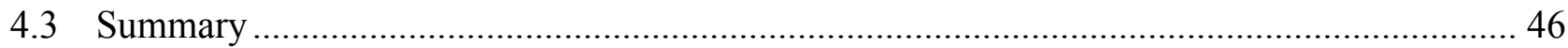

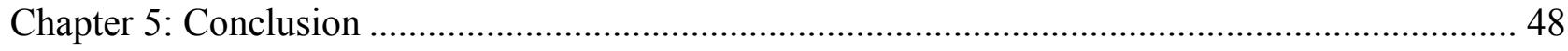

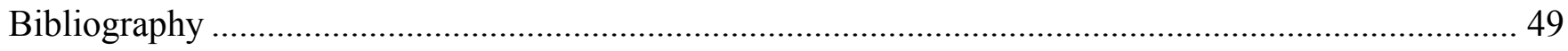




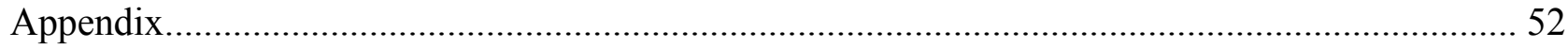

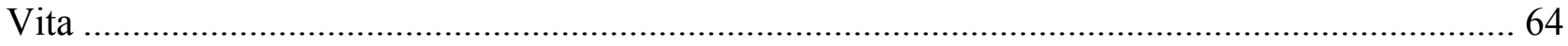




\section{List of Tables}

Table 1. Hydrogen generation from different chemical hydrides (8) ............................................ 10

Table 2. Reactive materials produced at the NJIT (4) ............................................................ 17

Table 3. The amounts of additives to ammonia borane that provide the adiabatic flame temperature of $1500^{\circ} \mathrm{C}$ and the values of $\mathrm{H}_{2}$ mole and mass fractions in the combustion products for these compositions. 


\section{List of Figures}

Figure 1. Comparison of hydrogen release from various boron-based chemical hydrides (8) ................. 7

Figure 2. Comparison of hydrogen release from various nitrogen-based chemical hydrides (8)............. 9 Figure 3. Particle evolution for an $\mathrm{Al}_{0.7} \mathrm{Mg}_{0.3}$ composite: (left) end of first milling stage; (center) immediately after addition of iodine; (right) final product after completion of second milling stage (31).

Figure 4. Schematic diagram of the experimental setup for laser ignition of the pellets.

Figure 5. The adiabatic flame temperature and hydrogen content in the products for the mixture of ammonia borane with $\mathrm{Al} / \mathrm{Ni}$ as a reactive material.

Figure 6. The adiabatic flame temperature and hydrogen content in the products for the mixture of

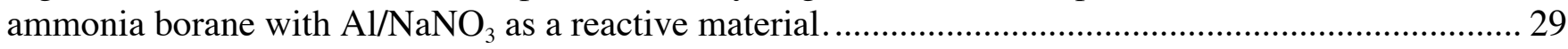

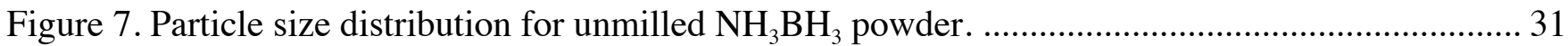

Figure 8. Particle size distribution for milled $\mathrm{NH}_{3} \mathrm{BH}_{3}$ powder. ................................................. 31

Figure 9. Combustion of $\mathrm{Al} / \mathrm{Mg}$-water mixture $\left(46.5 \mathrm{wt} \% \mathrm{H}_{2} \mathrm{O}\right)$ with $3 \mathrm{wt} \%$ polyacrylamide. ............. 32 Figure 10. Combustion front velocities in $\mathrm{Al} / \mathrm{Mg}$-water mixtures at $3 \mathrm{wt} \%$ polyacrylamide with respect

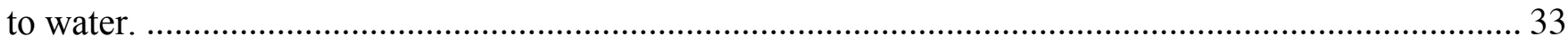

Figure 11. Hydrogen yield in $\mathrm{Al} / \mathrm{Mg}$-water mixtures at $3 \mathrm{wt} \%$ polyacrylamide with respect to water. .. 34 Figure 12. Combustion front velocities in $\mathrm{Al} / \mathrm{Mg}$-water mixtures at $1 \mathrm{wt} \%$ poly(acrylamide-co-acrylic

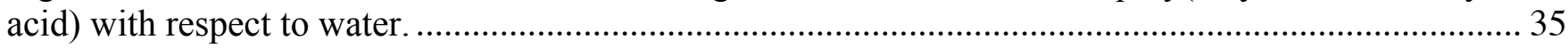

Figure 13. Hydrogen yield in $\mathrm{Al} / \mathrm{Mg}$-water mixtures at $1 \mathrm{wt} \%$ poly(acrylamide-co-acrylic acid) with

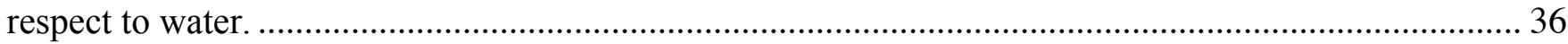

Figure 14. Comparison between $\mathrm{H}_{2}$ yield calculated from pressure readings (3\% polyacrylamide) and mass-spectrometer results.

Figure 15. XRD pattern of combustion products for the mixture of water and mechanically alloyed

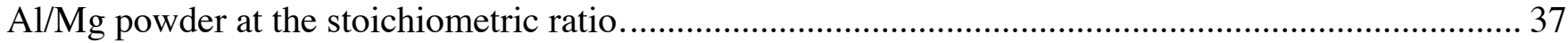

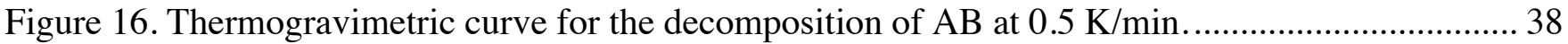

Figure 17. Thermogravimetric curve for $\mathrm{Al} / \mathrm{Mg}$ and $\mathrm{AB}$ mixture (1:1 mass ratio)............................ 39

Figure 18. Combustion of mixture \#3. Images taken at 1, 2, 3 and $5 \mathrm{~s}$ after ignition. ....................... 40

Figure 19. Combustion front velocity for each mixture. ..................................................... 41

Figure 20. Total amount of $\mathrm{H}_{2}$ (in moles) per unit mass of the total mixture .................................... 42

Figure 21. Total amount of HD (in moles) per unit mass of the total mixture. .................................. 43

Figure 22. Total amount of $\mathrm{D}_{2}$ (in moles) per unit mass of the total mixture ................................... 43

Figure 23. Released fraction of total available $\mathrm{H}$ via $\mathrm{AB}$ thermolysis and $\mathrm{AB}$ hydrolysis.................... 44

Figure 24. Released fraction of total available $\mathrm{D}$ via $\mathrm{Al} / \mathrm{Mg}$ hydrolysis and $\mathrm{AB}$ hydrolysis................. 44 Figure 25. Theoretical gravimetric hydrogen yield of $\mathrm{AB} / \mathrm{H}_{2} \mathrm{O} / \mathrm{Al} / \mathrm{Mg}$ mixtures and its experimental values, obtained by recalculating the data obtained in experiments with $\mathrm{AB} / \mathrm{D}_{2} \mathrm{O} / \mathrm{Al} / \mathrm{Mg}$ mixtures...... 45

Figure 26. XRD pattern of the product obtained after combustion of mixture \#2 ............................ 46 


\section{Chapter 1: Introduction}

The overarching goal of the proposed research is to develop application-customized chemical gas generators based on novel energetic materials that will exhibit improved effectiveness, process stability, and fire safety. Chemical gas generators typically include a solid compound that decomposes at increased temperatures and various heat-generating additives.

The development of efficient, compact and reliable energy storage system based on hydrogen production represents a challenge. Several hydrogen generating compositions such as ammonia borane or sodium borohydride have been studied. The compositions also include a reactive material or an oxidizer that would produce hydrogen from the hydrogen source by thermolysis, hydrolysis or both. As a result, hydrogen is generated through a self-sustained propagation of the reaction wave over the generator's chemical core.

The project objective is to determine the characteristics and reaction mechanisms of gasgenerating compositions involving novel nanocomposite and mechanically alloyed reactive materials, produced by arrested reactive milling, a technique developed recently at the New Jersey Institute of Technology (NJIT).

\subsection{Problem and Purpose Statement}

The requirement for efficient and safe methods for hydrogen storage is a major problem that must be overcome to allow the use of hydrogen as an alternative energy carrier. Even though many hydride complexes have certain features that might be attractive for chemical hydrogen storage, the large hydrogen capacities needed for transportation applications exclude most compounds. A promising compound such as ammonia borane $\left(\mathrm{AB}, \mathrm{NH}_{3} \mathrm{BH}_{3}\right)$ contains $19.6 \mathrm{wt} \% \mathrm{H}_{2}(1)$ (2), as well as possesses storage stability and non-toxicity. Therefore, $\mathrm{AB}$ has a remarkable potential for storing and delivering large amounts of hydrogen through dehydrogenation reactions.

Despite the fact that $\mathrm{NH}_{3} \mathrm{BH}_{3}$ has a negative formation enthalpy $(-178 \mathrm{~kJ} / \mathrm{mol})(1)$, it is not able to maintain a self-sustained combustion due to heat losses; therefore, energetic additives need to be added. Previous work has shown that hydrogen can be released from $A B$ hydrolytically and thermolytically (3). These processes are further discussed in Chapter 2 and 3. The requirements for 
hydrogen release for utilization in fuel cells are fast, controlled, and complete release. Thus, in order to achieve a high energy material weight percent, the amount of $\mathrm{AB}$ has to be maximized and most of the hydrogen needs to be released or the hydrogen yield will be low.

The energetic additives proposed include metal-metal, metal-metalloid, and metal-oxide (thermite) reactive nanocomposites as well as mechanically alloyed materials (4) (5). These new energetic materials could produce the required heat for achieving a complete thermolysis process of $\mathrm{AB}$. It was hypothesized that with these materials, hydrogen generators could display improved effectiveness. Testing this hypothesis requires measurements of the amount of energetic additive needed for having a self-sustained combustion process, the combustion front velocity, as well as the hydrogen yield. Comparison of the combustion characteristics for different energetic additives permits one to analyze the potential effect that they could provide for the production of hydrogen from AB.

\subsection{Overview of Methodology}

Initial selection of the most promising energetic additive candidates was based on thermodynamic calculations of the adiabatic flame temperatures and product compositions. Then the mixtures were compared based on the amount of additive needed for achieving the desired temperatures for decomposing AB. Once the best candidates were selected, experiments were conducted.

The first step of the experimental procedure was to test if the suggested energetic additives were reliable. Therefore, experiments were conducted for the most promising additives. As a result of these experiments, a mixture of $\mathrm{AB}$, gelled water and mechanically alloyed $\mathrm{Al} / \mathrm{Mg}$ powder was selected for a detailed investigation.

The second step was to analyze the combustion characteristics and measuring the hydrogen yield via different methods described in Chapter 3 and 4. Combustion experiments were conducted by making a pellet or a water-gelled mixture composed of the hydrogen source $\left(\mathrm{NH}_{3} \mathrm{BH}_{3}\right)$ and the desired energetic additive. Diagnostics were provided by a high-resolution video camera for visualization of the combustion wave propagation and measurement of the combustion front velocity. The pressure increase due to the gas formation was measured using a pressure transducer, which allowed calculating (using the ideal gas equation) the mass of produced hydrogen. The hydrogen yield was also calculated using mass- 
spectroscopy and then compared with the results acquired from the pressure increase. Isotopic tests (deuterium) were used for revealing the reaction mechanisms. 


\section{Chapter 2: Literature Review}

\section{$2.1 \quad$ Introduction}

President George W. Bush in 2003 announced the hydrogen fuel initiative, the main goals of which were the development of new technologies for the production, storage, and distribution of hydrogen. However, in order to have a competitive hydrogen energy market, its economy has to be as good as the current hydrocarbon based energy economy. Hydrogen offers several benefits as an energy carrier, it is not a pollutant as well as it is used for fuel cells applications (6).

There are many hurdles that prevent the implementation of a hydrogen economy. The main is the effort in replacing the current energy system based on gasoline, coal and natural gas. This is because these energy carriers are easy to transport and handle, and are inexpensive at the moment. They have the extra benefit of years of optimization and infrastructure that hydrogen does not have yet. However, in the near future new energy sources such as hydrogen are expected to replace this type of system. Currently, there is a need for portable systems that can generate hydrogen on demand. Such hydrogen generators could be used, for example, in fuel cell power systems for portable and mobile applications. This explains the importance of this study (6).

The overall study in this thesis focuses on the use of a chemical hydride, ammonia borane (AB), as a potentially efficient material for hydrogen storage. The main goals of this research are to develop a novel, combustion-based method for increasing the rate and extent of $\mathrm{H}_{2}$ release from $\mathrm{AB}$ and to interpret the mechanisms formed during the combustion process.

\subsubsection{Current hydrogen production process}

Mostly all hydrogen (around 95\%) is produced from natural gas. Steam at high temperatures $\left(700^{\circ} \mathrm{C}\right.$ to $\left.1000^{\circ} \mathrm{C}\right)$ is used to split methane to carbon monoxide and hydrogen. The overall reaction is explained in Equation 1 (5).

$$
\mathrm{CH}_{4}+\mathrm{H}_{2} \mathrm{O} \rightarrow \mathrm{CO}+3 \mathrm{H}_{2}
$$

The main concern is that if hydrogen is produced from hydrocarbons, then the hydrocarbon fuel sources will be exhausted earlier and pollution would still be a social problem since large amounts of 
carbon dioxide are produced. This is because carbon monoxide will eventually oxidize to carbon dioxide. Consequently, alternative hydrogen production methods are required for creating an environmental friendly world.

\subsubsection{Storability of Hydrogen}

Metrics developed by the U.S. Department of Energy (DOE) state that hydrogen, as an energy source, has to be economically viable compared to gasoline (7). Main methods currently used for hydrogen storage involve high-pressure (typically 350 bar or 700 bar) tanks for gaseous $\mathrm{H}_{2}$ and cryogenic $(20 \mathrm{~K})$ tanks for liquid $\mathrm{H}_{2}$. The development of novel materials for hydrogen storage offers a promising alternative to the conventional methods owing to the higher hydrogen density in these compounds than in gas or liquid hydrogen storage systems. Under the category of materials there are some subcategories: reversible metal hydrides, carbon absorption materials, and chemical hydrides. Owing to the high hydrogen yield (weight of $\mathrm{H}_{2}$ / total weight of the compound) that chemical hydrogen storage offers, research has been focused on boron hydrides such as sodium borohydride, ammonium borohydride, and ammonia borane (AB) (8).

In addition, one main goal for DOE is to maximize the total system weigh percent. For

understanding, the total system weight percent is the weight of hydrogen produced, divided by the weight of the fuel system including tanks, heaters, tubing, materials and so on. Therefore, in order to achieve an appealing total system weight percent, the material weight percent should be much higher than the total weight of the supplementary equipment. This makes $\mathrm{AB}$ an attractive compound because of its high $\mathrm{H}_{2}$ content and feasibility for easy storage.

\subsection{Hydrogen source compound selection}

Boron-based and nitrogen-based chemical hydrogen storage materials such as borohydrides (e.g. $\mathrm{LiBH}_{4}$ and $\left.\mathrm{NaBH}_{4}\right)$ and $\mathrm{AB}\left(\mathrm{NH}_{3} \mathrm{BH}_{3}\right)$, are promising compounds for hydrogen storage because of the high $\mathrm{H}_{2}$ content (9) (10) (11). Different applications for dehydrogenation of these compounds have been studied. 


\subsubsection{Borohydrides}

Among borohydrides, $\mathrm{LiBH}_{4}$ is a compound that contains $18 \mathrm{wt} \%$ hydrogen (12). Thermolysis of $\mathrm{LiBH}_{4}$ is possible: heating it to $368 \mathrm{~K}$ and below $623 \mathrm{~K}$ releases a large amount of hydrogen $(>10 \mathrm{wt} \%)$. Recent efforts have been dedicated to the incorporation of additives such as metal oxides, metal hydrides, metal halides, sulfides, nanoporous scaffolds, or lithium amide for thermal decomposition of borohydrides at a lower energy input. An alternative way for the release of hydrogen is through hydrolysis (13) (14). However, for this process $\mathrm{NaBH}_{4}$ has been more widely studied because this compound offers a safe and low-cost practical route for the production of hydrogen. The main reaction for the hydrolysis process of $\mathrm{NaBH}_{4}(15)$ (16) is shown in Equation 2.

$$
\mathrm{NaBH}_{4}+2 \mathrm{H}_{2} \mathrm{O} \rightarrow \mathrm{NaBO}_{2}+4 \mathrm{H}_{2}(2)
$$

Different catalysts have been added to the reaction such as $\mathrm{Pt}-\mathrm{LiCoO}_{2}$ which is the most promising catalyst for this reaction. Hydrogen generation from the hydrolysis of $\mathrm{NaBH}_{4}$ can be an excellent alternative for $\mathrm{H}_{2}$ production; however, this process is not reversible making it a single-use application.

\subsubsection{Ammonia Borane}

Ammonia borane contains more hydrogen than $\mathrm{LiBH}_{4}$, which makes this compound very appealing. As stated before, AB can be decomposed by thermolysis, hydrolysis, or both (17) (18). The section named Mechanism of combustion will explain this in detail. Figure 1 compares the hydrogen release from several boron-based chemical hydrides at different temperatures. The dehydrogenation temperatures for the $\mathrm{LiBH}_{4}$ are very high; on the other hand, the temperatures of the $\mathrm{NaBH}_{4}$ hydrolysis and the $\mathrm{NH}_{3} \mathrm{BH}_{3}$ hydrolysis and thermolysis are somewhat low. This makes $\mathrm{AB}$ the most interesting candidate for hydrogen storage, which is why it was selected for this investigation. 


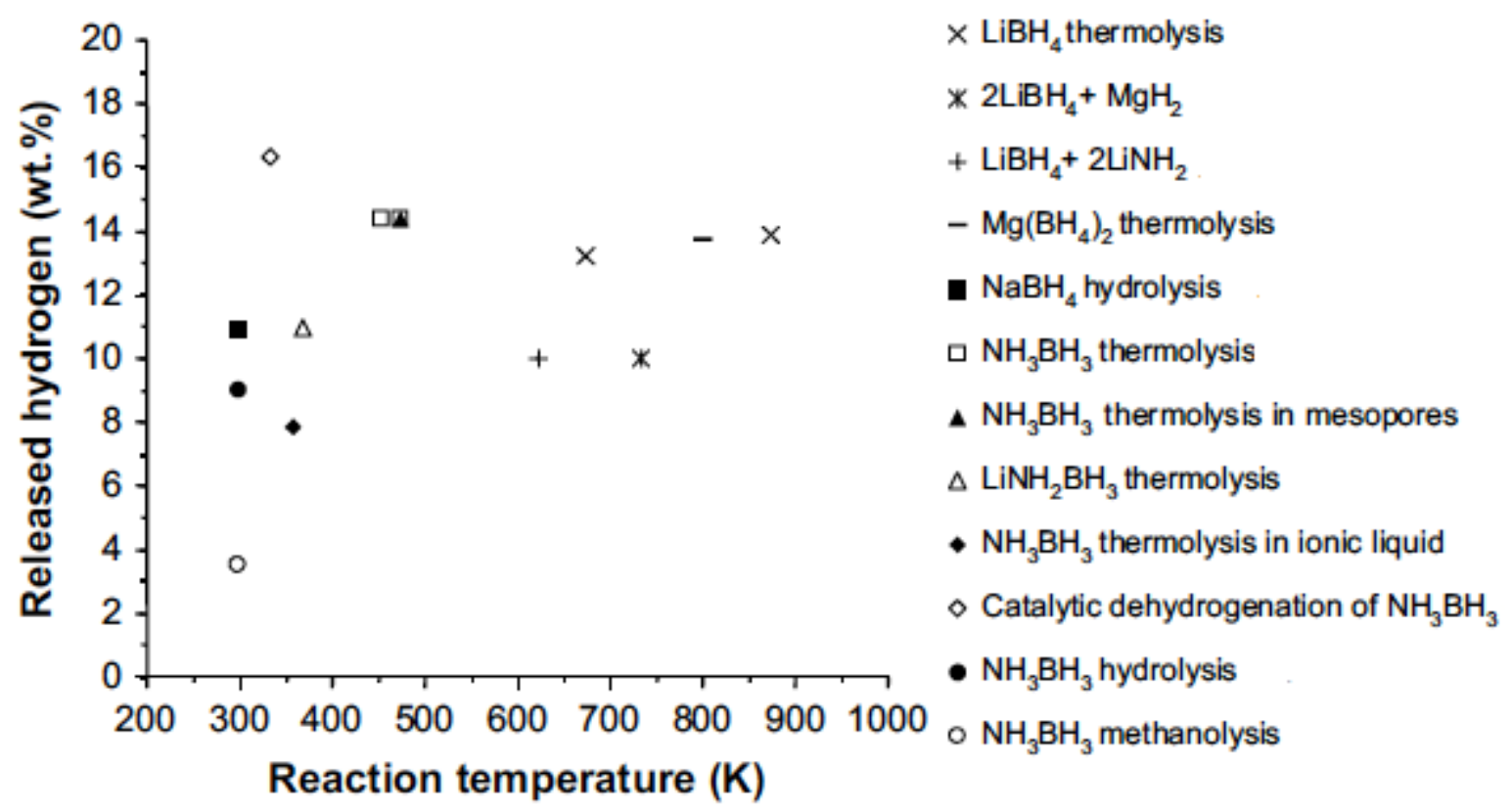

Figure 1. Comparison of hydrogen release from various boron-based chemical hydrides (8).

\subsubsection{Nitrogen-based hydrogen storage materials}

An interesting alternative to borohydrides could be nitrogen-based chemical hydrogen storage materials such as metal-N-H systems, ammonia, and hydrazine. These materials also offer an excellent potential for hydrogen storage due to the high content of $\mathrm{H}_{2}$.

\subsubsection{Metal-N-H systems}

Li-N-H hydrogen storage system is a promising alternative for $\mathrm{H}_{2}$ production. In 1910 , it was discovered that $\mathrm{LiNH}_{2}$ can be generated alongside $\mathrm{LiH}$ via the reaction (8) (9):

$$
\mathrm{Li}_{3} \mathbf{N}+2 \mathrm{H}_{2} \rightarrow \mathrm{LiNH}_{2}+2 \mathrm{LiH}
$$

Different additives such as metals and oxides have been used to improve the kinetics and lower the decomposition temperature. For example, the addition of $\mathrm{TiCl}_{3}$ to a mixture of $\mathrm{LiNH}_{2} / \mathrm{LiH}(1: 1$ molar ratio) can lower the dehydrogenation temperature from $673 \mathrm{~K}$ to $573 \mathrm{~K}$ in conjunction with faster kinetics. 
This system offers the potential for hydrogen production; still further improvements are required for achieving reasonable applications at reasonable temperatures. Furthermore, it was revealed that ammonia is formed as a reaction by-product of the metal-N-H systems, making it faulty for fuel cell applications because of electrode poisoning.

\subsubsection{Ammonia}

Ammonia $\left(\mathrm{NH}_{3}\right)$ contains $17.7 \mathrm{wt} \%$ hydrogen. This compound is normally encountered as a gas, but it can be liquefied under reasonable conditions. Ammonia can be decomposed to hydrogen and nitrogen by the following reaction (19) (20):

$$
2 \mathrm{NH}_{3} \rightarrow \mathrm{N}_{2}+3 \mathrm{H}_{2}
$$

This reaction is endothermic, thus it has a positive formation enthalpy of $92 \mathrm{~kJ} / \mathrm{mol}$. High temperatures are required for an efficient hydrogen generation. Consequently, various supported catalysts have been studied. Ruthenium catalysts are the most commonly used, which allows $80 \%$ conversion of $\mathrm{NH}_{3}$ to hydrogen at $673 \mathrm{~K}$. Ammonia could be a promising source of hydrogen, yet its toxic properties make it unusable for most applications.

\subsubsection{Hydrazine}

Hydrazine contains $12.6 \mathrm{wt} \%$ hydrogen (8). This compound is a colorless oily liquid that fumes in air. It is extremely toxic. It is also hypergolic, meaning that it reacts and explodes upon contact with oxidizing agents. Hydrazine needs to be stored under an inert gas atmosphere and its decomposition is controllable in the presence of a catalyst. Several catalysts have been studied; some require high temperatures for the decomposition of hydrazine, while others can allow hydrogen generation at room temperature. This means that the selection of catalysts is important for hydrogen generation from hydrazine.

Figure 2 compares the hydrogen release from different nitrogen-based chemical hydrides. The released hydrogen wt\% is calculated by measuring the total amount of hydrogen released divided by the total weigh of the hydrogen storage material plus the weight of the reactants. 


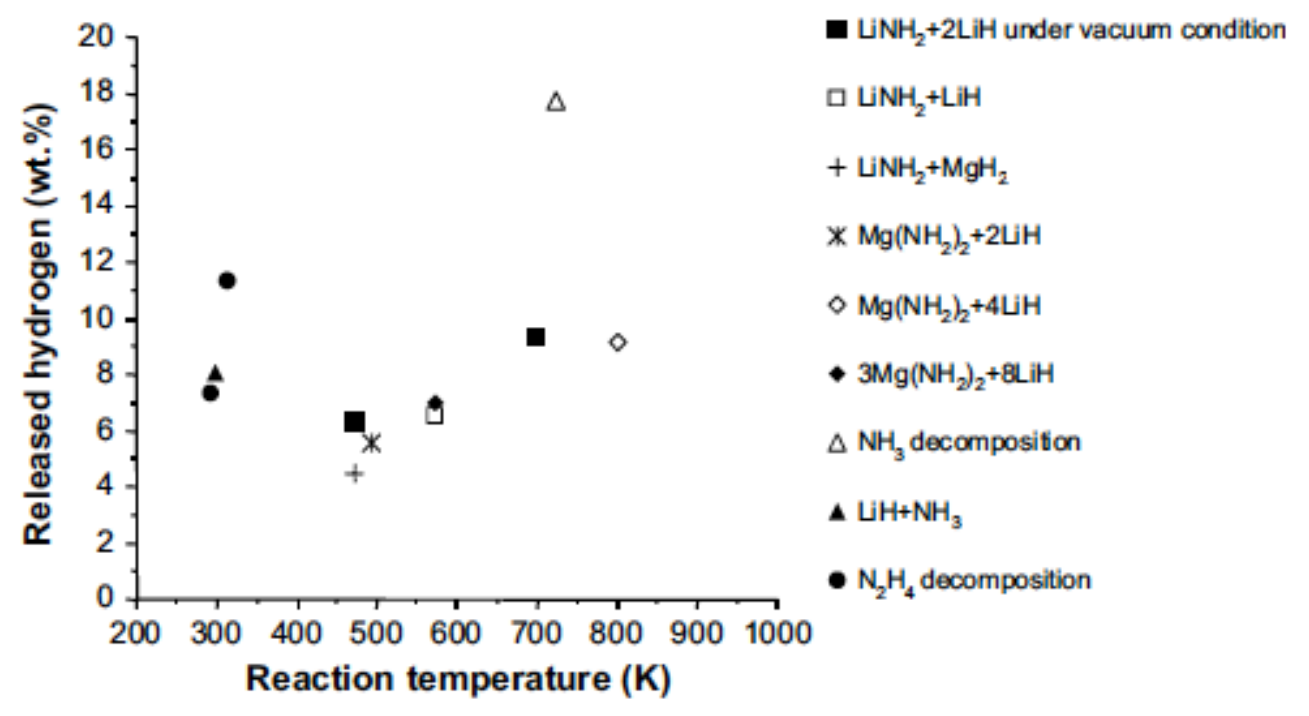

Figure 2. Comparison of hydrogen release from various nitrogen-based chemical hydrides (8).

\subsubsection{Conclusion for selection of hydrogen storing material}

Due to their high hydrogen contents, boron and nitrogen based hydrogen storage materials offer great potential for transportation, storage and production of hydrogen. Among all, ammonia borane was selected because of its high hydrogen content, stability at normal conditions, and its versatility for decomposition. In the 2003 hydrogen initiative, ammonia borane was recognized as an excellent and promising hydrogen storage candidate. This surpasses the US DOE goals for gravimetric and volumetric hydrogen density. Its stability at room temperatures and non-toxicity increased this appeal.

Table 1 summarizes the hydrogen yields and power levels using the chemical hydrogen storage materials mentioned before. 
Table 1. Hydrogen generation from different chemical hydrides (8).

\begin{tabular}{|c|c|c|}
\hline Reaction & $\begin{array}{l}\text { Hydrogen yield } \\
\text { ( } \mathrm{g} \mathrm{H}_{2} / \mathrm{g} \text { reactant) }\end{array}$ & $\begin{array}{c}\text { Capacity }^{\mathrm{a}} \\
\text { (Wh/g reactant) }\end{array}$ \\
\hline $\begin{array}{c}\mathrm{LiBH}_{4}+2 \mathrm{LiNH}_{2} \\
\mathrm{Li}_{3} \mathrm{BN}_{2}+4 \mathrm{H}_{2}\end{array}$ & 0.119 & 2.25 \\
\hline $\begin{array}{c}\mathrm{NaBH}_{4}+2 \mathrm{H}_{2} \mathrm{O} \rightarrow \\
\mathrm{NaBO}_{2}+4 \mathrm{H}_{2}\end{array}$ & 0.109 & 2.06 \\
\hline $\begin{array}{l}\mathrm{NH}_{3} \mathrm{BH}_{3} \rightarrow \\
\quad \mathrm{NHBH}+2 \mathrm{H}_{2}\end{array}$ & 0.131 & 2.47 \\
\hline $\begin{array}{c}\mathrm{NH}_{3} \mathrm{BH}_{3}+2 \mathrm{H}_{2} \mathrm{O} \rightarrow \\
\mathrm{NH}_{4} \mathrm{BO}_{2}+3 \mathrm{H}_{2}\end{array}$ & 0.090 & 1.71 \\
\hline $\begin{array}{l}\mathrm{LiNH}_{2}+\mathrm{LiH} \rightarrow \\
\mathrm{Li}_{2} \mathrm{NH}+\mathrm{H}_{2}\end{array}$ & 0.065 & 1.23 \\
\hline $2 \mathrm{NH}_{3} \rightarrow \mathrm{N}_{2}+3 \mathrm{H}_{2}$ & 0.178 & 3.35 \\
\hline $\begin{array}{l}\mathrm{LiH}+\mathrm{NH}_{3} \rightarrow \\
\mathrm{LiNH}_{2}+2 \mathrm{H}_{2}\end{array}$ & 0.081 & 1.52 \\
\hline $\mathrm{N}_{2} \mathrm{H}_{4} \rightarrow \mathrm{N}_{2}+2 \mathrm{H}_{2}$ & 0.126 & 2.38 \\
\hline
\end{tabular}

Based on the previous table, it can be concluded that ammonia borane along with ammonia are the most energy efficient chemical hydrides. However, ammonia has toxic properties that make it impossible to use in most applications. As a result, ammonia borane appears to be an appealing candidate for the production of hydrogen as a source of energy.

\subsection{Methods for releasing hydrogen from ammonia borane}

This section will describe the main methods for releasing hydrogen from ammonia borane. The main reactions involved for each process will be explained. The addition of energetic additives produced at the NJIT could aid for the production of hydrogen from AB. This section will include the reaction mechanisms for $\mathrm{Al}$ and $\mathrm{Mg}$ with $\mathrm{H}_{2} \mathrm{O}$, important for using mechanically alloyed $\mathrm{Al} / \mathrm{Mg}$ powder for the decomposition of ammonia borane. 


\subsubsection{Using thermolysis to release hydrogen from ammonia borane}

Thermolysis of $\mathrm{AB}$ has been widely studied. The process can be separated into three main steps, each releasing one mole equivalent of $\mathrm{H}_{2}$. The first step occurs at $100^{\circ} \mathrm{C}$ and reaches a maximum temperature range $107-117^{\circ} \mathrm{C}$. The first step is shown in the following equation releasing the first mole of hydrogen (3).

$$
\mathrm{NH}_{3} \mathrm{BH}_{3} \rightarrow \frac{1}{\mathrm{x}}\left(\mathrm{NH}_{2} \mathrm{BH}_{2}\right)_{\mathrm{x}}+\mathrm{H}_{2}(\mathbf{5})
$$

The second step occurs around $150^{\circ} \mathrm{C}$, and releases the second equivalent of $\mathrm{H}_{2}$ from $\left(\mathrm{NH}_{2} \mathrm{BH}_{2}\right)_{\mathrm{x}}$. As a result, further oxidized polyiminoborane-like material is produced $(\mathrm{NHBH})_{\mathrm{x}}$, an inorganic analog of benzene. The reaction equation would be as follows:

$$
\left(\mathrm{NH}_{2} \mathrm{BH}_{2}\right)_{\mathrm{x}} \rightarrow \frac{1}{\mathrm{x}}(\mathrm{NHBH})_{\mathrm{x}}+\mathrm{H}_{2}(6)
$$

To release all hydrogen contained in $\mathrm{AB}$ (3 equiv. $\mathrm{H}_{2}$ ), a temperature $>1500^{\circ} \mathrm{C}$ is needed. At such temperature, NHBH decomposes to boron nitride and hydrogen:

\section{$\mathrm{NHBH} \rightarrow \mathrm{BN}+\mathrm{H}_{2}(7)$}

Recently, new methods have been proposed for releasing hydrogen from $\mathrm{AB}$ at relatively lower temperatures. Unfortunately, these methods require expensive materials (nanoscaffolds and ionic liquds) that would also increase the overall material weight (3) (21). Another approach is based on mixing AB with solid oxidizers or combustible pairs of elements such as Al-Ni or Ti-B (22). Upon ignition, such mixtures exhibit a self-sustained combustion, accompanied by hydrogen release. In the present study, nanocomposite reactive materials obtained by arrested milling (see Section 2.3.4.2) were tested as potential additives to $\mathrm{AB}$. 


\subsubsection{Using hydrolysis to release hydrogen from ammonia borane}

An area that has received lots of attention in recent studies of $A B$ is hydrolysis. $A B$ has high solubility in water $(33.6 \mathrm{~g}$ per $100 \mathrm{~mL})$ and it is stable in neutral aqueous solutions at room temperature. Ammonia borane can undergo hydrolysis in basic water at room temperature very slowly, but the rate can be accelerated by lowering the $\mathrm{pH}$ or increasing the temperature. However, most research has been focused on the pursuit for a transition-metal catalyst that would increase the rate of the hydrolysis process. The governing reaction for $\mathrm{AB}$ hydrolysis at room temperature and ambient pressure using a metal catalyst is as follows (23):

$$
\mathrm{NH}_{3} \mathrm{BH}_{3}+2 \mathrm{H}_{2} \mathrm{O} \rightarrow \mathrm{NH}_{4}^{+}+\mathrm{BO}_{2}^{-}+3 \mathrm{H}_{2}(8)
$$

This reaction releases heat $\left(\Delta H_{\mathrm{rxn}}=-156 \mathrm{~kJ} / \mathrm{mol}\right)$ and produces $9.1 \mathrm{wt} \%$ hydrogen yield based on the amounts of $\mathrm{AB}$ and $\mathrm{H}_{2} \mathrm{O}$ reacted. Nevertheless, the usage of hydrolysis for hydrogen delivery is impractical for several reasons. There is a limit of solubility of $\mathrm{AB}$ in water (33.6:100 mass ratio); therefore, one mole of $\mathrm{AB}$ consumes two moles of water making the overall materials weight percent to $4.9 \mathrm{wt} \%$. Thus the reaction equation would now change to (3):

$$
\mathrm{NH}_{3} \mathrm{BH}_{3}+5.1 \mathrm{H}_{2} \mathrm{O} \rightarrow \mathrm{NH}_{4} \mathrm{OH}+\mathrm{B}(\mathrm{OH})_{3}+1.1 \mathrm{H}_{2} \mathrm{O}+3 \mathrm{H}_{2}(9)
$$

Nonetheless, if water is recycled from the product solution, this would provide 8.0 wt $\%$ hydrogen yield according to the equation:

$$
\mathrm{NH}_{3} \mathrm{BH}_{3}+2.5 \mathrm{H}_{2} \mathrm{O} \rightarrow \mathrm{NH}_{4} \mathrm{OH}+0.5 \mathrm{~B}_{2} \mathrm{O}_{3}+3 \mathrm{H}_{2}(10)
$$

However, regeneration of the used fuel is one of the reasons why hydrolytic hydrogen release will not be used in vehicle fuel cells because of the difficulty of reducing B-O bonds. It is too inefficient for the transportation sector. 


\subsubsection{A very promising alternative method for hydrogen release: hydrothermolysis}

Hydrothermolysis was proposed as a method where temperature is used instead of catalysts for enabling hydrolysis of $\mathrm{AB}$ (3). Hydrothermolysis can be achieved by increasing pressure so that the water boiling point will exceed the temperature at which the second step of thermolysis occurs. Alternatively, high temperature can also be obtained by adding a material that may exothermally react with water. Metals such aluminum and magnesium could be used as such materials (24) (25). At the beginning of this section, it was specified that the reaction mechanisms of aluminum and magnesium with water would be explained in detail. This section will explain the importance of using these metals due to the possibility of achieving a hydrothermolysis decomposition of $\mathrm{AB}$, meaning both thermloysis and hydrolysis would occur during the same process. Thermal energy would be used instead of a catalyst in reaction with water.

\subsubsection{Reaction of aluminum with water to produce hydrogen}

The reaction of $\mathrm{Al}$ with $\mathrm{H}_{2} \mathrm{O}$ to produce $\mathrm{H}_{2}$ is a well-known process. A typical $\mathrm{Al}-\mathrm{H}_{2} \mathrm{O}$ reaction is given by the equations below (26):

$$
\begin{gathered}
2 \mathrm{Al}+3 \mathrm{H}_{2} \mathrm{O} \rightarrow \mathrm{Al}_{2} \mathrm{O}_{3}+3 \mathrm{H}_{2}(11) \\
\mathrm{Al}+3 \mathrm{H}_{2} \mathrm{O} \rightarrow \mathrm{Al}(\mathrm{OH})_{3}+1.5 \mathrm{H}_{2}
\end{gathered}
$$

For every 1 mole of $\mathrm{Al}, 1.5$ moles of $\mathrm{H}_{2}$ are produced. This reaction is exothermic (Eq. (11) $\left.\Delta H_{\mathrm{rxn}}=-409.1 \mathrm{~kJ} / \mathrm{molAl}\right)$. However, it is well know that nanoscale aluminum powder is needed for making this reaction possible. Shafirovich et al. studied the combustion of nano- $\mathrm{Al} / \mathrm{H}_{2} \mathrm{O} / \mathrm{NaBH}_{4}$ mixtures as a process for hydrogen generation (28). Ignition is not achieved for micron-scale powders due to the fact that the ignition temperature is $2327 \mathrm{~K}$, which is close to the melting point of alumina $\left(\mathrm{Al}_{2} \mathrm{O}_{3}\right)$. Still nano-aluminum powder has some negative aspects that should be taken into account. The methods for producing nano-scale aluminum particles are quite expensive. Moreover, the free aluminum content in these powders is reduced to 50-80\%. This is due to the increase of surface area exposed to the atmosphere, which raises the content of the oxide layer surrounding every aluminum particle. 
Hydrothermolysis with $\mathrm{AB}$, achieved by either increasing pressure or adding nanoscale $\mathrm{Al}$, has been previously investigated by Diwan et al. (3). They reported the combustion of mixtures of nano$\mathrm{Al} / \mathrm{H}_{2} \mathrm{O}$ with $\mathrm{AB}$ as a source of hydrogen for portable fuel cell applications. This system has a theoretical yield of $9.5 \mathrm{wt} \%$ hydrogen from both $\mathrm{AB}$ and water. The experiments yielded $7.7 \mathrm{wt} \%$ hydrogen and a flame velocity of $3 \mathrm{~mm} / \mathrm{s}$.

\subsubsection{Reaction of magnesium with water to produce hydrogen}

It is well known that magnesium reacts with water. During combustion of $\mathrm{Mg}$ powder with water, the reaction for $\mathrm{Mg}$ is given by the equation below (25):

$$
\mathrm{Mg}+\mathrm{H}_{2} \mathrm{O} \rightarrow \mathrm{MgO}+\mathrm{H}_{2}(\mathbf{1 3})
$$

The maximum theoretical $\mathrm{H}_{2}$ yield for this reaction is $3.3 \mathrm{wt} \%$ including magnesium and water mass. This reaction releases heat (Eq. (13) $\Delta H_{\mathrm{rxn}}=-354 \mathrm{~kJ} / \mathrm{molMg}$ ), and it has a lower ignition temperature compared to micron-sized aluminum.

\subsubsection{An advantageous and promising alternative for the decomposition of ammonia borane: novel energetic additives}

As stated before, metals such as $\mathrm{Al}$ and $\mathrm{Mg}$ have high combustion enthalpies and they are widely used as energetic additives for propellants, explosives, and pyrotechnics. Nevertheless, the necessity to use nanoscale $\mathrm{Al}$, the high ignition temperature of $\mathrm{Al}$, and the aging problems of $\mathrm{Mg}$ prevent the usage of these metals for practical applications. Research related to the development of nanocomposite and mechanically alloyed reactive materials indicate that such materials ignite at relatively low temperatures and, at the same time, have excellent storage capabilities.

These materials provide interesting advantages over single-metal particles. Relatively large metal particles ignite with a delay; these delays are usually controlled by slow reactions leading to a selfsustained combustion process. These delays are related to the diffusion of the oxidizer and/or fuel through the protective layer of the metal oxide. Ideally, an energetic additive should be monomolecular, meaning that it has the most possible surface area (4). This enables the exothermic reaction to occur at a 
faster rate. This would lead to the idea of using materials with a high specific surface area (e.g. nanoAl). However, an alternative approach would be to use a homogeneous metal-oxidizer solution in which the components are not chemically bound. The reaction rate would not be limited by the specific surface area even though the particles are in the micron size range.

This paper explains the usage of energetic materials obtained by mechanically alloying and arrested reactive milling. These techniques are further described in the following sections.

\subsubsection{Mechanical alloying}

This process is a dry, high-energy ball milling process in which an initial mixture of powders is continuously kneaded together and re-fractured by the ball-powder collisions. This process includes repeated cold welding and fracturing leading to ultrafine mixing and alloying (28) (29). Around 1-5 wt\% of a process control agent (PCA), for example, stearic acid, hexane, and methanol, is added to the blend for avoiding cold welding and particle agglomeration.

Material produced by mechanical alloying offer high combustion enthalpies and reduced ignition delays. For instance, some tested alloys like $\mathrm{Al}$ with $\mathrm{Mg}$ (contents varied from 10 to $50 \mathrm{wt} \%$ ) required an ignition temperature from 1170 to $1020 \mathrm{~K}$ compared to $2327 \mathrm{~K}$ for micron-sized aluminum. Figure 3 shows the particle evolution for the mechanically alloyed $\mathrm{Al} / \mathrm{Mg}$ powders. The first milling stage is used to achieve the desired structural and compositional refinement, while the final stage is for reducing the particle size. Iodine was used as a process control agent. 

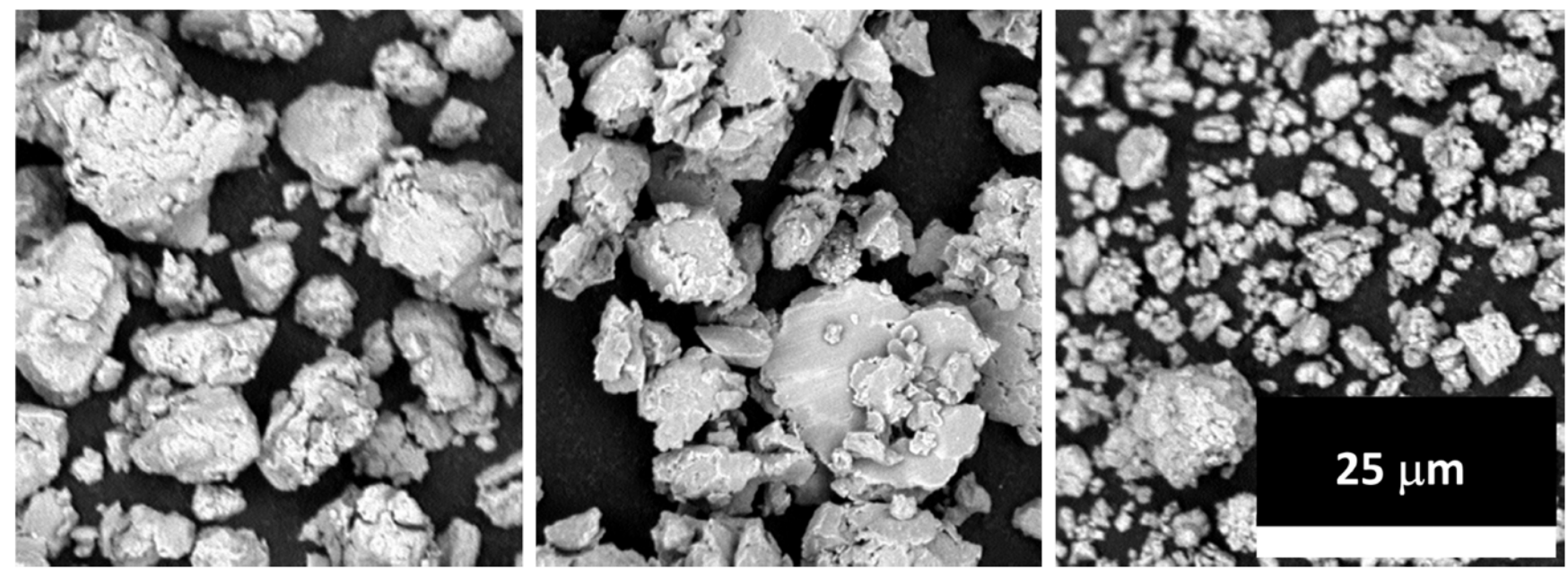

Figure 3. Particle evolution for an $\mathrm{Al}_{0.7} \mathrm{Mg}_{0.3}$ composite: (left) end of first milling stage; (center) immediately after addition of iodine; (right) final product after completion of second milling stage (30).

\subsubsection{Arrested reactive milling}

The nanocomposite reactive materials produced at the NJIT are produced by arrested reactive milling (ARM). These materials are mixtures of regular metal, metalloid, and/or oxide powders and a PCA. Having a specific initial particle size is not critical; in fact, having very fine or nano-sized powder is unwanted. These materials have the capacity of reacting; for instance, several thermites (mixture of a metal and a metal oxide) are produced. These powders are mixed and ball-milled; however, the milling process cannot be performed for a long periods of time since a self-sustained reaction could be triggered. On the other hand, if the milling process is stopped right before the reaction occurs, fully dense micronsized composite particles with nanoscaled structural features are produced. The product consists of inclusions of one component, fully embedded into the matrix of the other element. Since one material is embedded into a matrix of another component, aging or storage capabilities are improved (31). This opens the possibility of using these materials in gas generators.

\subsubsection{Reactive nanomaterials produced at the NJIT}

Table 2 shows the energetic materials produced at NJIT (4). THERMO (version 4.3) software was used for identifying the most promising energetic additives. Chapter 3 will further explain the 
characteristics of this software. However, thermodynamic calculations assume that the additive is reacting and decomposing ammonia borane, which cannot be the case for some mixtures because of kinetic problems. Therefore, experiments with the most promising additives were performed for validation of the thermodynamic results. Chapter 4 will discuss these experiments in more detail.

Table 2. Reactive materials produced at the NJIT (4).

\begin{tabular}{|c|c|c|c|c|c|c|c|}
\hline \multicolumn{8}{|c|}{ Nanocomposite Thermites } \\
\hline \multirow[t]{2}{*}{ Fuel } & \multicolumn{7}{|c|}{ Oxidizer } \\
\hline & $\mathrm{Fe}_{2} \mathrm{O}_{3}$ & $\mathrm{MoO}_{3}$ & $\mathrm{CuO}$ & $\mathrm{Bi}_{2} \mathrm{O}_{3}$ & $\mathrm{WO}_{3}$ & $\mathrm{SrO}_{2}$ & $\mathrm{NaNO}_{3}$ \\
\hline Al & $\mathrm{x}$ & $x^{a}$ & $x^{a}$ & $\mathrm{x}$ & $\mathrm{x}$ & $\mathrm{x}$ & $x^{b}$ \\
\hline $\mathrm{Mg}$ & & $\mathrm{x}$ & $x$ & & & & $x$ \\
\hline $\mathrm{Al}_{0.5} \mathrm{Mg}_{0.5}$ & & & & & & & $\mathrm{x}$ \\
\hline $\mathrm{MgH}_{2}$ & & $\mathrm{x}$ & $x$ & & & & \\
\hline $\mathrm{Si}$ & & $\mathrm{x}$ & $\mathrm{x}$ & $\mathrm{x}$ & & & \\
\hline $\mathrm{Zr}$ & & $\mathrm{x}$ & $\mathrm{x}$ & $\mathrm{x}$ & & & $\mathrm{x}$ \\
\hline $2 \mathrm{~B}+\mathrm{Ti}^{\mathrm{c}}$ & & & & & & & $x^{b}$ \\
\hline $2 \mathrm{~B}+\mathrm{Zr}^{\mathrm{c}}$ & & & & & & & $x^{b}$ \\
\hline \multicolumn{8}{|c|}{ Reactive metal-metalloid composites } \\
\hline B & \multicolumn{7}{|c|}{ Reactive metals: $\mathrm{Ti}, \mathrm{Zr}$, Hf } \\
\hline \multicolumn{8}{|c|}{ Nanostructured Al-based alloys } \\
\hline Al & \multicolumn{7}{|c|}{ Alloying components: W, Hf, Mg, MgH2, Ti, Li, Zr, C } \\
\hline \multicolumn{8}{|c|}{${ }^{a}$ Metal-rich nanocomposites also have been synthesized. } \\
\hline \multicolumn{8}{|c|}{${ }^{\mathrm{b}}$ Metal-lean nanocomposites also have been synthesized. } \\
\hline \multicolumn{8}{|c|}{${ }^{\mathrm{C}}$ Nanocomposite powder used as component for compound nanocomposite. } \\
\hline
\end{tabular}

\subsection{Summary}

A promising hydrogen source compound that can be used for fuel cell applications is ammonia borane because it can provide a high hydrogen yield, is stable at ambient temperatures, and is non-toxic. 
Hydrogen can be released from ammonia borane by thermolysis, catalytic hydrolysis, and hydrothermolysis. Nanocomposite and mechanically alloyed reactive materials have the potential to improve the performance of hydrogen generators based on ammonia borane. These reactive materials provide a more controllable heat release, and fewer amounts could be needed to provide a self-sustained combustion process, thus a possible increase in the hydrogen yield. Hydrothemolysis of ammonia borane can be achieved with no catalysts by either increasing pressure or adding a metal that reacts with water. The latter approach opens the possibility of using mechanically alloyed $\mathrm{Al} / \mathrm{Mg}$ powder, which offers several advantages over conventional $\mathrm{Al}$ or Mg powders. 


\section{Chapter 3: Methodology}

\subsection{Introduction}

The design of a combustion-based generator involves using reactive materials such as thermites, intermetallics, and other pyrotechnic mixtures. As noted above, the nanocomposite reactive materials obtained by ARM provide a number of advantages over conventional energetic compositions. The main objective of this research is to find the ideal energetic additive for the decomposition of ammonia borane. To select the most promising additives to ammonia borane, it is necessary to determine the materials that, with minimal additive content, provide a high hydrogen yield and simultaneously a sufficiently high combustion temperature, which allows for a self-sustained combustion.

First, thermodynamic calculations were completed for ammonia borane with every nanocomposite and mechanically alloyed reactive material produced at the NJIT. The top thermodynamically additives were then tested in an experimental facility equipped with laser ignition. Some mixtures were prepared as a pellet or a paste depending if water was used. Every mixture was then tested under the same conditions. Chapter 4 discuses and compares the tested compositions.

\subsection{Thermodynamic Calculations}

Thermodynamic calculations of the adiabatic combustion temperatures and combustion product compositions were conducted using the software THERMO (version 4.3), which is based on the Gibbs free energy minimization and contains a database of approximately 3,000 compounds (32). Of specific importance is the capability of this code to handle both intermetallic and thermite reactions in addition to conventional gas-phase combustion reactions.

The THERMO database, however, does not contain thermochemical properties of ammonia borane. For this reason, the formation enthalpy of this compound, required for the calculations, was taken from the literature: $178 \mathrm{~kJ} / \mathrm{mol}$ for $\mathrm{NH}_{3} \mathrm{BH}_{3}$. The calculated equilibrium products do not contain ammonia borane at any mixture ratio, i.e., this compound is decomposed in the calculations even at room temperature. This feature should be taken into account during analysis of the obtained results.

For each mixture, calculations were conducted over a wide range of AB-to-additive mixture ratios. The mass ratio of the additive components in the calculations corresponded to the maximum adiabatic 
flame temperature in the additive taken alone (i.e., with no ammonia borane). Pressure was equal to 1 atm in all calculations.

\subsection{Experimental}

Combustion experiments were conducted with the following reactive material additives:

- Nanocomposite thermites: Al/NaNO3 (5:3), $\mathrm{Al} / \mathrm{NaNO} 3$ (2.1:1), and $\mathrm{Al} / \mathrm{MoO}_{3}(8: 1)$.

- Reactive metal-metalloid composites: B/Ti (2:1).

- Mechanically alloyed $\mathrm{Al} / \mathrm{Mg}$ powder with $\mathrm{H}_{2} \mathrm{O}$.

Here the mole ratios are indicated. Note for $\mathrm{Al} / \mathrm{Mg}$ the mole ratio is 4.7:5.3, which corresponds to $1: 1$ mass ratio.

Nanocomposite and mechanically alloyed reactive materials were produced at the New Jersey Institute of Technology as follows.

The preparation of $\mathrm{Al} / \mathrm{MoO}_{3}$ powders included elemental powders of aluminum (99\% pure, -325 mesh, $44 \mu \mathrm{m}$ diameter, by Alfa Aesar) and molybdenum trioxide $\mathrm{MoO}_{3}$ (99.95\% pure, by Alfa Aesar). Powders were mechanically milled using a SPEX SamplePrep 8000 shaker mill with 50-ml flat-ended steel vials and steel milling media (5 mm diameter balls). Preparation was carried out in an argon environment using $5 \mathrm{~g}$ powder batches with different $\mathrm{Al} / \mathrm{MoO} 3$ ratios, and $4 \mathrm{ml}$ of hexane $\left(\mathrm{C}_{6} \mathrm{H}_{14}\right)$ was added as a PCA for inhibiting cold-welding and preventing partial reactions during the milling process. Milling time was 60 min (33) (34).

Every other material involving ball milling employed a Restsch-400 MA planetary mill equipped with an air conditioner that cools the milling compartment. The rotation speed used was set to $350 \mathrm{rpm}$ and the rotation direction changed every $15 \mathrm{~min}$.

Starting materials used in the synthesis of the $\mathrm{Al} / \mathrm{Mg}$ alloys included elemental powders of $\mathrm{Al}$ (Atlantic Equipment Engineers, 99.8\% pure, -325 mesh) and Mg (Alfa-Aesar, 99.8\% pure, -325mesh). Mechanically alloyed powders were prepared following a two-stage procedure (36). Powders of Al and $\mathrm{Mg}$ and $9.5 \mathrm{~mm}$ diameter hardened steel balls were loaded in steel milling vials in argon. The powder charge was $30 \mathrm{~g}$ per vial and the ball-to-power mas ratio (BPR) was $10.50 \mathrm{ml}$ of hexane was added to each milling vial as a PCA. Milling time was $120 \mathrm{~min}$. The rotation direction was changed every $15 \mathrm{~min}$. 
The first stage produced a coarse, mechanically alloyed powder. The second stage of milling, aimed to reduce the particle size (around $12 \mu \mathrm{m}$ ), involved the addition of a new PCA, iodine (I2, chips, Sigma Aldrich, 99\% pure), at $4 \mathrm{wt} \%$ of the initial powder load. The $9.5 \mathrm{~mm}$ balls were removed and replaced with the same mass of $3 \mathrm{~mm}$ hardened steel balls. The duration of the second milling stage varied between 65 and $125 \mathrm{~min}$, depending on the effectiveness of the air-conditioner cooling the milling compartment which was affected by the air humidity.

Preparation of $\mathrm{B} / \mathrm{Ti}$ (36) composite powders started with amorphous powders of boron (nominal size $0.7 \mu \mathrm{m}, 98.5 \%$ pure, by SB Boron) and titanium (-325 mesh, 99.7\% pure, by Atlantic Equipment Engineers). The nanocomposite powders were prepared in this project using a sequence of two milling steps. In the first step, the powders were milled with a small amount of liquid process control agent (heptane) until the desired nanostructured refinement was achieved. In the second step, the amount of heptane was substantially increased and the resulting slurry was milled to minimize agglomeration and achieve the desired particle size distribution.

Preparation of $\mathrm{Al} / \mathrm{NaNO}_{3}$ started with blends of sodium nitrate (99\%, Alfa Aesar) and aluminum (99.9\%, -325 mesh, Atlantic Equipment Engineers). Custom made steel jars suitable for high pressure applications (18 $\mathrm{mm}$ wall thickness) and $9.53 \mathrm{~mm}$ balls made of AISI/SAE 1013 low-carbon Steel were used. Synthesis was carried out in argon environment with $20 \mathrm{~g}$ batches and a BPR of 5 . For safety and ease of handling of the prepared reactive composites, $25 \mathrm{~mL}$ of hexane was added into each milling jar, also under argon. This was followed by a brief 5 min period of wet milling, which was intended to break loose agglomerates, and did not affect the structure of the prepared composites. To prevent slow reaction of the respective metal component with atmospheric oxygen, the samples were stored under hexane as well.

\subsection{Preparation of mixtures}

\subsubsection{Nanocomposite thermites and metal-metalloid composites}

Tested compositions for thermites and metal-metalloid composites included ammonia borane with no binder. In order to make a more uniform mixture, an attempt for decreasing $\mathrm{NH}_{3} \mathrm{BH}_{3}$ particle size was made. Ammonia borane was milled in a planetary ball mill (Fritsch Pulverisette 7 Premium 
Line) at a rotation speed of $750 \mathrm{rpm}$. The milling time was set to $5 \mathrm{~min}$ and the balls-mixture mass ratio was 10. However, the results were not as expected due to sticking the powder to the walls of the milling bowl (around $70 \%$ of the material was lost). The particle size distribution of unmilled and milled $\mathrm{NH}_{3} \mathrm{BH}_{3}$ was characterized using a sieve shaker (Octagon 2000) and a set of sieves (63 to $600 \mu \mathrm{m}$ ).

The milled and unmilled $\mathrm{AB}$ were mixed with the corresponding reactive material during $1 \mathrm{hr}$ in a tumbler mixer (BioEngineering Inversina 2L). The mixtures were compacted into cylindrical pellets using a uniaxial hydraulic press (Carver). A trapezoidal split sleeve pressing die (composed of three sleeves) was used for compressing the mixture. The use of this die simplified the removal of the pellet and cleaning of the die components. The pressing force was equal to $19.6 \mathrm{kN}$.

\subsubsection{Mechanically alloyed $\mathrm{Al} / \mathrm{Mg}$ powder with water}

To prevent sedimentation of relatively coarse $\mathrm{Al} / \mathrm{Mg}$ particles, water was gelified by adding a small amount of poly(acrylamide-co-acrylic acid) (Sigma Aldrich), for simplicity called polyacrylamide in the present paper. First, the gellant was added to distilled water and then the $\mathrm{Al} / \mathrm{Mg}$ powder was

mixed with the obtained gel. The mass fraction of water in the metal-water mixture was varied from 10 to $60 \%$. Two concentrations of polyacrylamide in water were tested: $1 \mathrm{wt} \%$ and $3 \mathrm{wt} \%$. A sample of the resulting mixture was then placed in a quartz tube $(6.35 \mathrm{~mm} \mathrm{OD}$, height $25.4 \mathrm{~mm})$ for the combustion experiments.

\subsubsection{Ternary mixture: ammonia borane, mechanically alloyed $\mathrm{Al} / \mathrm{Mg}$ powder, and heavy water}

To obtain information on the mechanisms of the involved reactions through isotopic tests, $\mathrm{D}_{2} \mathrm{O}$ was used instead of $\mathrm{H}_{2} \mathrm{O}$ for every mixture preparation. Heavy water $\left(\mathrm{D}_{2} \mathrm{O}\right.$, Sigma Aldrich, 99.9 atom \% D), was mixed with polyacrylamide. For these mixtures only the $3 \mathrm{wt} \%$ polyacrylamide concentration was used. The mass fraction of heavy water in the metal-water mixture was varied from 49.2 to 61.7 wt\%. The resulting mixture was mixed with ammonia borane using an acoustic mixer (Resodyne LabRAM). The product was then placed in a quartz tube $(6.35 \mathrm{~mm} \mathrm{OD}$, height $25.4 \mathrm{~mm})$ with the addition of a booster pellet on top of the sample. The booster pellet composed of heavy water and mechanically alloyed $\mathrm{Al} / \mathrm{Mg}$ power mixed at the stoichiometric ratio. 


\subsection{Combustion Experiments}

Combustion of the obtained mixtures was investigated using an experimental setup with laser ignition (Fig. 1). The setup includes a stainless steel chamber (volume: $11.35 \mathrm{~L}$ ), equipped with a door port, three windows for observation and video recording, a zinc selenide window for introducing the laser beam, and a pressure transducer (Omegadyne PX-409-030AI). The chamber is connected to a mass-spectrometer (Pfeiffer Omnistar GSD 320) for analysis of gases generated during combustion. One of the observation windows was made of sapphire to enable infrared video recording (which, however, was not used in the present work). The pellet or the quartz tube with the mixture was installed vertically on a brass pedestal.

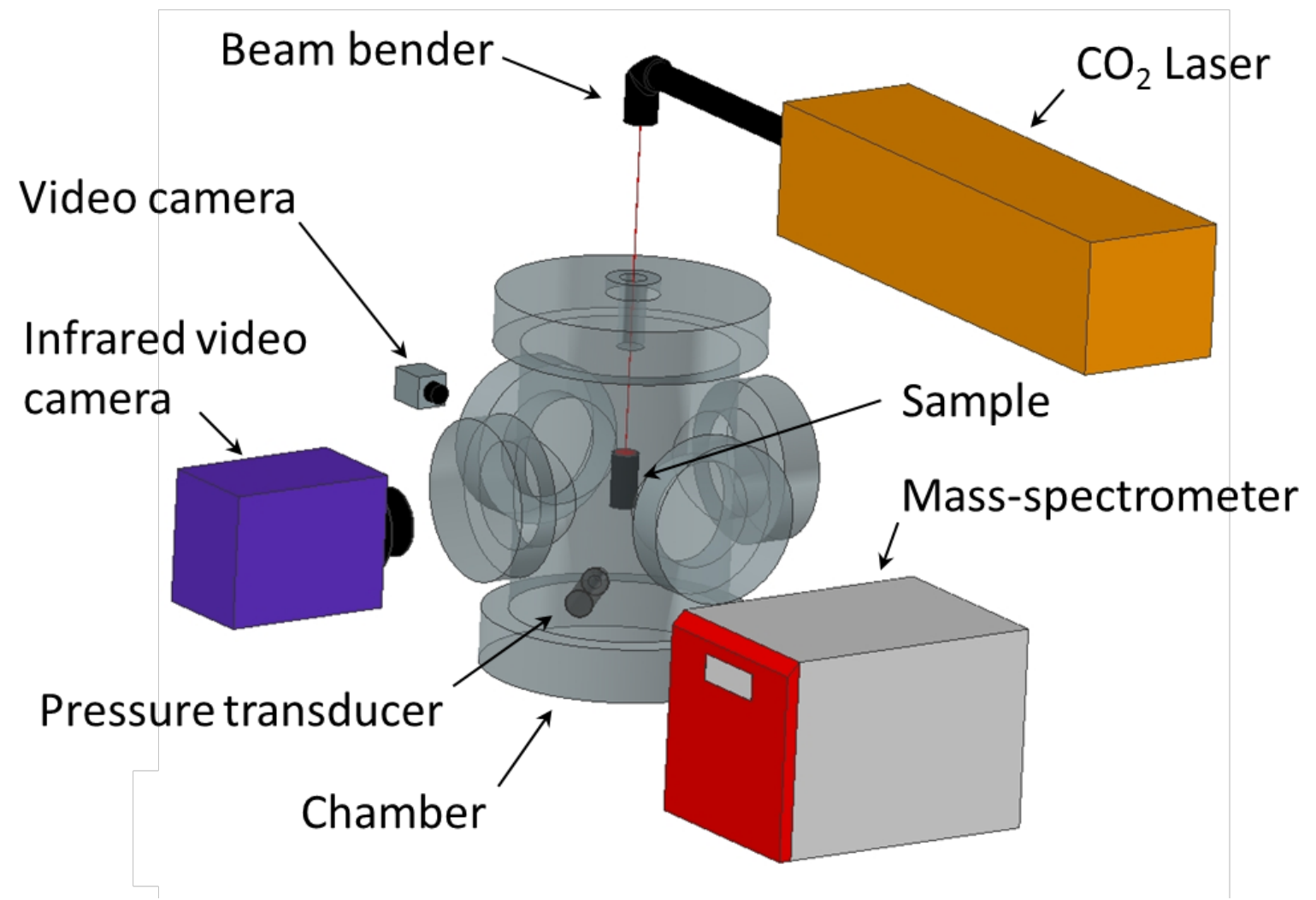

Figure 4. Schematic diagram of the experimental setup for laser ignition of the pellets.

Before each experiment, the chamber was evacuated and filled with ultra-high purity argon to a pressure of $1 \mathrm{~atm}$. An infrared beam (wavelength: $10.6 \mu \mathrm{m}$, diameter: $2.0 \pm 0.3 \mathrm{~mm}$ ) of a $\mathrm{CO}_{2}$ laser 
(Synrad Firestar ti-60) was introduced into the chamber vertically through the ZnSe window, located at

the chamber lid. The beam was directed to the top of the pellet. For alignment of the optical system, a laser diode (Synrad Diode Pointer) was used. The power of the beam after passing the beam delivery system and ZnSe window was measured with a powermeter (Synrad PW-250) and controlled using a laser controller (Synrad UC-2000), while the duration of the laser pulse was controlled using LabVIEW (National Instruments) software.

After ignition, the combustion front propagated downward through the sample. The propagation was monitored using a digital video camera (Sony XCD-SX90CR). The pressure increase due to the released gases was recorded with the pressure transducer. Analysis of the released gases was performed using a mass-spectrometer (Pfeiffer Omnistar GSD 320). First, the released products have to cool down to room temperature. Then the exit valve is opened for gas recording. After of couple of minutes of constant reading, the current intensity for each of the gases stabilizes and the values now can be saved for future calculations. Combustion products were then characterized using X-ray diffraction analysis (Bruker D8 Discovery XRD).

\subsubsection{Mass-spectrometer gas calibration}

Every time an experiment is performed, a calibration of the mass-spectrometer (MS) for a quantitative analysis of the desired gases has to be done. Since hydrogen is the main gas evolved from ammonia borane, a hydrogen pressurized tank was used for each of the calibrations. The calibration process worked as follows:

1. The chamber was purged, then evacuated and filled three times with ultra-high purity argon to $1 \mathrm{~atm}$.

2. After the filling the chamber with argon for a third and final time, the hydrogen tank is connected to the chamber and filled to a known pressure (e.g. $1 \mathrm{kPa})$.

3. The gases are left inside the chamber for $5 \mathrm{~min}$ for settlement and mixing (in this case is argon and hydrogen). 
4. The MS software (Quadera) is opened and a multiple ion detection (MID) program is started.

5. The exit valve is opened and the MS will read a current intensity (amps) for the calibrated gas (hydrogen).

6. This process is repeated several times until the current intensity of the calibrated gas is closely matched to the intensity recorded from the experiment.

For ternary mixtures, the calibrated gases used were hydrogen $\left(\mathrm{H}_{2}\right.$, Airgas, Ultra High Purity 5.0 grade), deuterium hydride (HD, Sigma Aldrich, 96 mol \% DH, 98 atom \% D), and deuterium $\left(\mathrm{D}_{2}\right.$, Sigma Aldrich, 99.8 atom \% D). These three gases were used because heavy water reacts with the metal fuel

producing $\mathrm{D}_{2}, \mathrm{H}_{2}$ is extracted from ammonia borane due to thermolysis decomposition, and HD is produced from hydrolysis reaction between $\mathrm{D}_{2} \mathrm{O}$ and $\mathrm{NH}_{3} \mathrm{BH}_{3}$.

\subsection{Thermogravimetric analysis}

Thermal decomposition of ammonia borane was studied using a thermogravimetric analyzer (Netzsch TGA $209 \mathrm{~F} 1$ Iris) .The heating rate in each experiment was $0.5 \mathrm{~K} / \mathrm{min}$. The experiments were conducted in an argon atmosphere at a volumetric flow rate of $20 \mathrm{ml} / \mathrm{min}$. The crucible was made of alumina $\left(\mathrm{Al}_{2} \mathrm{O}_{3}\right)$, and the sample mass was set to $5 \mathrm{mg}$.

\subsection{Thermal diffusivity measurements}

Thermal diffusivities of $\mathrm{Al} / \mathrm{Mg} /$ water mixtures were measured using a laser flash apparatus (Netzsch LFA 457 MicroFlash). The mixture was set in a special container used for low conductivity liquid materials. The thickness of the sample was $0.62 \mathrm{~mm}$.

\section{9 $\quad$ Summary}

Thermodynamic calculations of the adiabatic combustion temperatures and combustion product compositions were conducted for mixtures of ammonia borane with various reactive materials fabricated at NJIT. For each mixture, calculations were conducted over a wide range of AB-to-additive mixture ratios. The mass ratio of the additive components in the calculations corresponded to the maximum 
adiabatic flame temperature in the additive taken alone (i.e., with no ammonia borane). Pressure was equal to $1 \mathrm{~atm}$ in all calculations.

Experimental procedures included preparation of mixtures. Solid mixtures were compacted to pellets. Mixtures of $\mathrm{Al} / \mathrm{Mg}$ powder and water were prepared by gelifying water and making a paste-like sample. for investigating the reaction mechanisms of $\mathrm{AB} / \mathrm{Al} / \mathrm{Mg} /$ water mixtures, heavy water was used.

The samples were placed vertically inside a windowed reaction chamber and ignited by a $\mathrm{CO}_{2}$ laser. Video recording of the combustion process was performed in parallel with pressure measurements. Gaseous and condensed products were characterized using mass-spectroscopy and X-ray diffraction analysis, respectively.

Thermal decomposition of ammonia borane with or without $\mathrm{Al} / \mathrm{Mg}$ powder was studied using a thermogravimetric analyzer. Thermal diffusivities of some mixtures were measured using a laser flash apparatus. 


\section{Chapter 4: Results and Discussion}

\subsection{Thermodynamic calculation results}

Table 3 shows the amounts of 22 binary mixtures that, being added to ammonia borane, provide the adiabatic flame temperature of $1500^{\circ} \mathrm{C}$, which is required for the full decomposition of $\mathrm{NH}_{3} \mathrm{BH}_{3}$ to hydrogen and boron nitride. The table also shows the mole and mass fractions of $\mathrm{H}_{2}$ in the combustion products. The order in the table corresponds to increasing the additive mass fraction in the composition. It is seen that the additives that are more efficient in increasing the temperature are usually also more efficient in increasing the hydrogen yield from the unit mass of the entire composition.

As an example, Figure 5 and 6 shows the calculated adiabatic flame temperatures and hydrogen mole fraction in the combustion products $v s$ the additive mass fraction for the mixtures of ammonia borane with two additives: $\mathrm{Al} / \mathrm{Ni}$ and $\mathrm{Al} / \mathrm{NaNO}_{3}$. It is seen that the latter additive is much more effective in increasing the combustion temperature and maintaining a high hydrogen yield. For $\mathrm{NBH}_{6} / \mathrm{Al} / \mathrm{Ni}$ mixture, the desired temperature of $1500^{\circ} \mathrm{C}(1773 \mathrm{~K})$ is reached at $87 \mathrm{wt} \% \mathrm{Al} / \mathrm{Ni}$ additive, which decreases the hydrogen mole fraction in the products from 0.75 (for pure ammonia borane) to 0.45 . For $\mathrm{NBH}_{6} / \mathrm{Al} / \mathrm{NaNO}_{3}$ mixture, the same temperature is reached at a much smaller additive of $\mathrm{Al} / \mathrm{NaNO}_{3}(40$ $\mathrm{wt} \%)$, while the hydrogen mole fraction remains very high (0.68). The plots obtained for other mixtures are shown in the Appendix.

The calculated adiabatic flame temperatures and equilibrium product compositions can be used for preliminary selection of the additives that are effective in simultaneously providing heat for a selfsustained combustion and maintaining high yield of the desired gas. Since the actual combustion system may be far away from equilibrium, experimental verification is required. 
Table 3. The amounts of additives to ammonia borane that provide the adiabatic flame temperature of $1500^{\circ} \mathrm{C}$ and the values of $\mathrm{H}_{2}$ mole and mass fractions in the combustion products for these compositions.

\begin{tabular}{|c|c|c|c|}
\hline Additive Composition & Additive, wt $\%$ & $\mathrm{H}_{2}$ Mole Fraction & $\mathrm{H}_{2}$ Mass Fraction \\
\hline $\mathrm{Al}$ and $\mathrm{NaNO}_{3}$ & 39 & 0.688 & 0.119 \\
\hline $\mathrm{Mg}$ and $\mathrm{NaNO}_{3}$ & 46 & 0.643 & 0.105 \\
\hline $\mathrm{Zr}$ and $\mathrm{NaNO} 3$ & 52 & 0.673 & 0.093 \\
\hline $\mathrm{Al}$ and $\mathrm{WO}_{3}$ & 55 & 0.609 & 0.057 \\
\hline $\mathrm{Mg}$ and $\mathrm{CuO}$ & 59 & 0.614 & 0.079 \\
\hline $\mathrm{Al}$ and $\mathrm{MoO}_{3}$ & 58.8 & 0.691 & 0.077 \\
\hline $\mathrm{Al}$ and $\mathrm{CuO}$ & 58.8 & 0.65 & 0.08 \\
\hline $\mathrm{Al}$ and $\mathrm{SrO}_{2}$ & 60.2 & 0.674 & 0.078 \\
\hline $\mathrm{Al}$ and $\mathrm{Fe}_{2} \mathrm{O}_{3}$ & 63 & 0.636 & 0.072 \\
\hline $\mathrm{B}$ and $\mathrm{Ti}$ & 62.6 & 0.63 & 0.073 \\
\hline $\mathrm{Zr}$ and $\mathrm{MoO}_{3}$ & 67 & 0.672 & 0.064 \\
\hline $\mathrm{Zr}$ and $\mathrm{CuO}$ & 68.4 & 0.644 & 0.061 \\
\hline Zr and B & 67.5 & 0.654 & 0.063 \\
\hline $\mathrm{Si}$ and $\mathrm{CuO}$ & 75 & 0.532 & 0.048 \\
\hline $\mathrm{Si}$ and $\mathrm{MoO}_{3}$ & 73.8 & 0.602 & 0.051 \\
\hline Hf and B & 78.4 & 0.655 & 0.042 \\
\hline $\mathrm{MgH}_{2}$ and $\mathrm{MoO}_{3}$ & 85.5 & 0.558 & 0.044 \\
\hline $\mathrm{Al}$ and $\mathrm{Bi}_{2} \mathrm{O}_{3}$ & 80 & 0.64 & 0.037 \\
\hline $\mathrm{Al}$ and $\mathrm{Ni}$ & 85.8 & 0.471 & 0.028 \\
\hline $\mathrm{Zr}$ and $\mathrm{Bi}_{2} \mathrm{O}_{3}$ & 83.7 & 0.609 & 0.032 \\
\hline $\mathrm{Mg}$ and $\mathrm{MoO}_{3}$ & 86 & 0.319 & 0.02 \\
\hline $\mathrm{Si}$ and $\mathrm{Bi}_{2} \mathrm{O}_{3}$ & 91 & 0.52 & 0.0195 \\
\hline
\end{tabular}




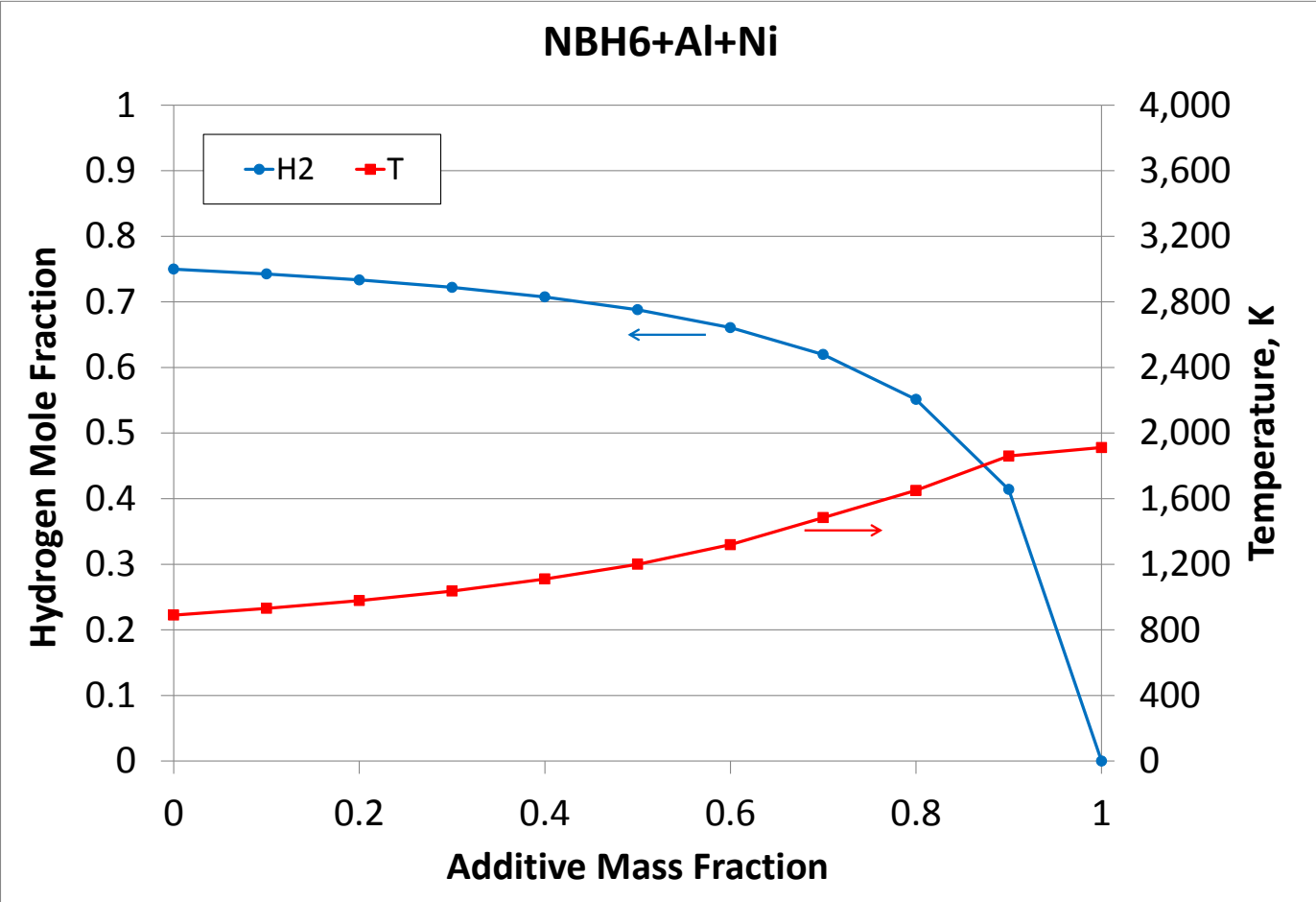

Figure 5. The adiabatic flame temperature and hydrogen content in the products for the mixture of ammonia borane with $\mathrm{Al} / \mathrm{Ni}$ as a reactive material.

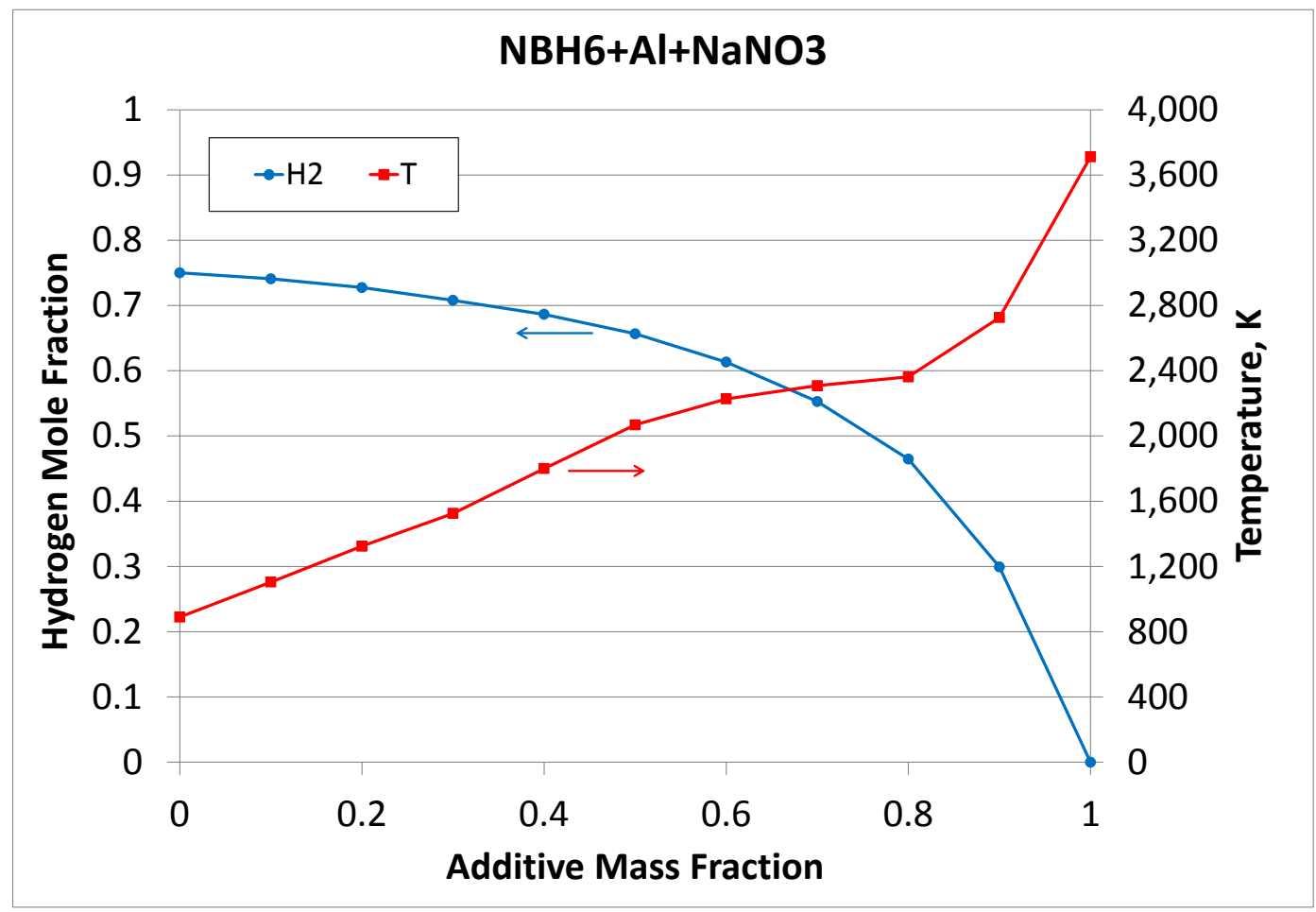

Figure 6. The adiabatic flame temperature and hydrogen content in the products for the mixture of ammonia borane with $\mathrm{Al} / \mathrm{NaNO}_{3}$ as a reactive material. 


\subsection{Experimental results}

\subsubsection{Nanocomposite thermites and metal-metalloid composites results}

Mixtures based on ammonia borane $\left(\mathrm{BH}_{3} \mathrm{NH}_{3}\right)$ were studied as hydrogen-generating compositions. Based on thermodynamic calculations decsribed in the previous section, the following reactive nanocomposites were tested as energetic additives to ammonia borane: $\mathrm{Ti} / \mathrm{B}, \mathrm{Al} / \mathrm{NaNO}_{3}$, and $\mathrm{Al} / \mathrm{MoO}_{3}$. The mixtures were prepared using the tumbler mixer and compacted into pellets. Laser ignition experiments with the mixtures of $\mathrm{BH}_{3} \mathrm{NH}_{3}$ and these additives have shown that for successful ignition, the additive concentrations should be as high as $80 \mathrm{wt} \%$, i.e., significantly higher that the optimal values obtained by thermodynamic calculations (30-50 wt\% depending on the system).

At such high amounts of the additive, hydrogen yield per unit mass of the mixture is low, making the addition of these materials impractical. The unsuccessful experimental results are apparently associated with the large size of ammonia borane particles. Figure 7 and 8 show the particle size distribution for un-milled and milled ammonia borane powder. Ammonia borane was milled in a planetary ball mill (Fritsch Pulverisette 7 Premium Line) at a rotation speed of $750 \mathrm{rpm}$ (the milling time: $5 \mathrm{~min}$; the balls-mixture mass ratio: 10). The average particle size for unmilled $\mathrm{AB}$ is $351 \mu \mathrm{m}$, while for milled powder it is $183 \mu \mathrm{m}$. In both cases, the particle size is very large compared with the energetic additives, for which particle sizes are $<50 \mu \mathrm{m}$. Since the particle size difference between $A B$ and the additive was large, the area of contact between the mixture components was low, thus making it impossible to ignite. 


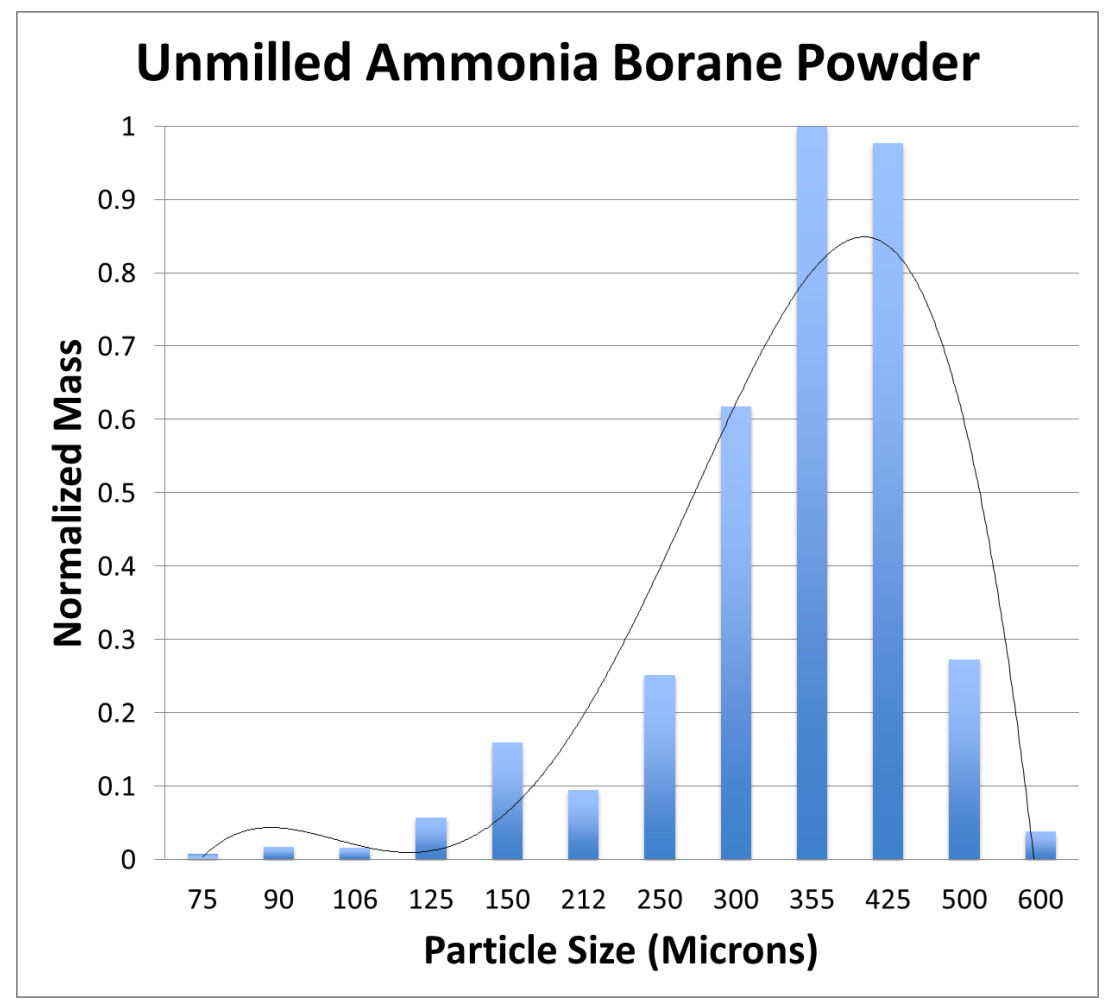

Figure 7. Particle size distribution for unmilled $\mathrm{NH}_{3} \mathrm{BH}_{3}$ powder.

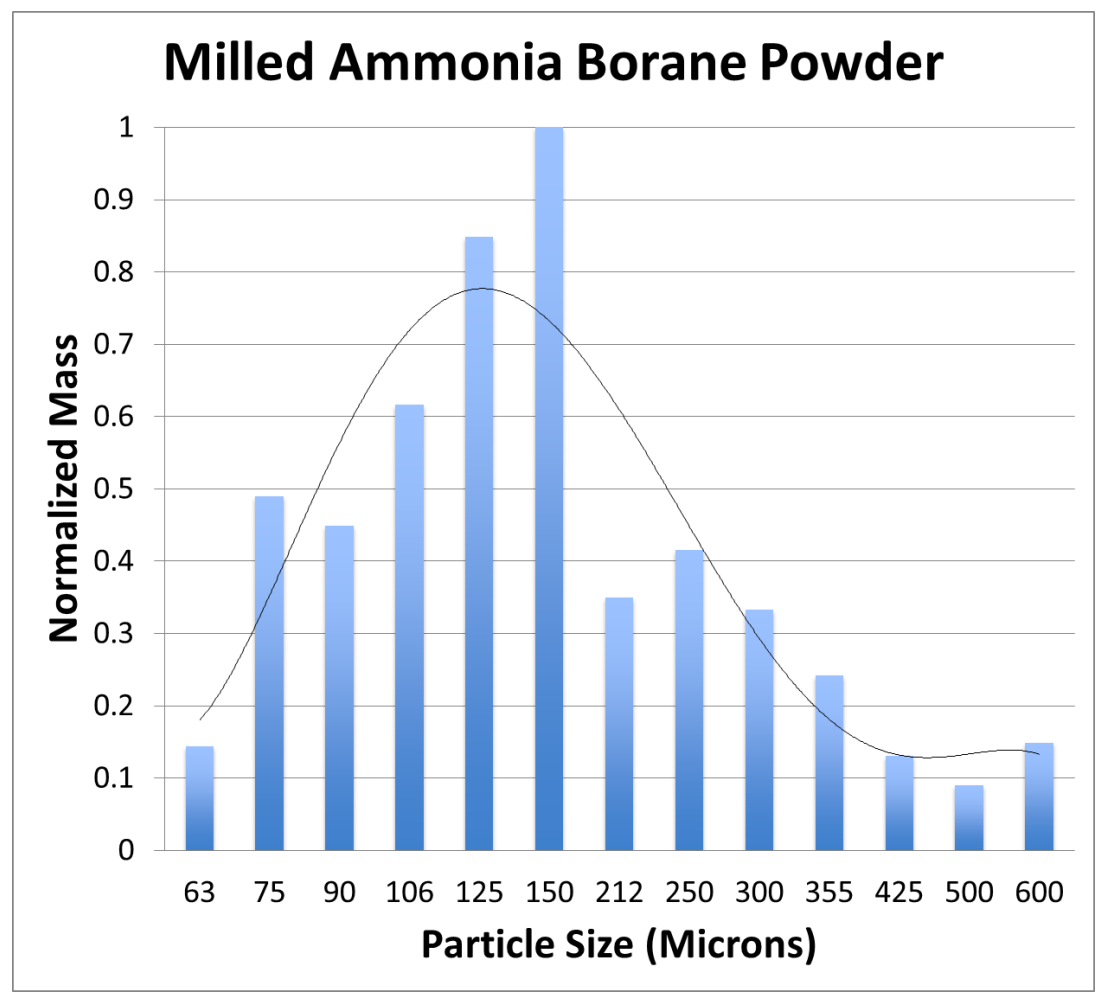

Figure 8. Particle size distribution for milled $\mathrm{NH}_{3} \mathrm{BH}_{3}$ powder. 


\subsubsection{Mechanically alloyed $\mathrm{Al} / \mathrm{Mg}$ powder with water results}

To eliminate the problem of $\mathrm{AB}$ coarse particles, it was decided to focus on using a metal-water mixture as the energetic additive to $\mathrm{AB}$. Since this involves dissolution of $\mathrm{AB}$ in water, the particle size problem is absent. Mechanically alloyed $\mathrm{Al} / \mathrm{Mg}$ powders were tested. To prevent sedimentation of micron-sized metal particles, water has to be gelified. Initially, experiments were conducted at $3 \mathrm{wt} \%$ polyacrylamide.

Experiments have shown that mixtures with water concentration up to $60 \mathrm{wt} \%$ are combustible. Figure 9 shows images of the combustion wave propagation over Al/Mg-water mixture $\left(46.5\right.$ wt $\left.\% \mathrm{H}_{2} \mathrm{O}\right)$.
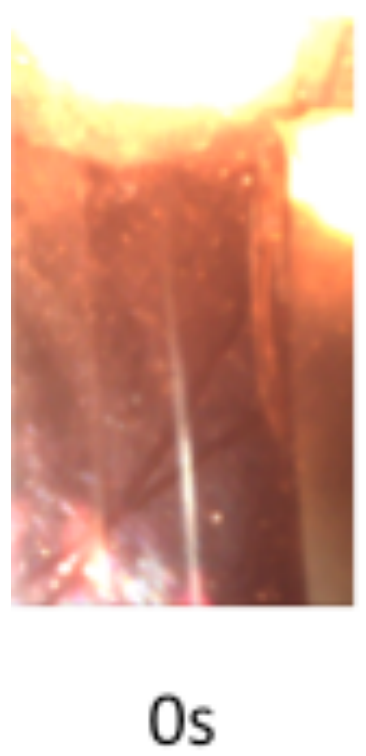
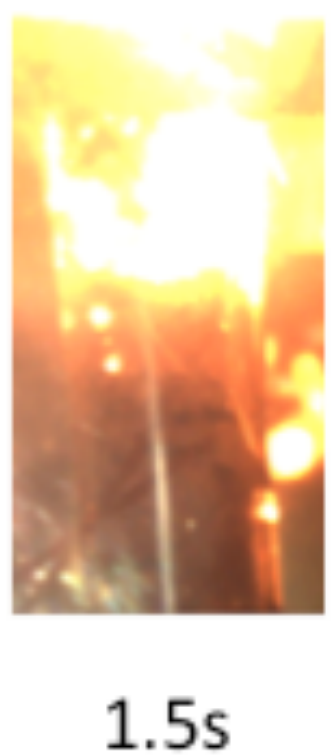

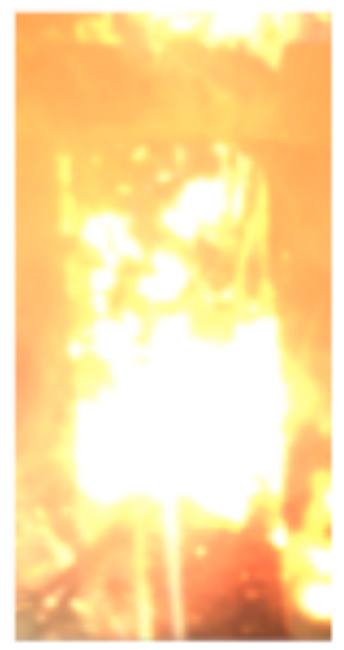

$2 \mathrm{~s}$

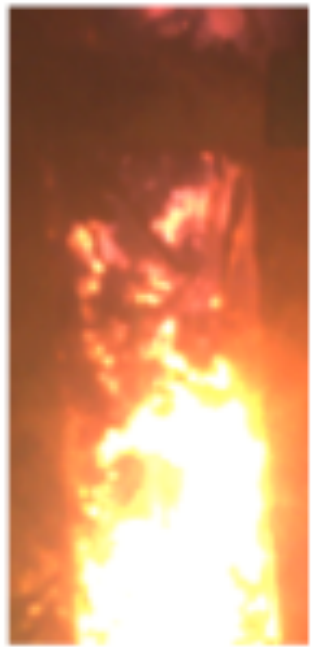

3s

Figure 9. Combustion of $\mathrm{Al} / \mathrm{Mg}$-water mixture $\left(46.5 \mathrm{wt} \% \mathrm{H}_{2} \mathrm{O}\right)$ with $3 \mathrm{wt} \%$ polyacrylamide.

Figure 10 shows the measured combustion front velocities in mixtures with different concentrations of the energetic additive. Temperature readings with a C-type thermocouple showed that temperatures of $1900^{\circ} \mathrm{C}$ were obtained at stoichiometry. Note that for nano-Al/water combustion experiments, a flame temperature of $1527^{\circ} \mathrm{C}$ was documented (24). The difference in the combustion temperatures explains the observed difference between the combustion front velocities. Mechanically alloyed $\mathrm{Al} / \mathrm{Mg}$ powders mixed with gelled water produced flame speeds over $15 \mathrm{~mm} / \mathrm{s}$, whereas the 
front velocity in mixtures of nanoscale $(38 \mathrm{~nm}) \mathrm{Al}$ with gelled water was only $7 \mathrm{~mm} / \mathrm{s}$ in experimenst at $1 \mathrm{~atm}(37)$.

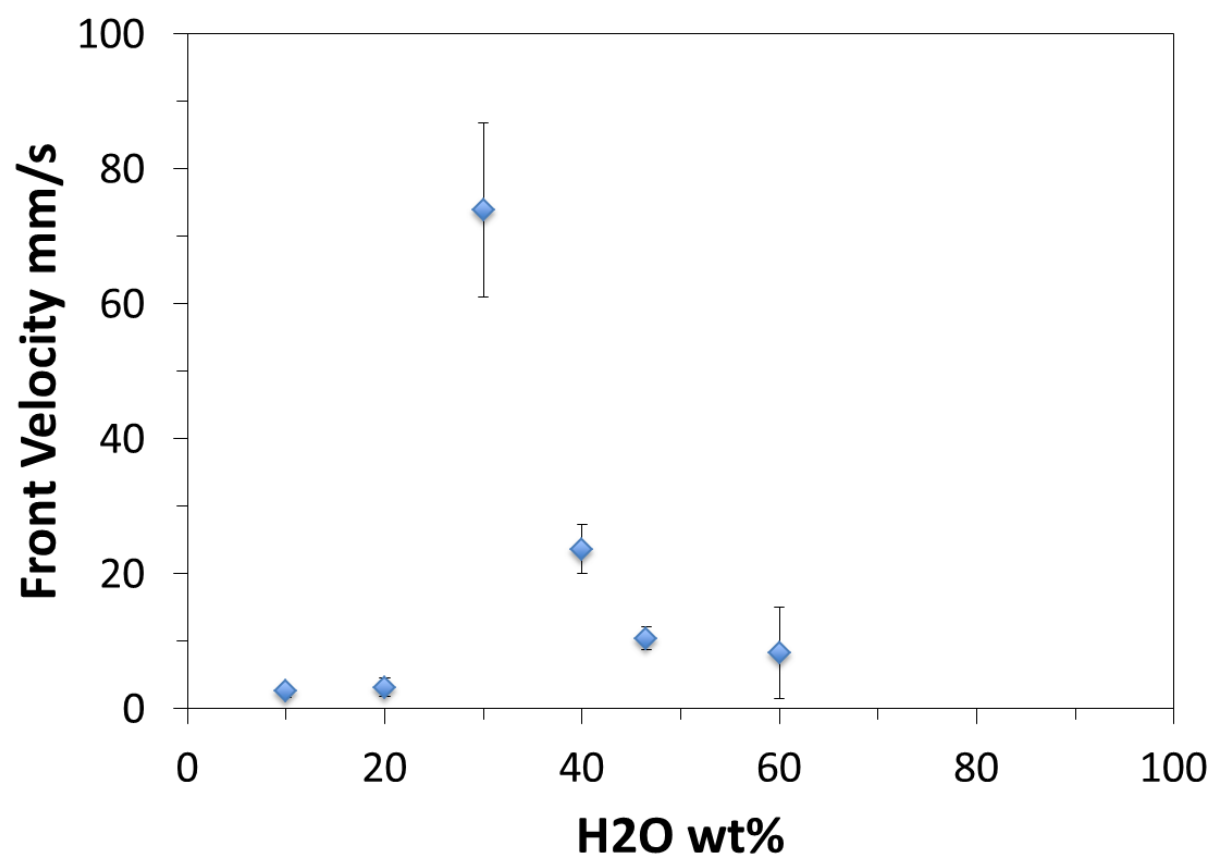

Figure 10. Combustion front velocities in $\mathrm{Al} / \mathrm{Mg}$-water mixtures at $3 \mathrm{wt} \%$ polyacrylamide with respect to water.

Hydrogen yield was initially calculated based on the pressure increase after the combustion, measured with the pressure transducer. Figure 11 shows that, with this approach, the experimental values were higher than theoretically possible, which is obviously impossible. 


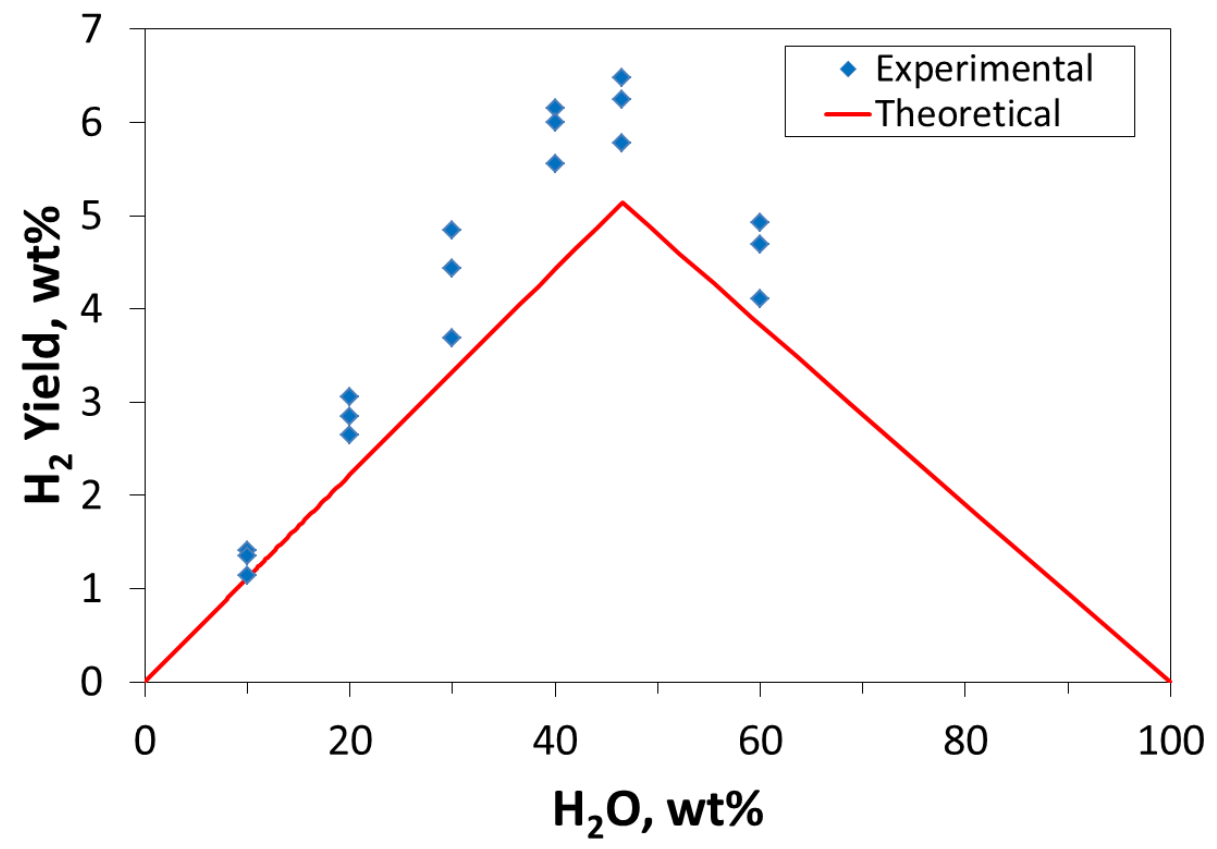

Figure 11. Hydrogen yield in $\mathrm{Al} / \mathrm{Mg}$-water mixtures at $3 \mathrm{wt} \%$ polyacrylamide with respect to water.

It was suggested that decomposition of polyacrylamide generates a significant amount of gases that increase the pressure in the chamber. To verify this hypothesis, experiments were conducted at $1 \mathrm{wt} \%$ polyacrylamide. Figures 12 and 13 show the obtained values of the front velocity and hydrogen yield. It is seen that the mixtures are still combustible, but the front velocities are lower. The pressure increase, indeed, significantly decreased, leading to a better correlation between the experimental and theoretical values of the hydrogen yield. 


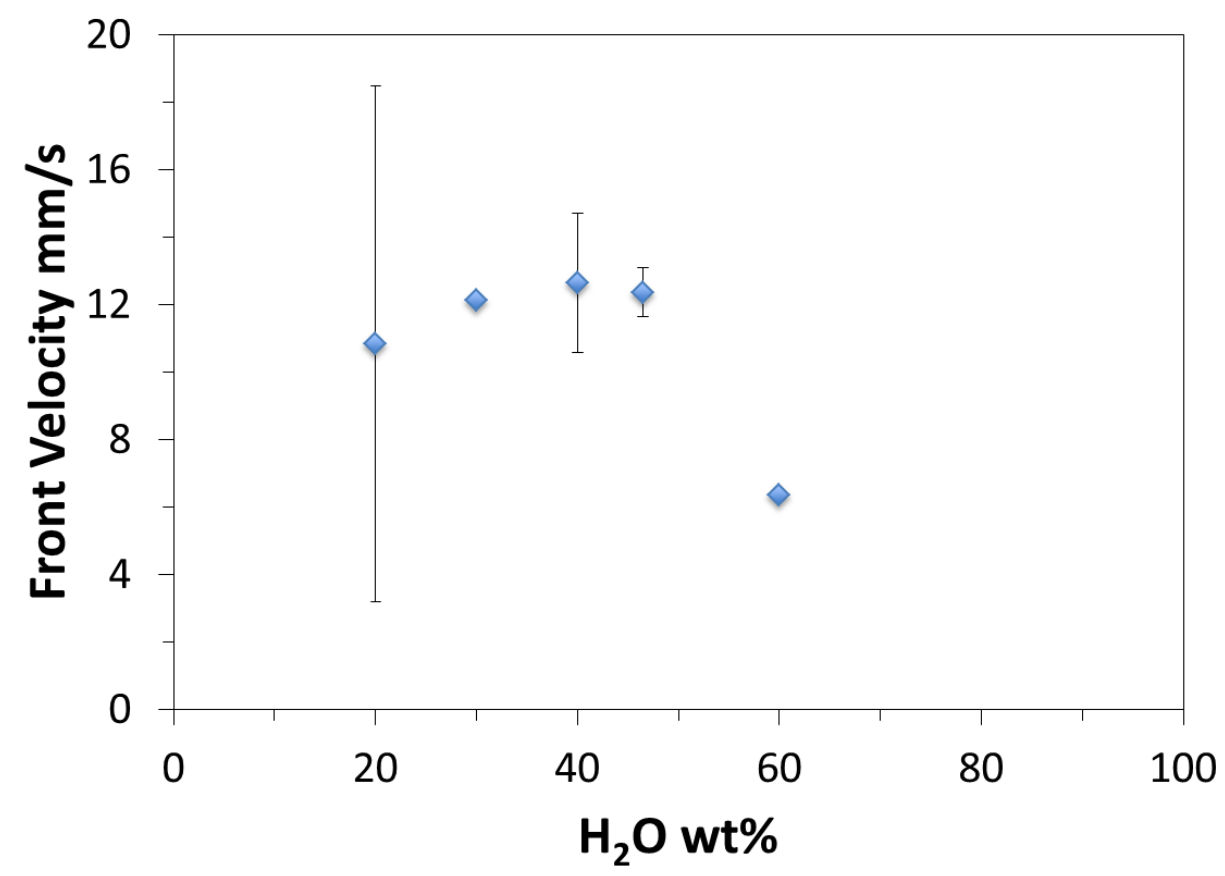

Figure 12. Combustion front velocities in $\mathrm{Al} / \mathrm{Mg}$-water mixtures at $1 \mathrm{wt} \%$ poly(acrylamide-co-acrylic acid) with respect to water.

Mass-spectroscopic analysis of the gas environment in the chamber after combustion has detected peaks at 31 and 44 in addition to argon, hydrogen, and air traces. This confirms the presence of gases evolved from polyacrylamide. Calibration of the mass-spectrometer was performed with the goal of measuring the $\mathrm{H}_{2}$ yield. Figure 14 show that the hydrogen yield is below the maximum theoretical value, which confirms that polyacrylamide produces gases. 


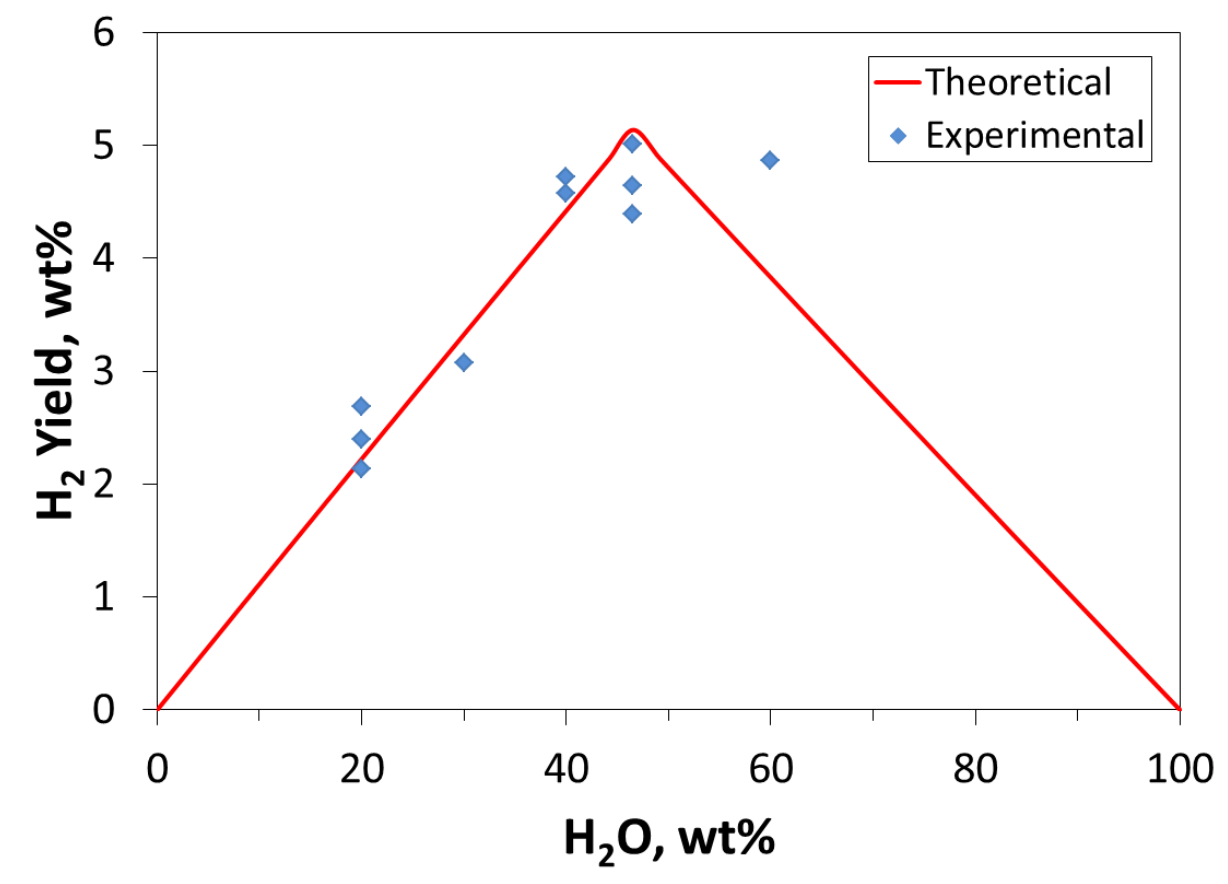

Figure 13. Hydrogen yield in $\mathrm{Al} / \mathrm{Mg}$-water mixtures at $1 \mathrm{wt} \%$ poly(acrylamide-co-acrylic acid) with respect to water.

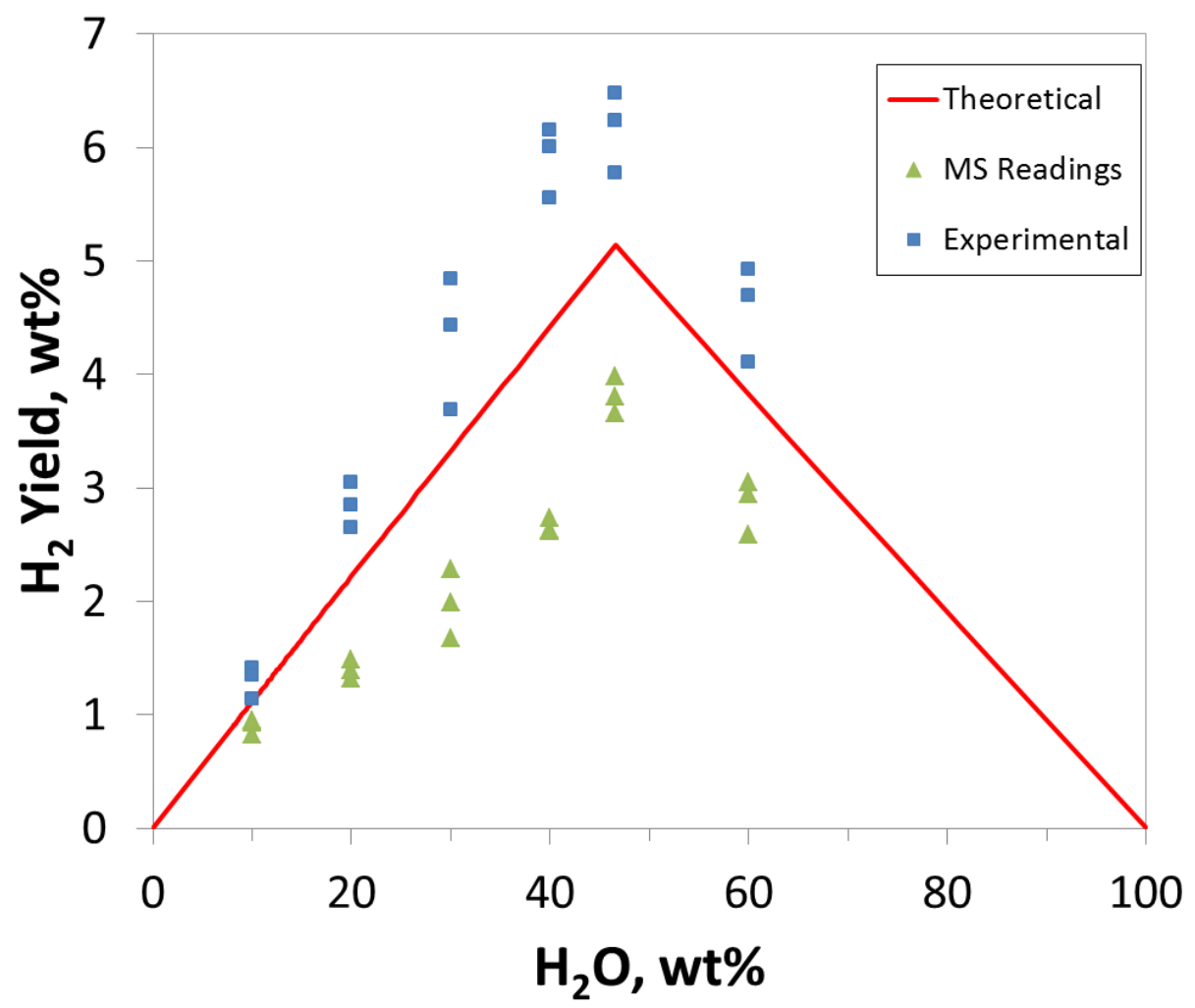

Figure 14. Comparison between $\mathrm{H}_{2}$ yield calculated from pressure readings ( $3 \%$ polyacrylamide) and mass-spectrometer results. 
The product samples were characterized by $\mathrm{X}$-ray diffraction (XRD) using $\mathrm{Cu} \mathrm{K} \alpha$ radiation. Figure 15 presents an XRD pattern of the combustion product of water and mechanically alloyed $\mathrm{Al} / \mathrm{Mg}$ powder (stoichiometric ratio). Peaks for pure $\mathrm{Al}$ of $\mathrm{Mg}$ were not found; therefore, it can be concluded that they fully reacted with water. The identified compounds are $\mathrm{MgO}$ and $\mathrm{MgAl}_{2} \mathrm{O}_{4}$.

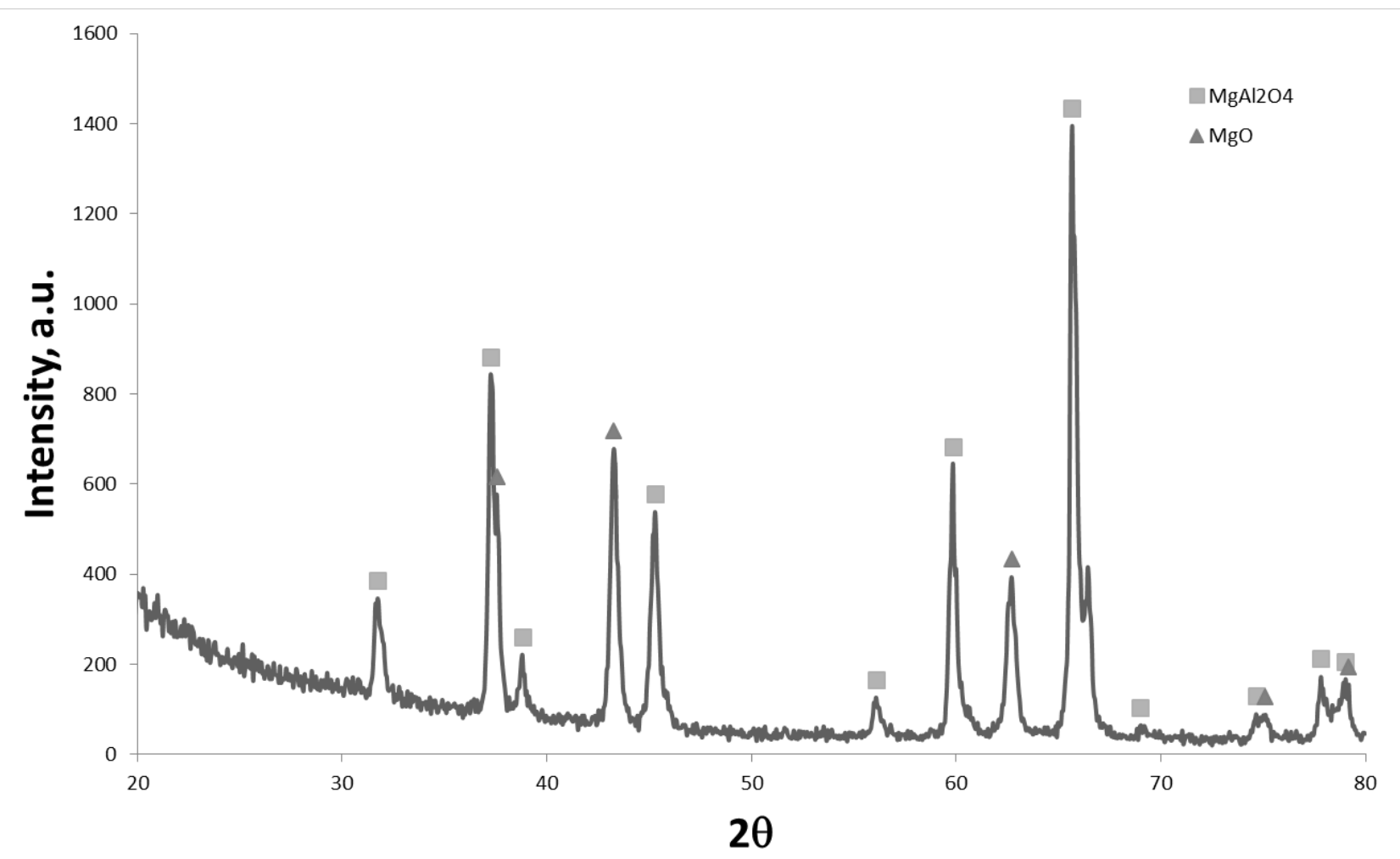

Figure 15. XRD pattern of combustion products for the mixture of water and mechanically alloyed $\mathrm{Al} / \mathrm{Mg}$ powder at the stoichiometric ratio.

The thermal diffusivities of the mixtures were measured using a laser flash apparatus (Netzsch LFA 457 MicroFlash). The thermal diffusivity of water at room temperature is $0.146 \mathrm{~mm}^{2} / \mathrm{s}$. When mechanically alloyed $\mathrm{Al} / \mathrm{Mg}$ powder is added (at stoichiometry), the thermal diffusivity increases to $0.167 \mathrm{~mm}^{2} / \mathrm{s}$. These results are very close to each other, thus the addition of $\mathrm{Al}$ or $\mathrm{Mg}$ does not significantly affect the thermal diffusivity. In addition, measurements for the thermal diffusivity of nano-Al and water were performed for comparison. Aluminum powder (Alfa Aesar, $70 \mathrm{~nm}$ ) was used in these experiemnts. The diffusivity value was $0.167 \mathrm{~mm}^{2} / \mathrm{s}$, i.e., the same as for $\mathrm{Al} / \mathrm{Mg}$ powder. Thus, 
the observed faster combustion of the mixtures with $\mathrm{Al} / \mathrm{Mg}$ powder is associated with the higher combustion temperature and not with different thermophysical properties of the mixtures.

\subsubsection{Ternary mixture: ammonia borane, mechanically alloyed Al/Mg powder, and heavy water results}

Figure 16 shows the thermogravimetric (TG) curve obtained for thermolysis of ammonia borane. The crucible was made of alumina $\left(\mathrm{Al}_{2} \mathrm{O}_{3}\right)$, and the sample mass was set to $5 \mathrm{mg}$. The experiment was conducted in an argon atmosphere with a volumetric flow rate of $20 \mathrm{ml} / \mathrm{min}$. The heating rate was 0.5 $\mathrm{K} / \mathrm{min}$. It can be seen that the first event occurs at about $100^{\circ} \mathrm{C}$, which is the temperature that releases the first equivalent of $\mathrm{H}_{2}$ from $\mathrm{AB}$. The second, much broader event starts at about $115^{\circ} \mathrm{C}$ and ends at about $150^{\circ} \mathrm{C}$. These results are in good agreement with the literature data for $\mathrm{AB}$ thermolysis.

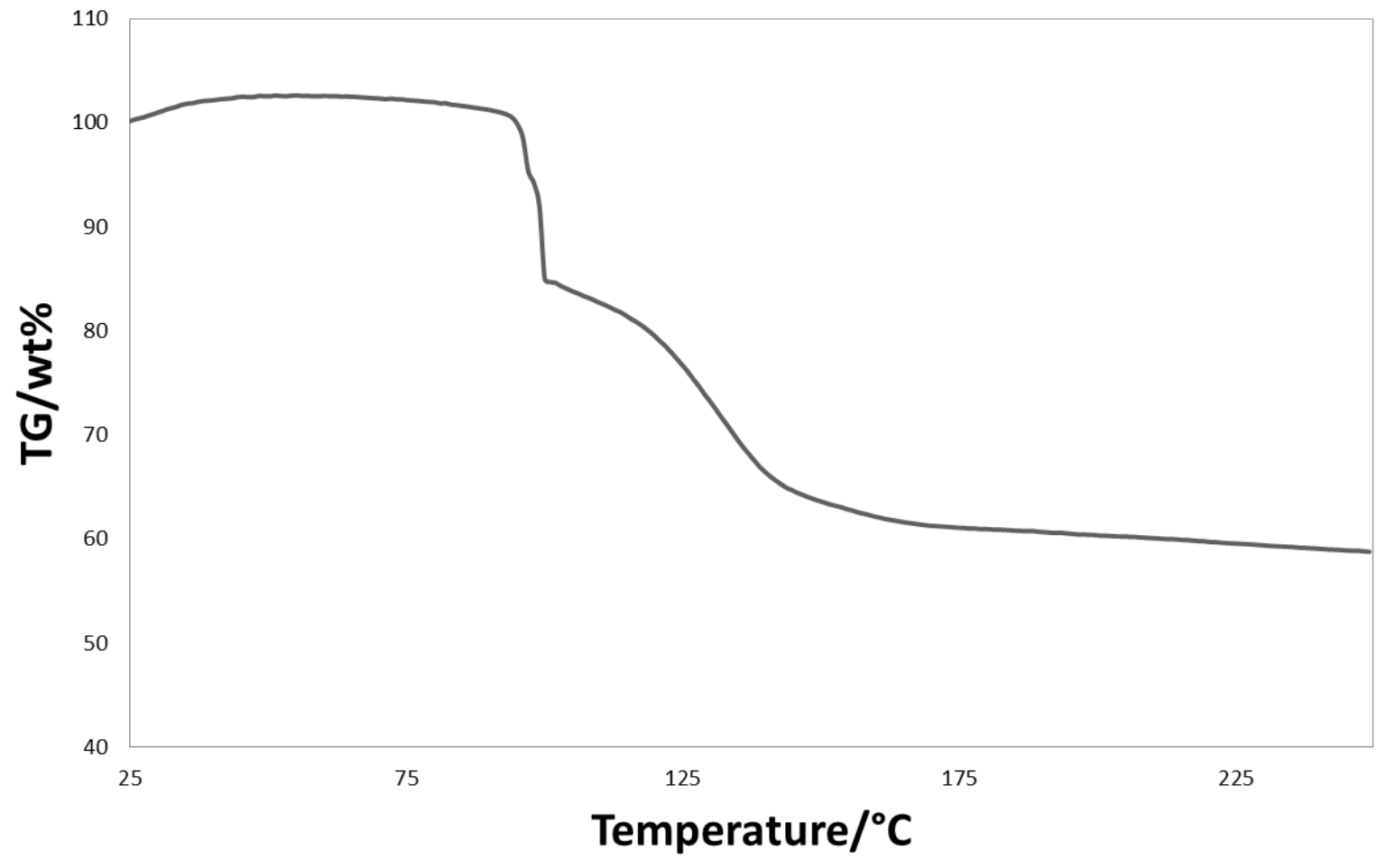

Figure 16. Thermogravimetric curve for the decomposition of $\mathrm{AB}$ at $0.5 \mathrm{~K} / \mathrm{min}$.

Figure 17 shows a $\mathrm{TG}$ curve for a mixture of $\mathrm{Al} / \mathrm{Mg}$ powder with $\mathrm{BH}_{3} \mathrm{NH}_{3}(1: 1$ mass ratio). It is seen that the curve is virtually identical to that shown in Fig. 16. Thus, $\mathrm{Al} / \mathrm{Mg}$ is not a catalyst for $\mathrm{AB}$ decomposition. 


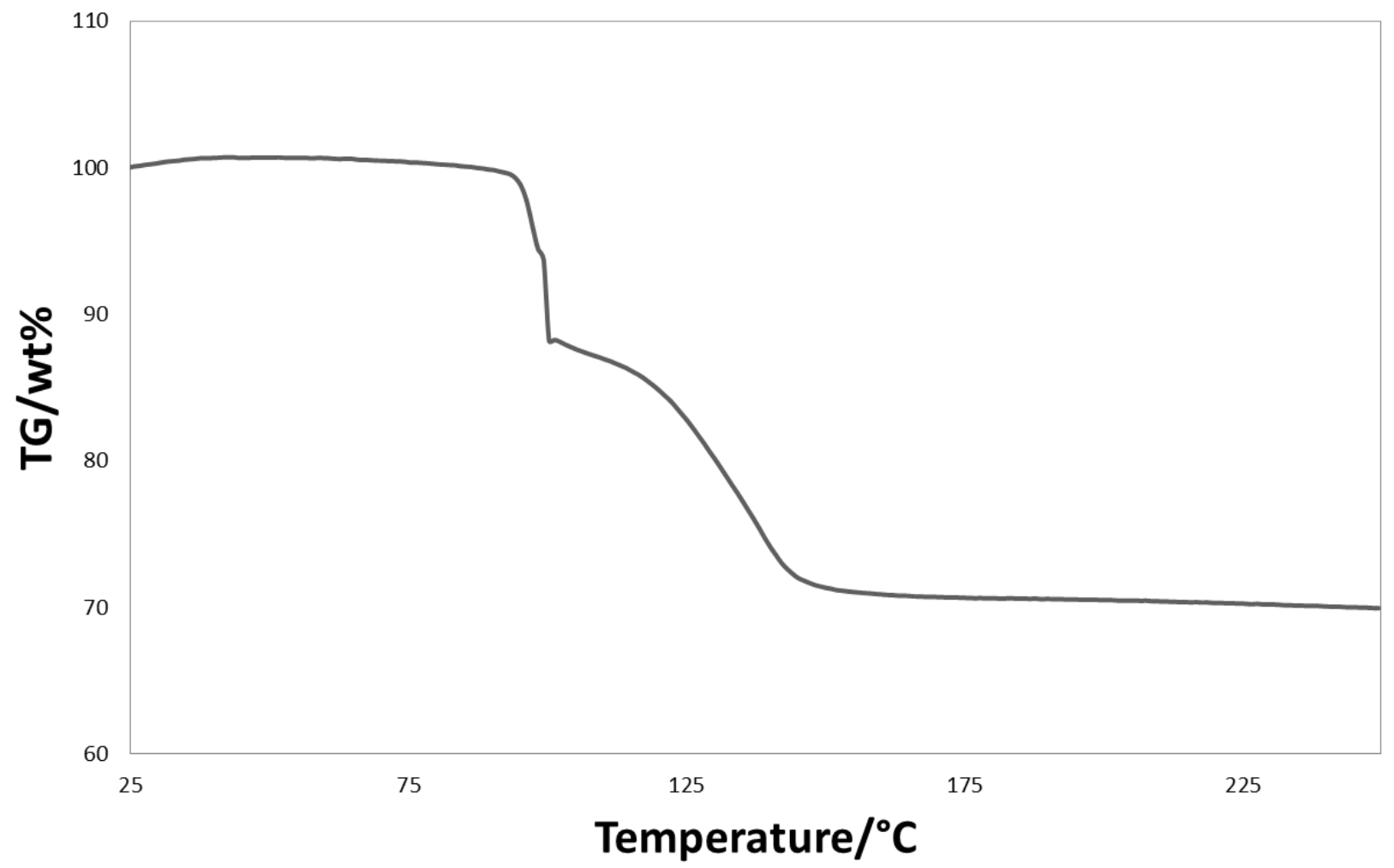

Figure 17. Thermogravimetric curve for $\mathrm{Al} / \mathrm{Mg}$ and $\mathrm{AB}$ mixture (1:1 mass ratio).

\subsubsection{Combustion of ternary mixture}

Experiments for three mixture ratios were conducted:

- Mixture \#1: $20 \mathrm{~mol} \% \mathrm{AB} / 44 \mathrm{~mol} \% \mathrm{D}_{2} \mathrm{O} / 36 \mathrm{~mol} \% \mathrm{Al} / \mathrm{Mg}$

- Mixture \#2: $9.2 \mathrm{~mol} \% \mathrm{AB} / 56.5 \mathrm{~mol} \% \mathrm{D}_{2} \mathrm{O} / 34.3 \mathrm{~mol} \% \mathrm{Al} / \mathrm{Mg}$

- Mixture \#3: $9.4 \mathrm{~mol} \% \mathrm{AB} / 50 \mathrm{~mol} \% \mathrm{D}_{2} \mathrm{O} / 40.6 \mathrm{~mol} \% \mathrm{Al} / \mathrm{Mg}$

Mixture \# 1 was designed based on the assumption that $\mathrm{AB}$ decomposes thermally, while the amount of water corresponds to the stoichiometric reaction with $\mathrm{Al} / \mathrm{Mg}$ (Eqs. 11 and 13). Mixture \#3 was designed based on the same assumption, but the amount of $\mathrm{AB}$ was decreased. Mixture \# 2 included more water to enable hydrolysis of $\mathrm{AB}$ while maintaining enough water for the reaction with $\mathrm{Al} / \mathrm{Mg}$.

Use of $\mathrm{D}_{2} \mathrm{O}$ instead of $\mathrm{H}_{2} \mathrm{O}$ does not change the mole ratio, but changes the mass fractions. In the experiments (which involved $\mathrm{D}_{2} \mathrm{O}$ and not $\mathrm{H}_{2} \mathrm{O}$ ), the mixture compositions in wt $\%$ were as follows:

- Mixture \#1: $25 \mathrm{wt} \% \mathrm{AB} / 36.9 \% \mathrm{D}_{2} \mathrm{O} / 38.1 \% \mathrm{Al} / \mathrm{Mg}$

- Mixture \#2: 12.5 wt\% AB/49.4 wt $\% \mathrm{D}_{2} \mathrm{O} / 38.1 \mathrm{wt} \% \mathrm{Al} / \mathrm{Mg}$ 
- Mixture \#3: $12.5 \mathrm{wt} \% \mathrm{AB} / 43.05 \mathrm{wt} \% \mathrm{D}_{2} \mathrm{O} / 44.45 \mathrm{wt} \% \mathrm{Al} / \mathrm{Mg}$

The experiments were initially conducted with mixture \#1. They have shown that this mixture is combustible, but it was close to the limit of combustibility. A mixture with $33 \mathrm{wt} \% \mathrm{AB}$ did not ignite. Consequently, experiments with a lower amount of $\mathrm{AB}(12.5 \mathrm{wt} \% \mathrm{AB})$ were conducted for comparison.

Figure 18 shows images of the combustion wave traveling through the ignited sample of mixture \#3. The bright area at the top is apparently associated with a booster pellet used for ignition and made of the mixture of $\mathrm{A} / \mathrm{Mg}$ powder and gelled water, with no $\mathrm{AB}$. The reaction of $\mathrm{Al} / \mathrm{Mg}$ with water provides enough heat to support the combustion wave propagation. Thermolysis of $\mathrm{AB}$, hydrolysis of $\mathrm{AB}$, and combustion of $\mathrm{Al} / \mathrm{Mg}$ particles with water may occur in the combustion wave.

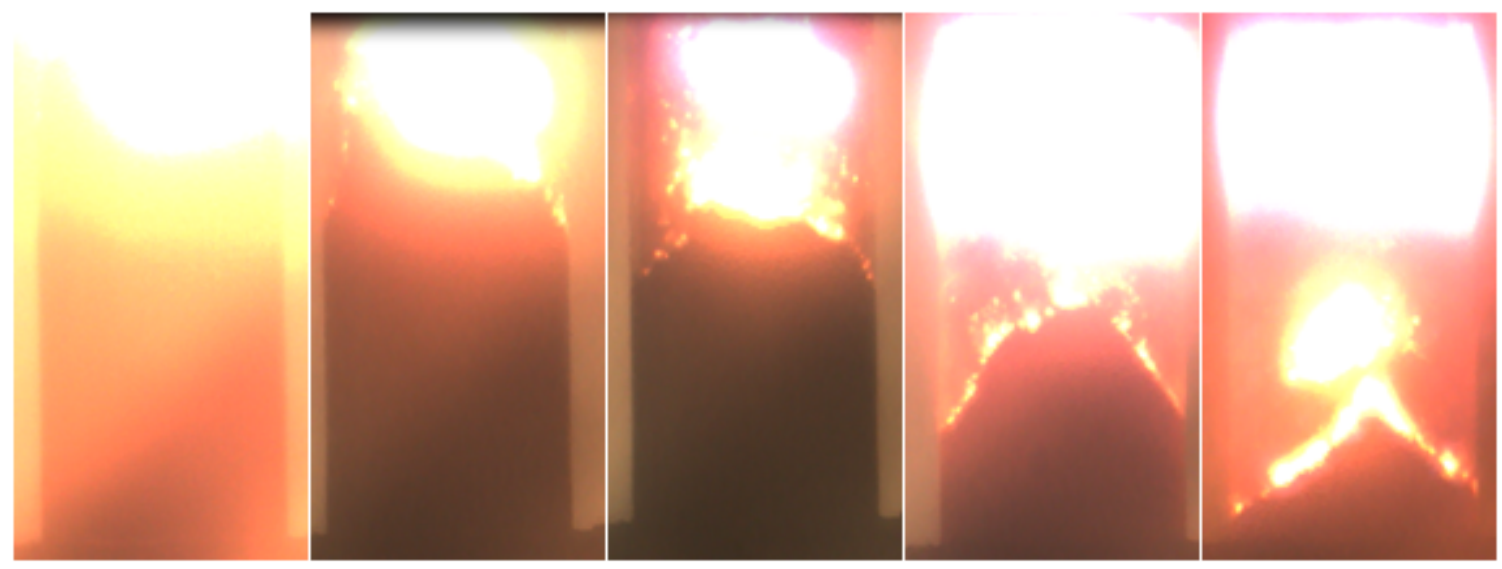

Figure 18. Combustion of mixture \#3. Images taken at 1,2,3 and $5 \mathrm{~s}$ after ignition.

Figure 19 shows the combustion flame velocities for the three mixture ratios, where each point was obtained based on the results of three tests. Comparison with the data for $\mathrm{Al} / \mathrm{Mg}$-water mixtures (Figs. 10 and 12) shows that the addition of $\mathrm{AB}$ decreases the front velocity. This is quite understandable because the heat releases of $\mathrm{AB}$ thermolysis and hydrolysis are much smaller than the heat release of $\mathrm{Al} / \mathrm{Mg}$ reaction with water. As for the difference between the front velocities of the three mixtures shown in Fig. 19, it is difficult to make any reasonable explanations and the scatter for mixture $\# 3$ is too large. 


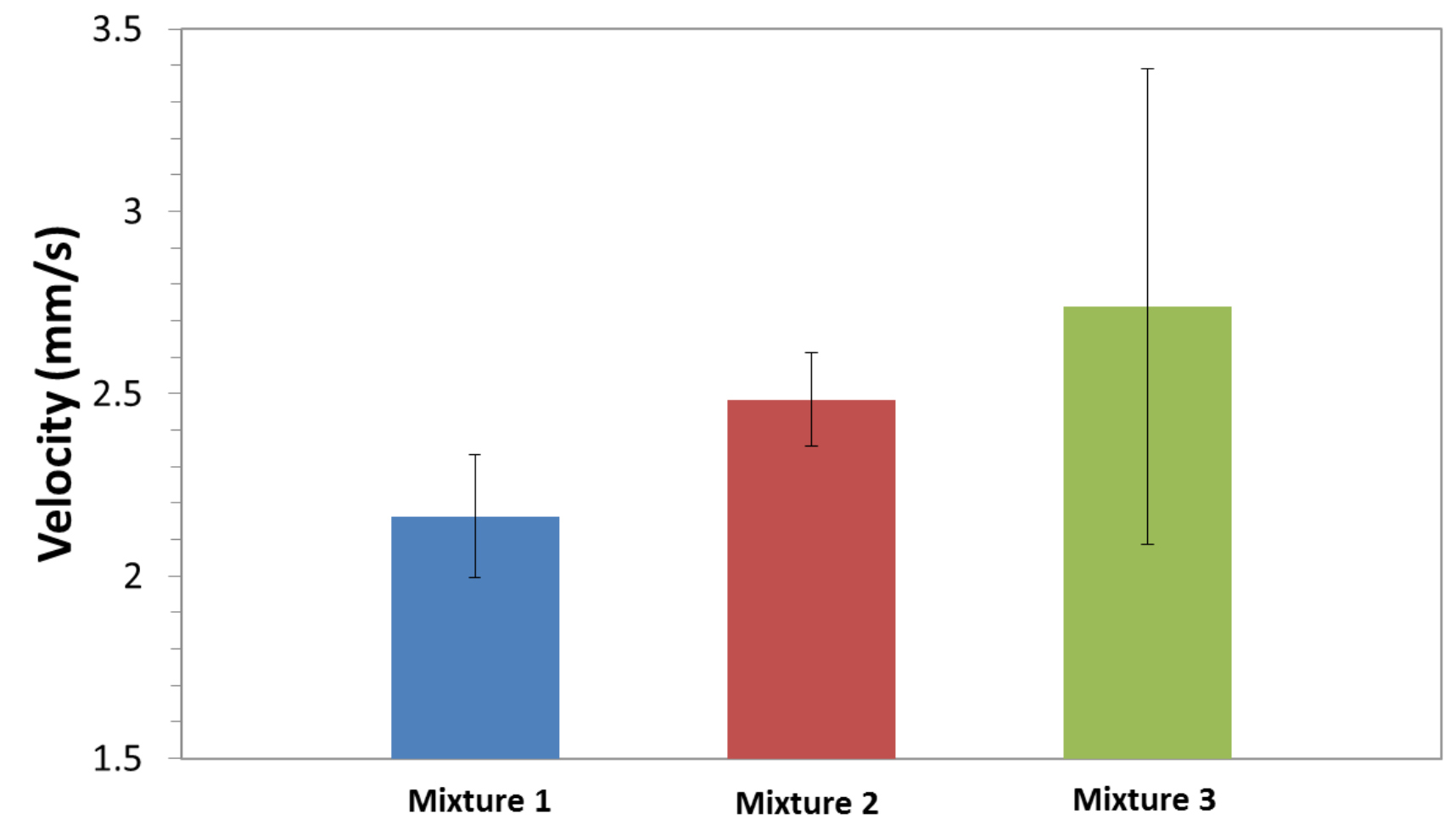

Figure 19. Combustion front velocity for each mixture.

Mass-spectroscopic analysis of the produced gases was performed for each mixture ratio. The use of $\mathrm{D}_{2} \mathrm{O}$ has allowed for the conclusions on the reaction mechanisms. Indeed, $\mathrm{H}_{2}$ is released from the thermal decomposition of $\mathrm{NH}_{3} \mathrm{BH}_{3}$, deuterium hydride (HD) is produced from $\mathrm{AB}$ hydrolysis (reaction between $\mathrm{D}_{2} \mathrm{O}$ and $\mathrm{AB}$ ), and $\mathrm{D}_{2}$ is extracted from the reaction between $\mathrm{Al} / \mathrm{Mg}$ and $\mathrm{D}_{2} \mathrm{O}$. Thus, the roles of the three pathways can be revealed based on the ratios between the amounts of three gases $\left(\mathrm{H}_{2}, \mathrm{HD}\right.$, and $\left.\mathrm{D}_{2}\right)$.

Figures 20-22 show the measured amounts of $\mathrm{H}_{2}, \mathrm{HD}$, and $\mathrm{D}_{2}$ per unit mass of the initial mixture. Each point was obtained based on three tests.

Based on the data for $\mathrm{H}_{2}$ (Fig. 20) and HD (Fig. 21), a plot was generated (Fig. 23) that shows what fraction of the total available $\mathrm{H}$ was detected in gas phase. It is seen that for the mixtures \#1 and \#2 about $62 \%$ of $\mathrm{H}$, available in $\mathrm{AB}$, was released to gas phase and detected by MS as either $\mathrm{H}_{2}$ or part of $\mathrm{HD}$, while for mixture \#3, the released fraction of $\mathrm{H}$ increased to $87 \%$. In addition, the same figure shows what percentage of the produced hydrogen $\left(\mathrm{H}_{2}\right.$ plus $\mathrm{H}$ from $\left.\mathrm{HD}\right)$ comes from thermal 
decomposition of ammonia borane as $\mathrm{H}_{2}$, and how much comes from hydrolysis as " $\mathrm{H}$ " part of the formed HD.

Based on the data for $\mathrm{HD}$ (Fig. 21) and $\mathrm{D}_{2}$ (Fig. 22), a plot was generated (Fig. 24) that shows what fraction of the total available deuterium was detected in gas phase as either $\mathrm{D}_{2}$ or part of HD. It is seen that about $60 \%$ of deuterium was released to gas phase and detected by MS. In addition, the same figure shows what percentage of the released deuterium came from $\mathrm{Al} / \mathrm{Mg}$ hydrolysis and how much came from $\mathrm{AB}$ hydrolysis.

Based on these results, a conclusion can be made that thermal decomposition of $\mathrm{AB}$ and hydrolysis of $\mathrm{Al} / \mathrm{Mg}$ play major roles in hydrogen generation during combustion of the tested mixtures, while hydrolysis of AB plays a secondary role.

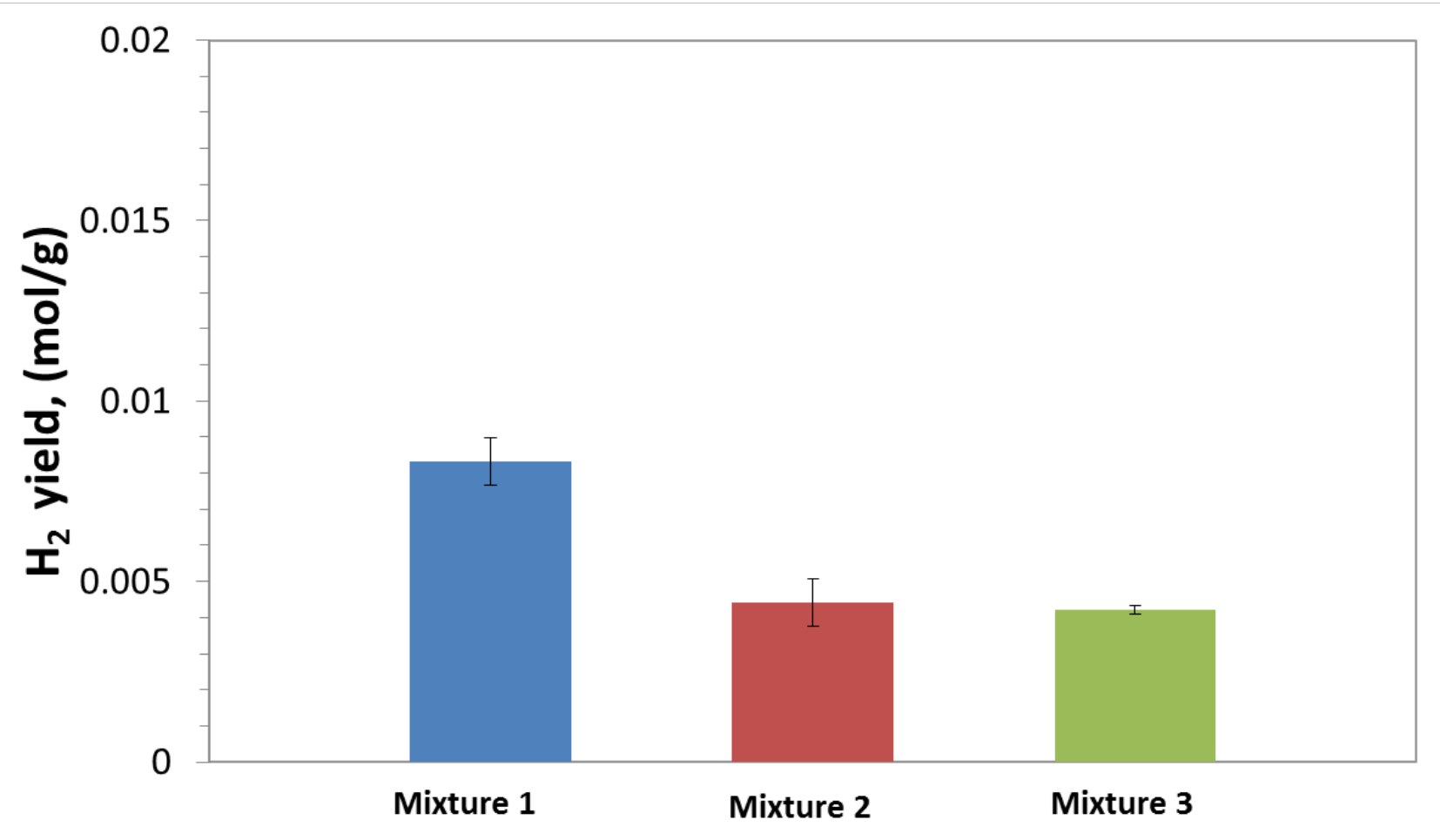

Figure 20. Total amount of $\mathrm{H}_{2}$ (in moles) per unit mass of the total mixture. 


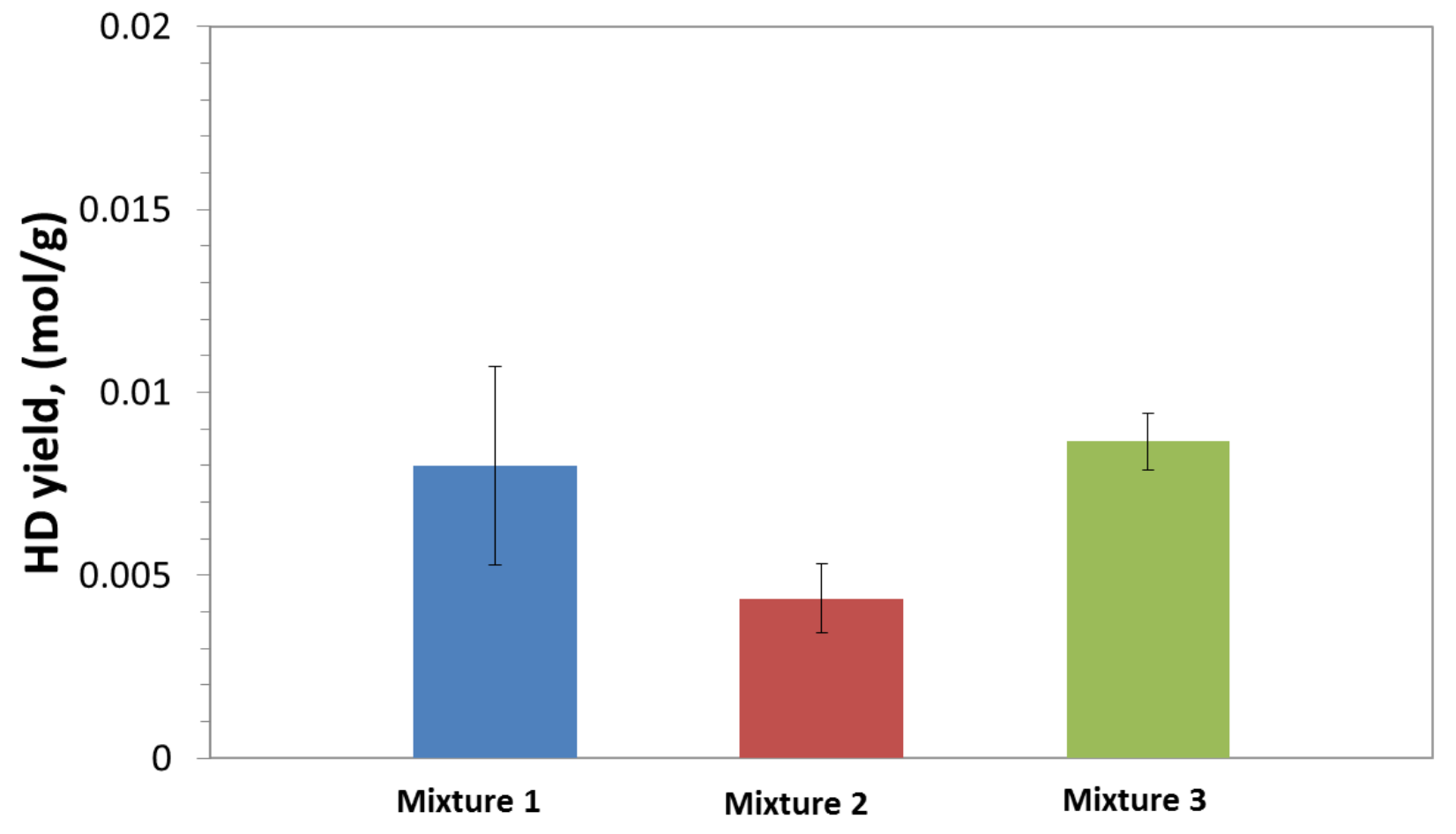

Figure 21. Total amount of HD (in moles) per unit mass of the total mixture.

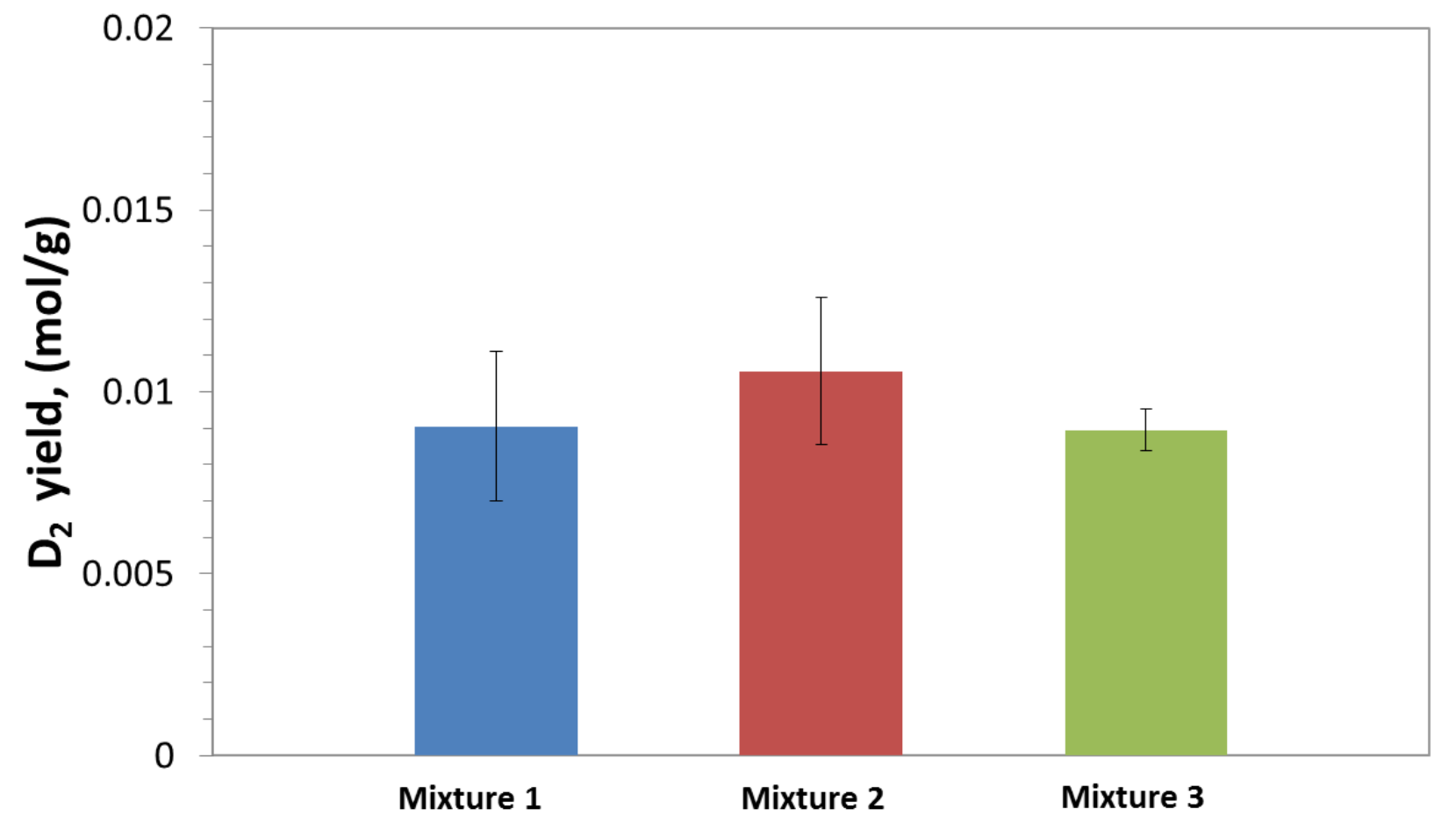

Figure 22. Total amount of $\mathrm{D}_{2}$ (in moles) per unit mass of the total mixture. 


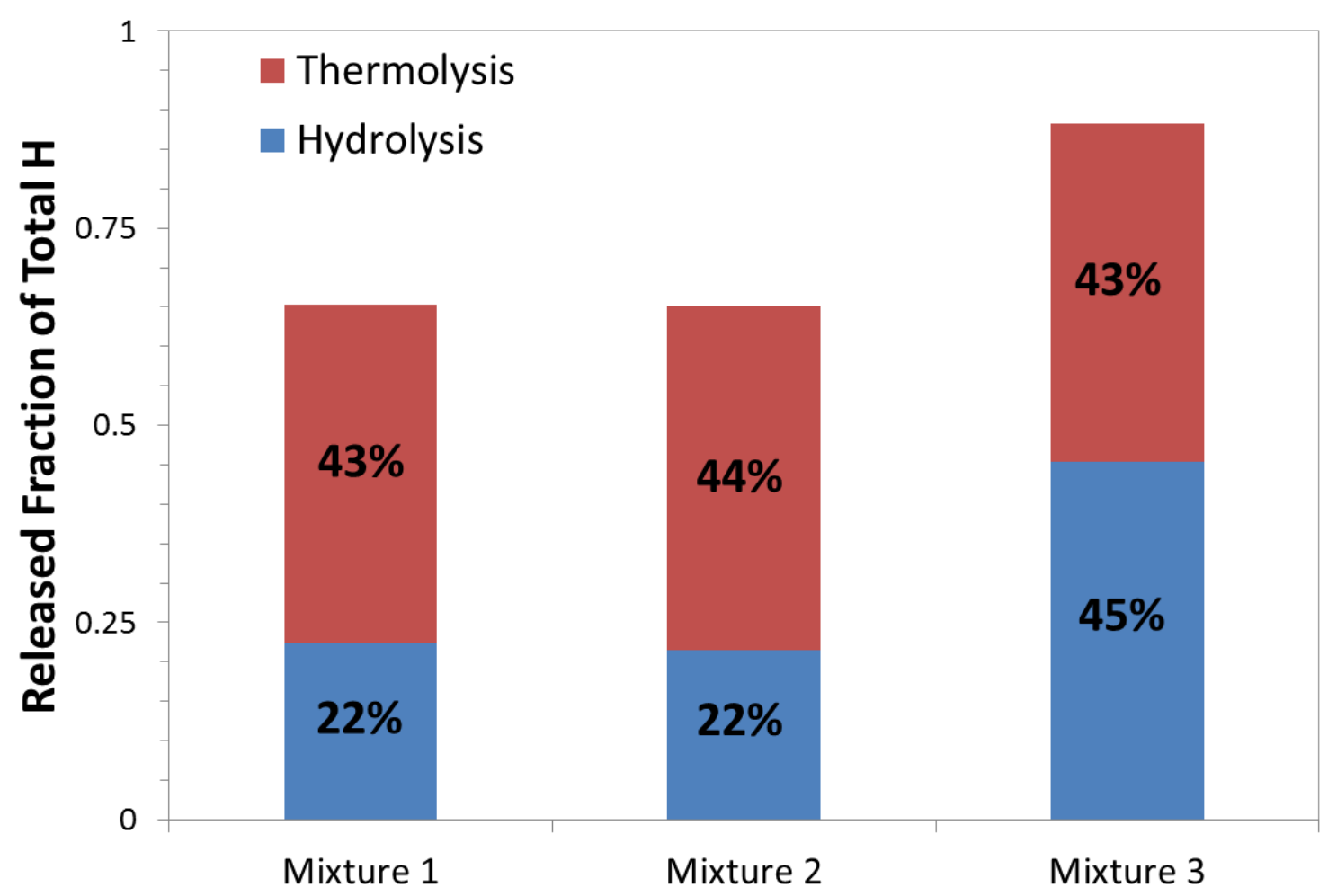

Figure 23. Released fraction of total available $\mathrm{H}$ via $\mathrm{AB}$ thermolysis and $\mathrm{AB}$ hydrolysis.

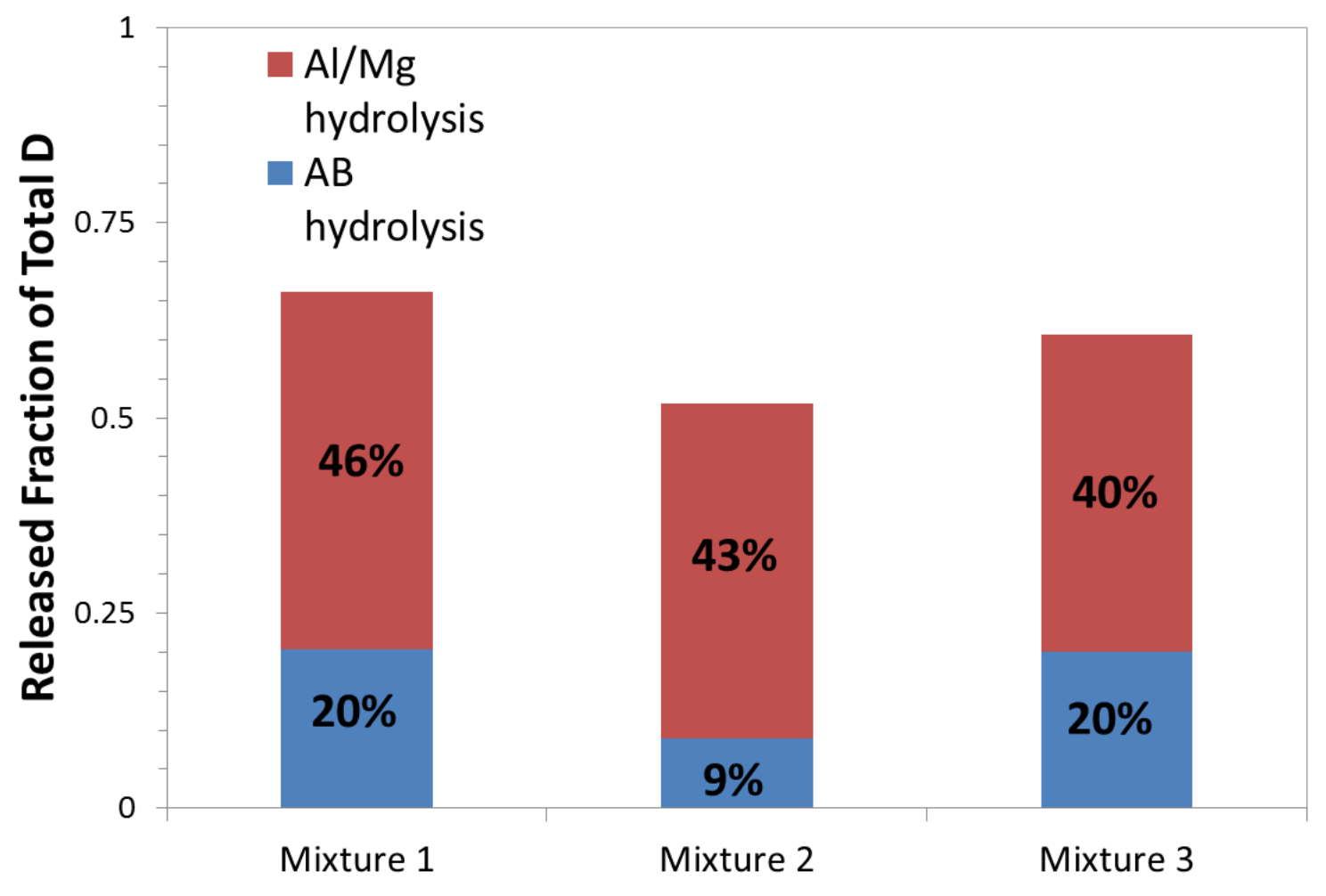

Figure 24. Released fraction of total available $\mathrm{D}$ via $\mathrm{Al} / \mathrm{Mg}$ hydrolysis and $\mathrm{AB}$ hydrolysis. 
To determine the maximum hydrogen yield for the tested compositions, the mass fractions of all components in the initial mixtures and in the released gases were recalculated for $\mathrm{H}$ as the only isotope of hydrogen. Figure 25 shows the resulting total hydrogen yield per unit mass of mixture for each composition. The maximum theoretical yield for each mixture (based on the assumption that all hydrogen is released) is also shown in this figure. It is seen that mixture \#1 provides the highest hydrogen yield, while mixture \# 3 is the most efficient from the standpoint of approaching the theoretical limit.

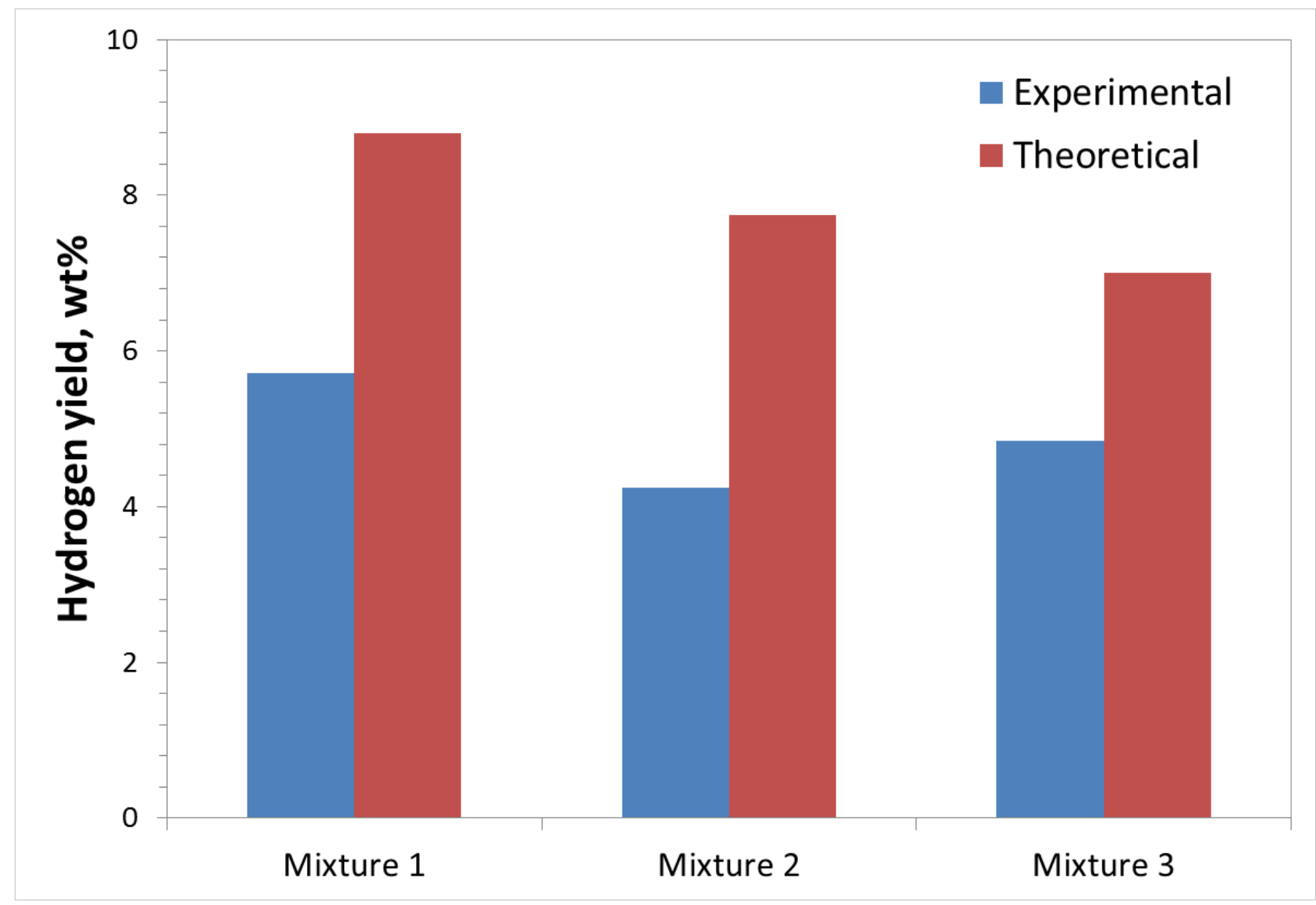

Figure 25. Theoretical gravimetric hydrogen yield of $\mathrm{AB} / \mathrm{H}_{2} \mathrm{O} / \mathrm{Al} / \mathrm{Mg}$ mixtures and its experimental values, obtained by recalculating the data obtained in experiments with $A B / D_{2} O / A l / M g$ mixtures.

Analysis of condensed products was performed using XRD. Figure 26 shows XRD pattern of the products obtained after combustion of mixture \#2. $\mathrm{MgO}, \mathrm{MgAl}_{2} \mathrm{O}_{4}$ and $\mathrm{Mg}\left(\mathrm{BO}_{2}\right)_{2}$ were detected. The first two compounds are produced by the reaction between water and $\mathrm{Al} / \mathrm{Mg}$ particles. The absence of $\mathrm{Al}$ 
and $\mathrm{Mg}$ phases indicates that both metals were fully oxidized by $\mathrm{D}_{2} \mathrm{O}$. The presence of $\operatorname{Mg}\left(\mathrm{BO}_{2}\right)_{2}$ phase is explained by the fact that $\mathrm{AB}$ hydrolysis produces $\left(\mathrm{BO}_{2}\right)^{-}$ion (see Eq. 8). The absence of $\mathrm{BN}$ indicates that the third stage of $\mathrm{AB}$ decomposition was not achieved. The condensed products of the first and second stages of $\mathrm{AB}$ thermolysis are amorphous according to the literature (38) and hence they cannot be seen in XRD patterns.

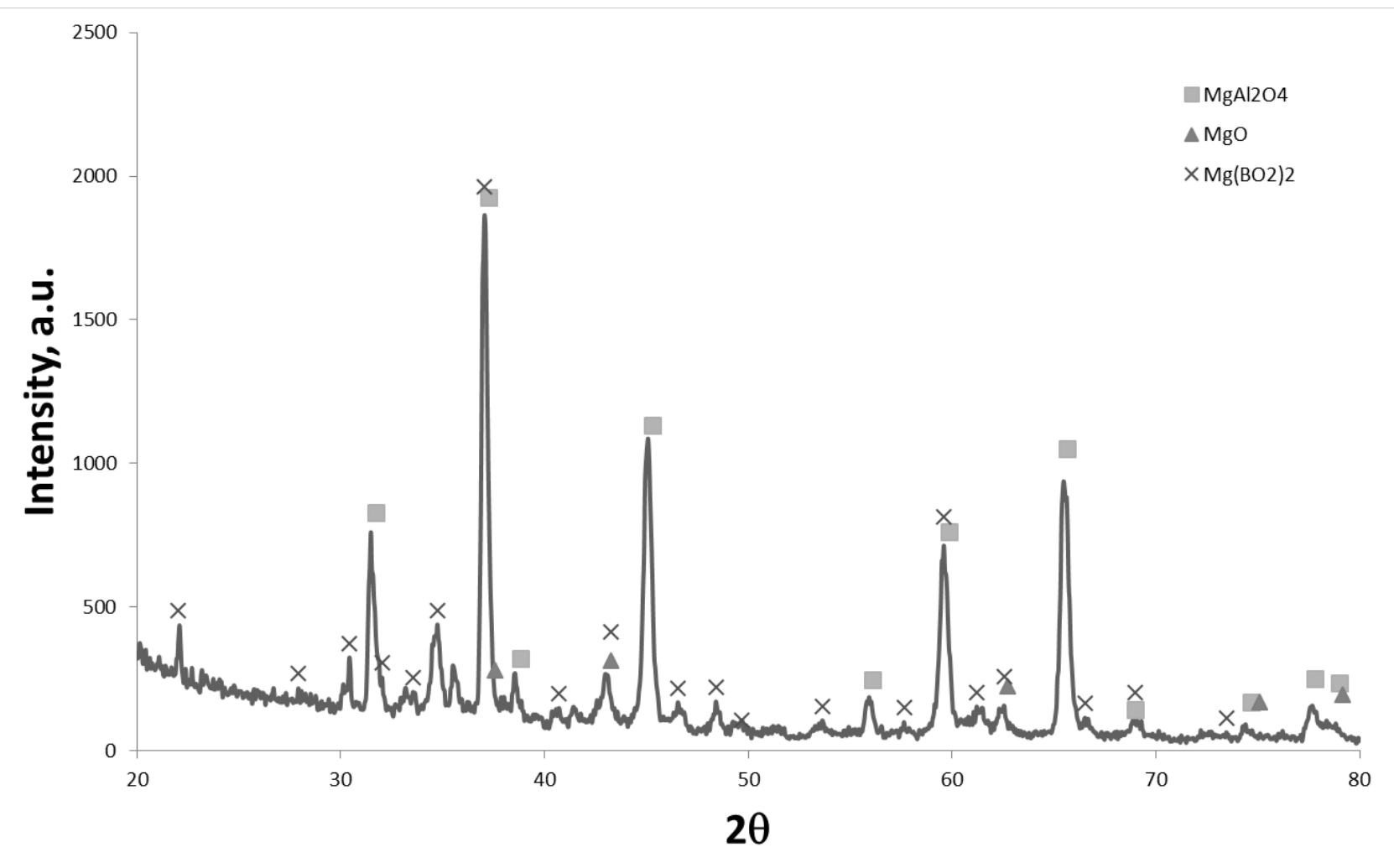

Figure 26. XRD pattern of the product obtained after combustion of mixture \#2.

\subsection{Summary}

The experiments with nancomposite reactive materials $\mathrm{Ti} / \mathrm{B}, \mathrm{Al} / \mathrm{NaNO}_{3}$, and $\mathrm{Al} / \mathrm{MoO}_{3}$ as energetic additives to ammonia borane were unsuccessful. This is apparently associated with the large particle size of $\mathrm{AB}$.

A different approach was proposed that involves the reaction of mechanically alloyed $\mathrm{Al} / \mathrm{Mg}$ powder with water as a source of heat for $\mathrm{AB}$ decomposition. Experiments have shown that mixtures of 
this powder with gelled water are combustible. The velocities of combustion front propagation exceed the values obtained for mixtures of nanoscale Al with gelled water.

Experiments have been conducted with mixtures of $\mathrm{AB}$ with mechanically alloyed $\mathrm{Al} / \mathrm{Mg}$ powder and heavy water $\left(\mathrm{D}_{2} \mathrm{O}\right)$. Heavy water was used for investigating the reaction mechanisms through mass-spectroscopy of released $\mathrm{H}_{2}, \mathrm{HD}$, and $\mathrm{D}_{2}$ gases. The addition of ammonia borane to the $\mathrm{Al} / \mathrm{Mg}$-water mixture increased the total hydrogen yield. A total hydrogen efficiency of $71 \%$ was achieved by using this additive with water and mechanically alloyed $\mathrm{Al} / \mathrm{Mg}$ powder. The isotopic tests have shown that $\mathrm{AB}$ participates in two parallel processes - thermolysis and hydrolysis. Also, it has been shown that thermal decomposition of $\mathrm{AB}$ and hydrolysis of $\mathrm{Al} / \mathrm{Mg}$ play major roles in hydrogen generation during combustion of the tested mixtures, while hydrolysis of AB plays a secondary role. 


\section{Chapter 5: Conclusion}

The goal of this research project was to investigate combustible mixtures for hydrogen generation based on ammonia borane and novel reacting materials fabricated at the new Jersey Institute of Technology. Thermodynamic calculations predicted that mixtures of ammonia borane with several thermites and intermetallics would be promising, but in experiments, too much additive was needed for ignition. Experiments with mixtures of gelled water and mechanically alloyed $\mathrm{Al} / \mathrm{Mg}$ powder were successful. It was shown that these mixtures are combustible, with burn rates being higher than for nanoAl-water mixtures. Isotopic tests involving heavy water, $\mathrm{Al} / \mathrm{Mg}$ powder, and ammonia borane were conducted. The addition of ammonia borane to the $\mathrm{Al} / \mathrm{Mg}$-water mixture increased the total hydrogen yield. A total hydrogen efficiency of $71 \%$ was achieved by using this additive with water and mechanically alloyed $\mathrm{Al} / \mathrm{Mg}$ powder. Moreover, the isotopic tests have shown that ammonia borane participates in two parallel processes - thermolysis and hydrolysis. Also, it has been shown that thermal decomposition of $\mathrm{AB}$ and hydrolysis of $\mathrm{Al} / \mathrm{Mg}$ play major roles in hydrogen generation during combustion of the tested mixtures, while hydrolysis of $\mathrm{AB}$ plays a secondary role.

The results of the present work indicate that combustible mixtures of ammonia borane, water, and mechanically alloyed $\mathrm{Al} / \mathrm{Mg}$ powder are promising for the development of hydrogen generators that release large amounts of hydrogen upon ignition. 


\section{Bibliography}

1. A. T-Raissi, "Hydrogen from Ammonia Borane and Ammonia Borane Complex for Fuel Cell Applications." Florida Solar Energy Center, 2002.

2. F.H. Stephens, V. Pons, and R.T. Baker. "Ammonia-borane: the hydrogen source par excellence?" Dalton Transactions, 2007, pp. 2613-2626.

3. M. Diwan, V. Diakov, E. Shafirovich, and A. Varma. "Noncatalytic hydrothermolysis of ammonia borane." International Journal of Hydrogen Energy, Vol. 33, No. 4, 2007, pp. 1135-1141.

4. E. Dreizin, "Metal-based reactive nanomaterials." Progress in Energy and Combustion Science, Vol. 35, No. 2, 2009, pp 141-167.

5. C. C. Cormos, L. Petrescu, and A. M. Comos, "Assessment of Hydrogen production systems based on natural gas conversion with carbon capture and storage." Computer Aided Chemical Engineering, Vol. 33, 2014, pp. 1081-1086.

6. "The Path to a Hydrogen Economy." Committee on Science, House of Representatives. Washington, DC, 2003. Serial No. 108-4.

7. S. Dillich, "2009 DOE Hydrogen Program \& Vehicle Technologies Program." 2009.

8. T. Umegaki, J.M. Yan, X. B. Zhang, H. Shioyama, N. Kuriyama, and Q. Xu, "Boron- and nitrogenbased chemical hydrogen storage materials." International Journal of Hydrogen Energy, Vol. 34, No. 5, 2009, pp. 2303-2311.

9. P. Chen, Z. Xiong, J. Luo, J. Lin, and K.L. Tan, "Interaction of hydrogen with metal nitrides and imides." Nature, Vol. 420, 2002, pp. 420; 302-304.

10. S.C. Amendola, S.L. Sharp-Goldman, M. Saleem Janjua, M.T. Kelly, P.J. Petillo, and M. Binder. "An ultrasafe hydrogen generator: aqueous, alkaline borohydride solutions and Ru catalyst." Journal of Power Sources, Vol. 85, No. 2, 2000, pp. 186-189.

11. S.C. Amendola, S.L. Sharp-Goldman, M. S. Janjua, N.C. Spencer, M.T. Kelly, and P.J. Petillo, "A safe, portable, hydrogen gas generator using aqueous borohydride solution and Ru catalyst." International Journal of Hydrogen Energy, Vol. 25, No. 10, 2000, pp. 969-975.

12. H.I. Schlesinger, and H.C. Brown, "Metal borohydrides. III.Lithium borohydride." Journal of the American Chemical Society, 1940, pp. 3429-3435.

13. Y. Kojima, Y. Kawai, M. Kimbara, H. Nakanishi, and S. Matsumoto, "Hydrogen generation by hydrolysis reaction of lithium borohydride." International Journal of Hydrogen Energy, Vol. 29, No. 12, 2004, pp. 1213-1217.

14. H.I. Schlesinger, H.C. Brown, A.E. Finholt, J.R. Gilbreath, H.R Hoekstra, and E.K. Hyde, "Sodium borohydride, its hydrolysis and its use as a reducing agent and in the generation of hydrogen." Journal of the American Chemical Society, 1953, pp. 215-219.

15. C. Wu, H. Zhang, and B. Yi, "Hydrogen generation from catalytic hydrolysis of sodium borohydride for proton exchange membrane fuel cells." Catalysis Today, Vol. 93-95, 2004, pp. 477-483.

16. J.S. Zhang, W.N. Delgass, T.S. Fisher, and J.P. Gore, "Kinetics of Ru catalized sodium borohydride hydrolysis." Journal of Power Sources, Vol. 164, No. 2, 2007, pp. 772-781.

17. M. Chandra, and Q. Xu, "A high-performance hydrogen generation system: transitionmetalcatalyzed dissociation and hydrolysis of ammonia-borane." Journal of Power Sources, Vol. 156, No. 2, 2006, pp. 190-194.

18. J.M. Yan, X.B. Zhang, S. Han, H. Shioyama, and Q. Xu, "Iron nanoparticle catalyzed hydrolytic dehydrogenation of ammonia borane for chemical hydrogen storage." Angewandte Chemie International Edition, Vol. 47, No. 12, 2008, pp. 2287-2289.

19. R. Schlogl, "Catalytic synthesis of ammonia-A "never ending story? " Angewandte Chemie International Edition, 2003, pp.2004-2008. 
20. G. Thomas, and G. Parks "Potential roles of ammonia in a hydrogen economy." 2006. http://www.hydrogen .energy.gov/.

21. A. Gutowska, L. Li, Y. Shin, C. M. Wang, S. Li. Xiaohong, J. C. Linehan, R. S. Smith, B. D. Kay, B. Schmid, W. Shaw, M. Gutowski, and T. Autrey, "Nanoscaffold Mediates Hydrogen Release and Reactivity of Ammonia Borane." Angewandte Chemie International Edition, 2005, pp. 3378-3582.

22. M. Diwan, D. Hanna, and A. Varma, "Method to release hydrogen from ammonia borane for portable fuel cell applications." International Journal of Hydrogen Energy, Vol. 35, 2009, pp. 577 584.

23. C.F. Yao, L. Zhuang, Y.L. Cao, X.P. Ai, and H.X. Yang, "Hydrogen release from hydrolysis of borazane on Pt- and Ni-based alloy catalysts." International Journal of Hydrogen Energy, Vol. 33, No. 10, 2008, pp. 2462-2467.

24. D. S. Sundaram, V. Yang, Y. Huang, G. A. Risha, and R. A. Yetter, "Effects on particle size and pressure on combustion of nano-aluminum particles and liquid water." Combustion and Flame, Vol. 160, No. 10, 2013, pp. 2251-2259.

25. S.H. Hong, H. J. Kim, and M. Youp, "Rate enhancement of hydrogen generation through the reaction of magnesium hydride with water by $\mathrm{MgO}$ addition and ball milling." Journal of Industrial and Engineering Chemistry, Vol. 18, No. 1, 2012, pp. 405-408.

26. S. Elitzur, V. Rosenband, and A. Gany, "Study of hydrogen production and storage based on aluminum water reaction." International Journal of Hydrogen Energy, Vol. 39, No. 12, 2014, pp. 6328-6334.

27. E. Shafirovich, V. Diakov, and A. Varma, "Combustion-assisted hydrolysis of sodium borohydride for hydrogen generation." International Journal of Hydrogen Energy, Vol. 32, 2006, pp. 207-211.

28. Y. Aly, M. Schoenitz, and E. Dreizin, "Ignition and combustion of mechanically alloyed Al-Mg powders with customized particle sizes." Combustion and Flame, Vol. 160, No. 4, 2013, pp. 835842. 29. E. Dreizin, and Y. L. Shoshin, "Particle combustion rates for mechanically alloyed Al-Ti and aluminum powders in burning air." Combustion and Flame, Vol. 145, No. 4, 2006, pp. 714 722.

30. Y. Aly, V. Hoffman, M. Schoenitz, and E. Dreizin Reactive, "Mechanically Alloyed A1/Mg powders with Customized particle sizes and compositions." Journal of Propulsion and Power, Vol. 30, No. 1, 2014, pp. 96-104.

31. H.Habu, "Application of Magnalium to solid rocket propellant." Journal of Japan Institute of Light Metals, 2008, pp. 162-166.

32. A. E. Sytschev, S. G. Vadchenko, O. K. Kamynina, and N. V. Sachkova, " Simultaneous synthesis and joining of a Ni-Al-Based layer to a Mo foil by SHS." International Journal of SHS, Vol. 18, No. 3, 2009, pp 213-216.

33. M. Schoenitz, S. Umbrajkar and E. Dreizin, "Kinetic analysis of thermite reactions in Al-MoO3 nanocomposites." Journal of Propulsion and Power, Vol. 23, No. 4. 2007, pp. 683-687.

34. S. Umbrajkar, S. Seshadri, M. Schoenitz, V. Hoffmann and E. Dreizin, "Aluminum-rich Al-MoO3 nanocomposite powders prepared by arrested reactive milling." Journal of Propulsion and Power, Vol. 24, No. 2,. 2008, pp. 192-198.

35. Y. Aly, V. Hoffmann, M. Schoenitz and E. Dreizin, "Ignition and combustion of mechanically alloyed Al-Mg powders with customized particle sizes." Combustion and Flame, Vol. 160, No. 4, 2013, pp. 835-842.

36. M. Trunov, V. Hoffmann, M. Schoenitz and E. Dreizin, "Combustion of boron-titanium nanocomposite powders." Journal of Propulsion and Power, Vol. 24, No. 2. 2008, pp. 184-191.

37. G.A Risha, S. F. Son, R.A. Yetter, V. Yang, and B.C Tappan, "Combustion of nano-aluminum and liquid water." Proceedings of the Combustion Institute, Vol. 31, No. 2, 2006, pp. 2029-2036. 
38. H. T. Hwang, A. Al-Kukhum, and A. Varma, "High and rapid hydrogen release from thermolysis of ammonia borane near PEM fuel cell operating temperatures." International Journal of Hydrogen Energy, Vol. 37, No. 3, 2012, pp. 2407-2411.

39. M. E. Bluhm, M. G. Bradley, R. Butterick, U. Kusari, and G. Larry, "Amineborane-Based Chemical Hydrogen Storage: Enhanced Ammonia Borane Dehydrogenation in Ionic Liquids." Journal of the American Chemical Society, 2006, pp. 7748-7749.

40. M. Bowden, T. Kemmit, W. Shaw, N. Hess, J. Linehan, M. Gutowski, B. Schmid, and T. Autrey, "Mechanistic Studies of Hydrogen Release from Solid Amine Borane Materials." Materials Research Society, Vol. 927, 2006.

41. J. Larminie and A. Dicks, "Fuel cell systems explained", Wiley, Chichester, UK, 2003.

42. S. Satyapal, J. Petrovic, C. Read, G. Thomas, and G. Ordaz, "Progress towards meeting hydrogenpowered vehicle requirements." Catalysis Today, Vol. 120, Nos. 3-4, 2007, pp. 246-256.

43. M. Umbrajkar, R. Broad, M. Trunov, M. Schoenitz, and E. Dreizin, "Arrested reactive milling synthesis and characterization of sodium-nitrate based reactive composites," Propellants, Explosives and Pyrotechnics, Vol. 32, No. 1, 2007, pp. 32-41.

44. H.C. Kelly and V.B. Marriott, "Reexamination of the mechanism of acid-catalyzed amine-borane hydrolysis. The hydrolysis of ammonia borane." Inorganic Chemistry, 1979, pp. 2875-2878.

45. L. Schlapbach and A.Zuttel, "Hydrogen-storage materials for mobile applications." Nature, Vol. 414, 2001, pp. 353-358. 


\section{Appendix}

\section{Thermodynamic Calculations}

The following figures show the calculated adiabatic flame temperatures and product gases mole fractions (including hydrogen) in the combustion products $v s$ the additive mass fraction for the mixtures of ammonia borane with additives.

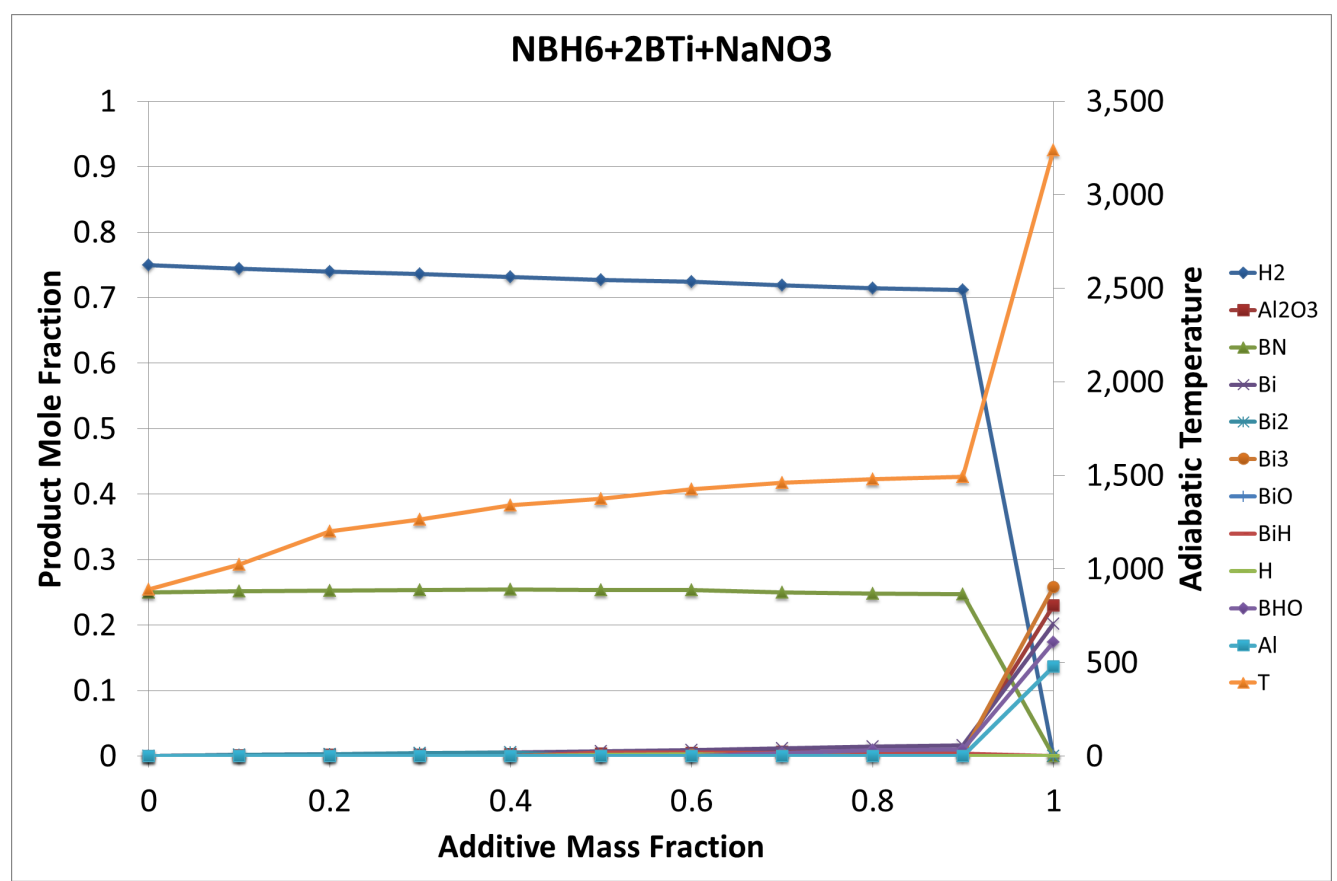



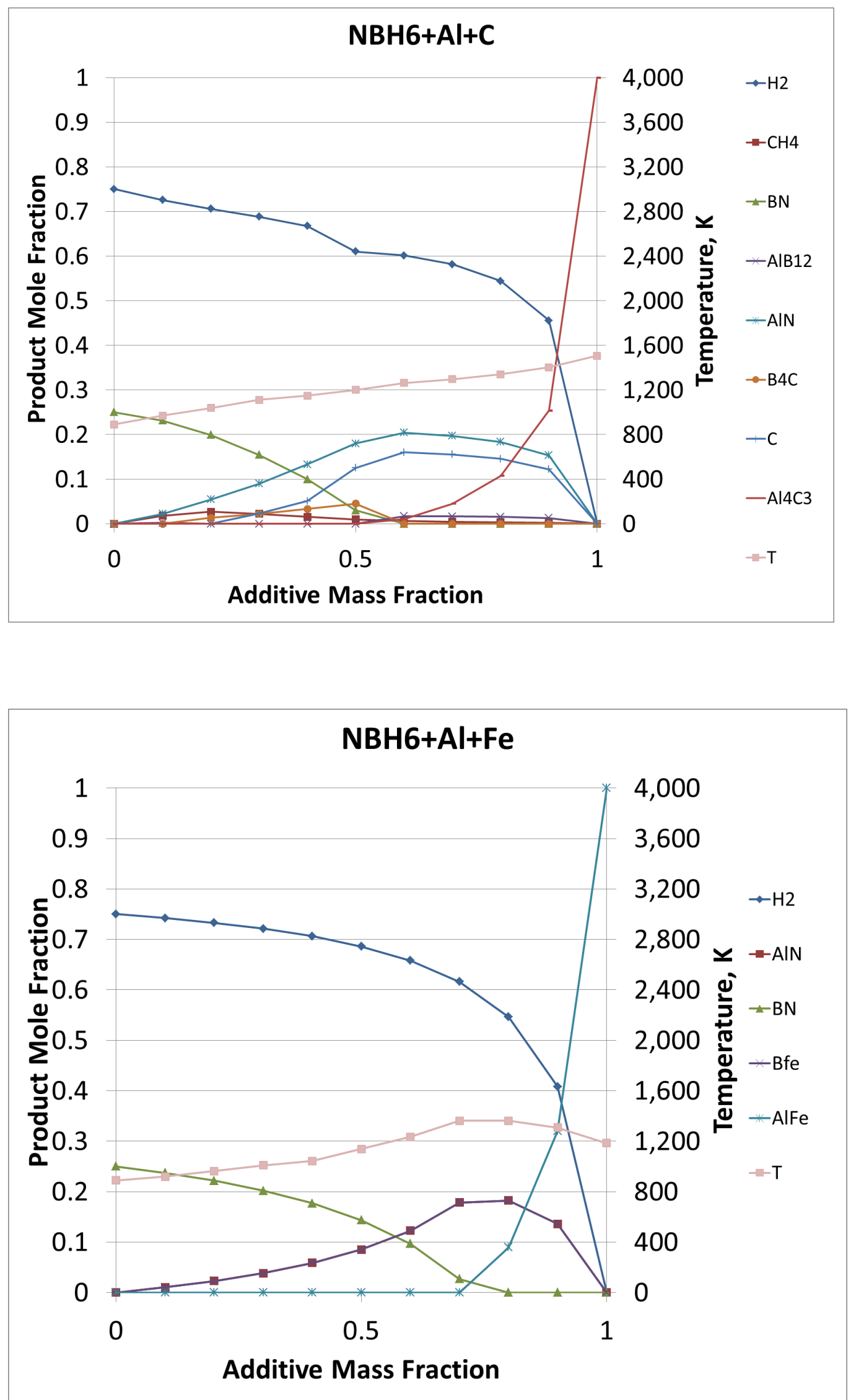


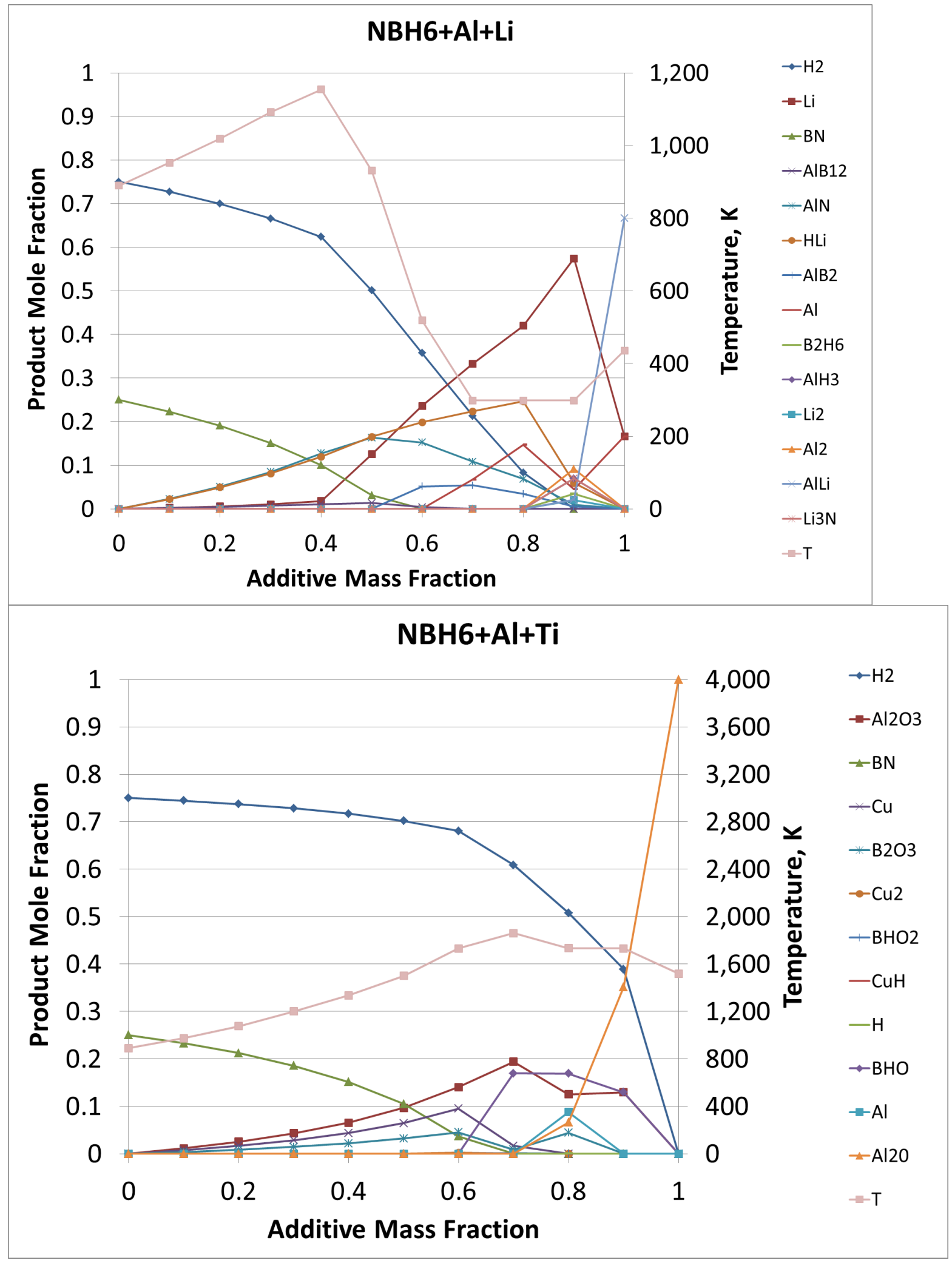



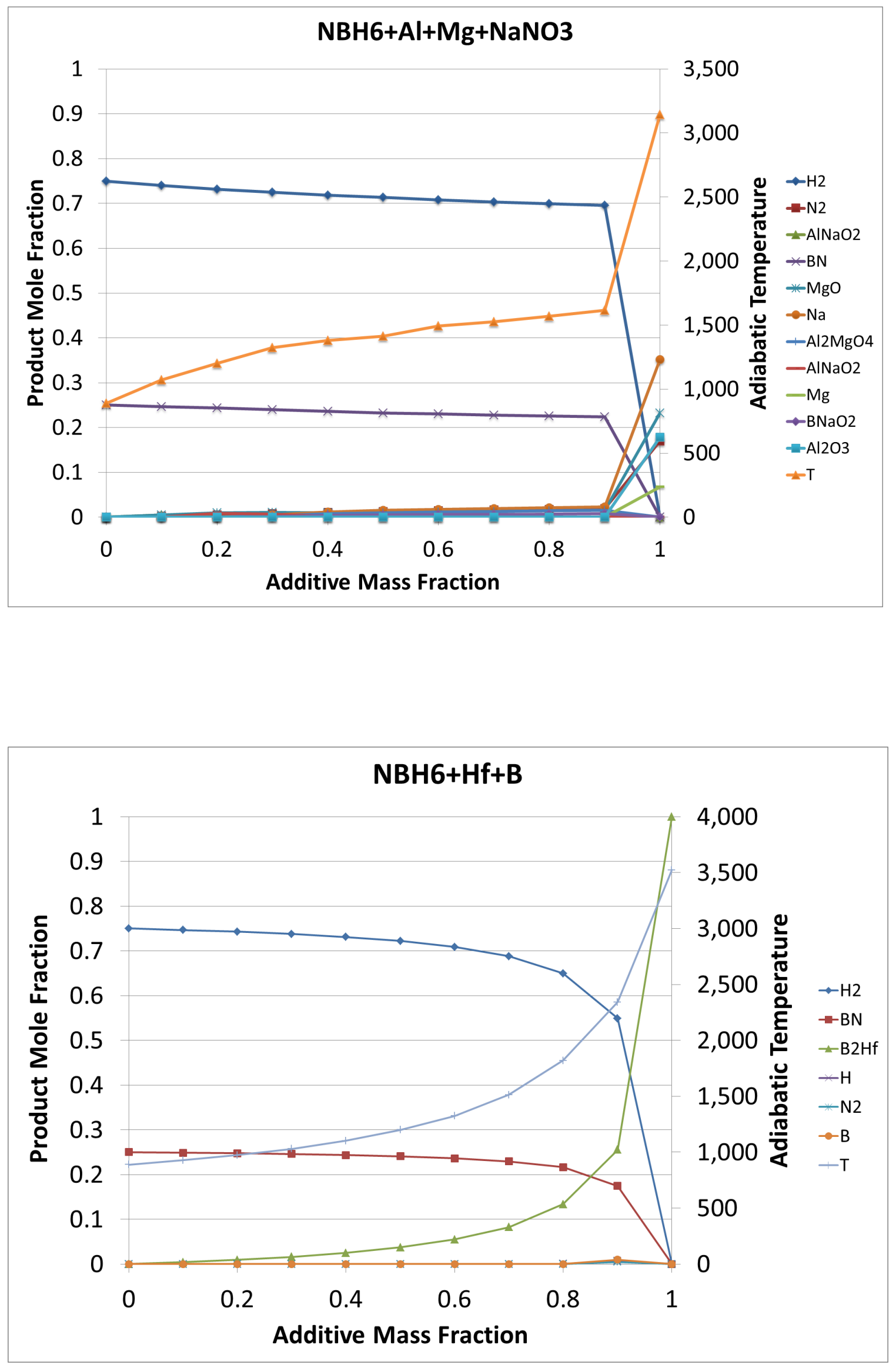

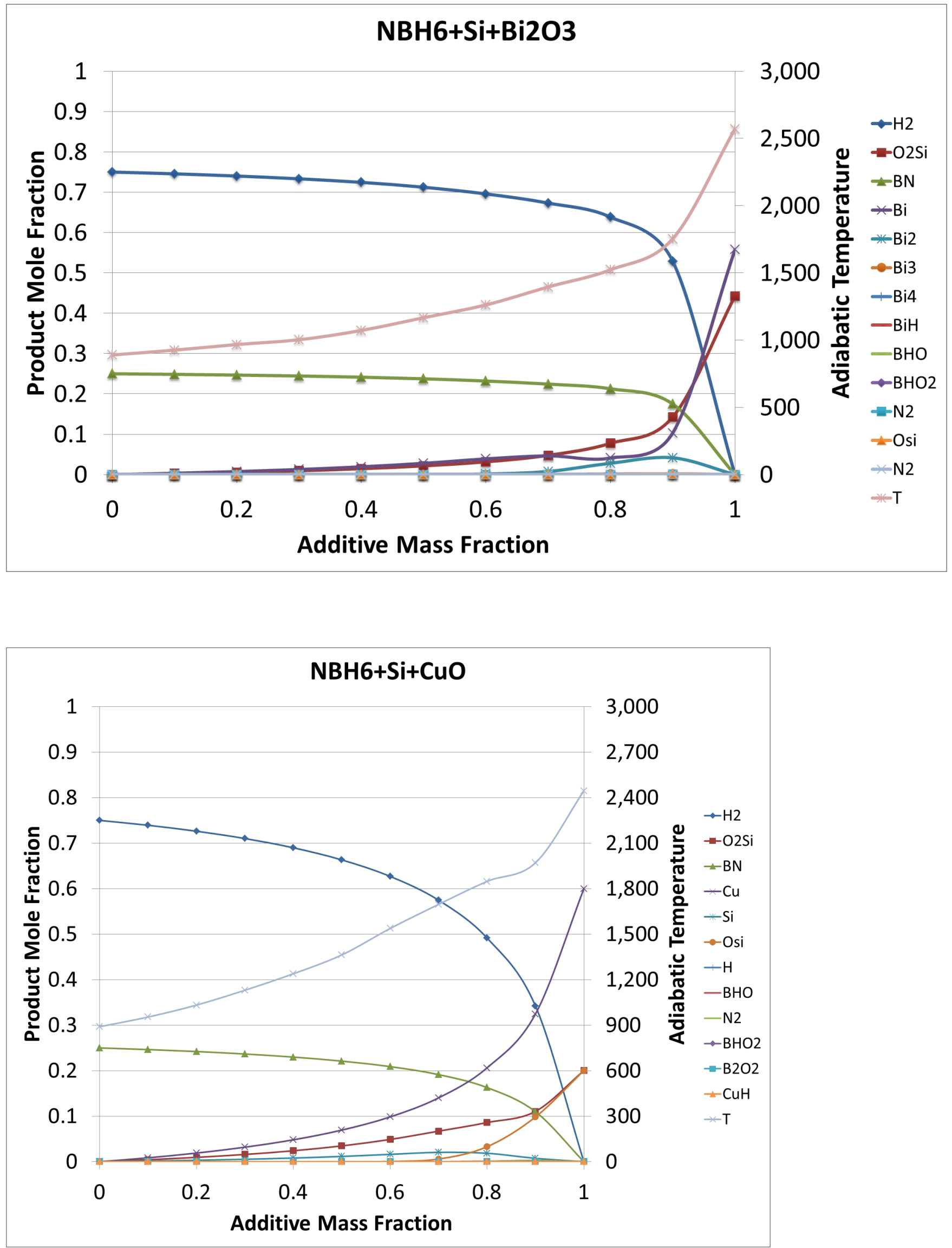

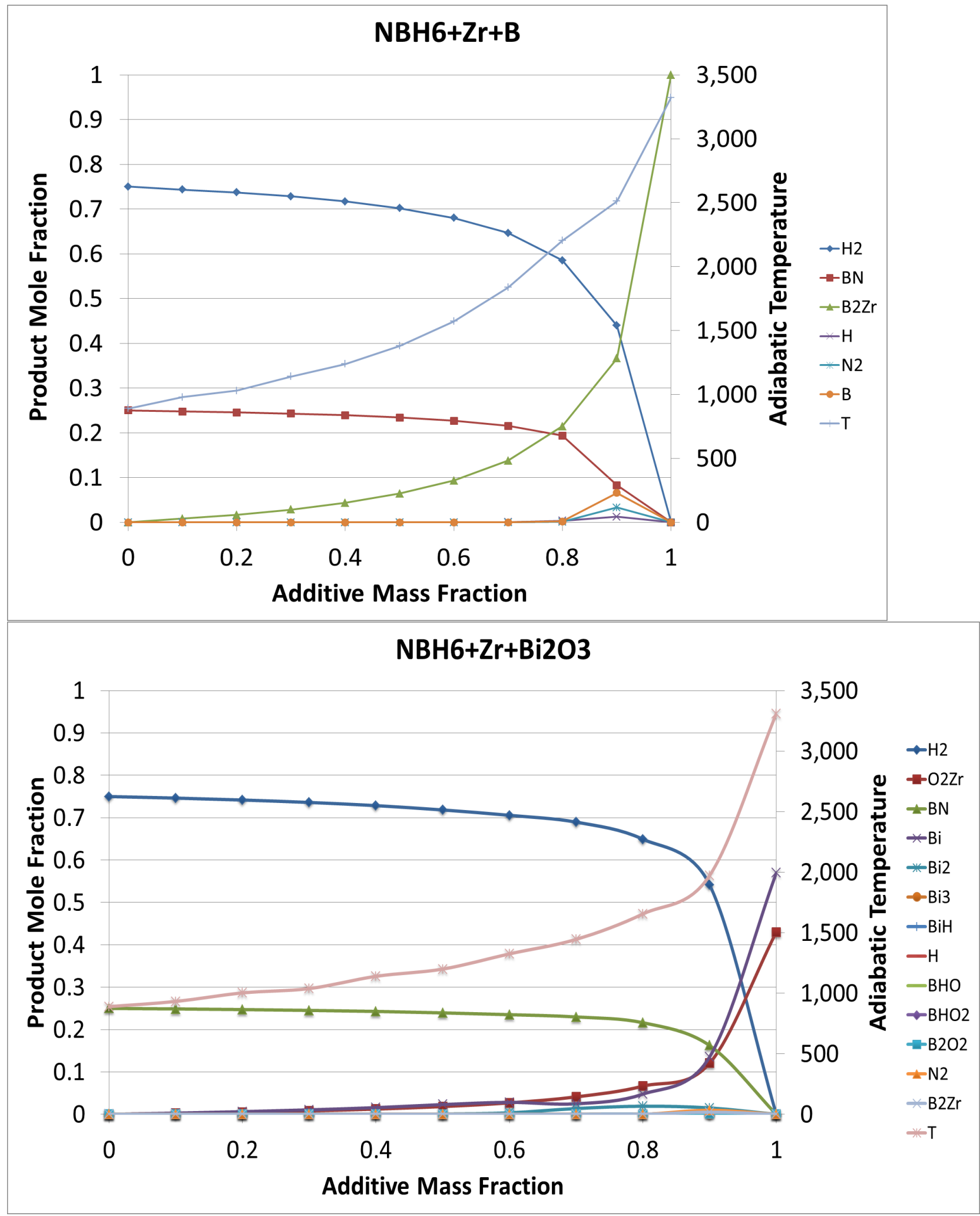


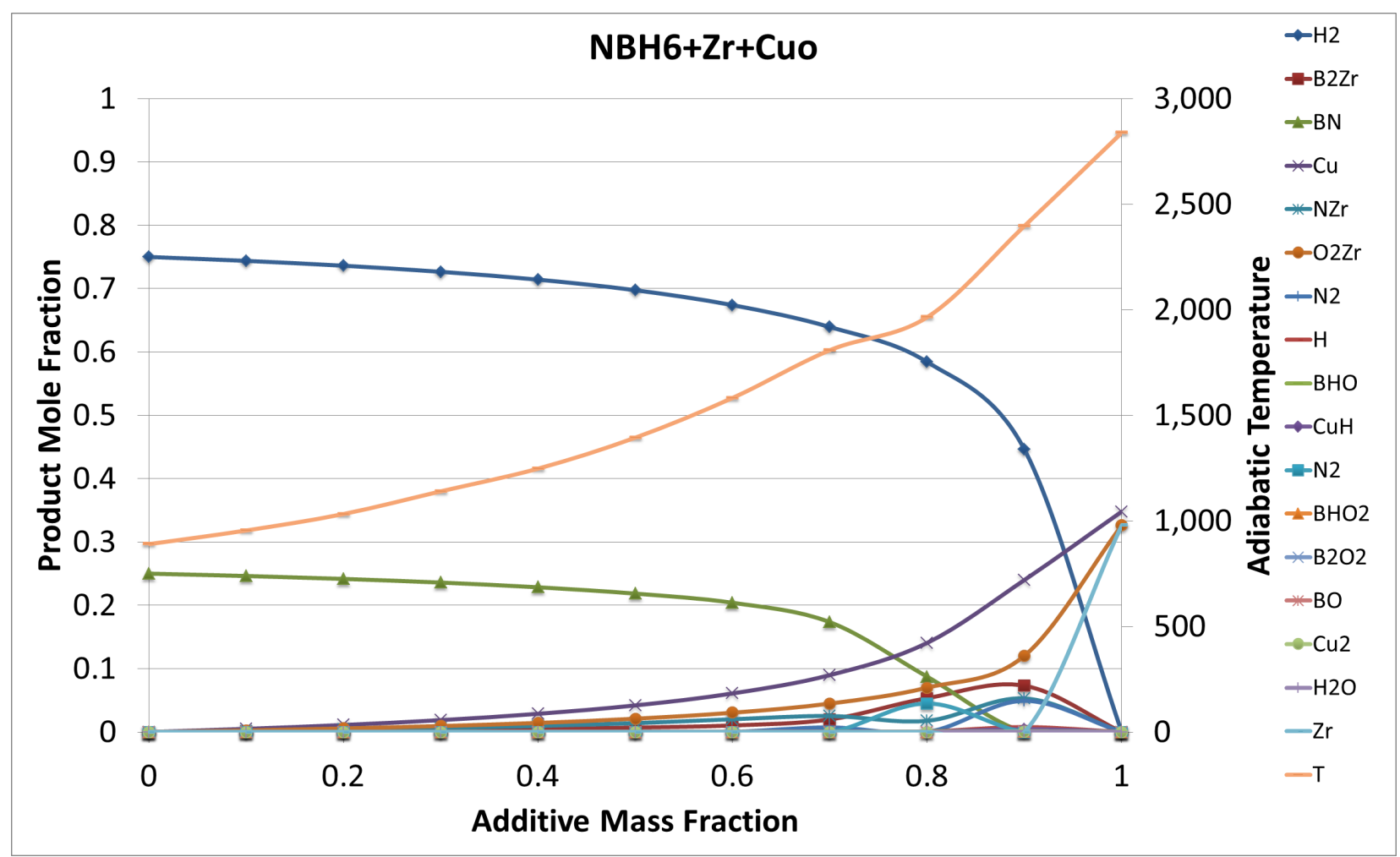



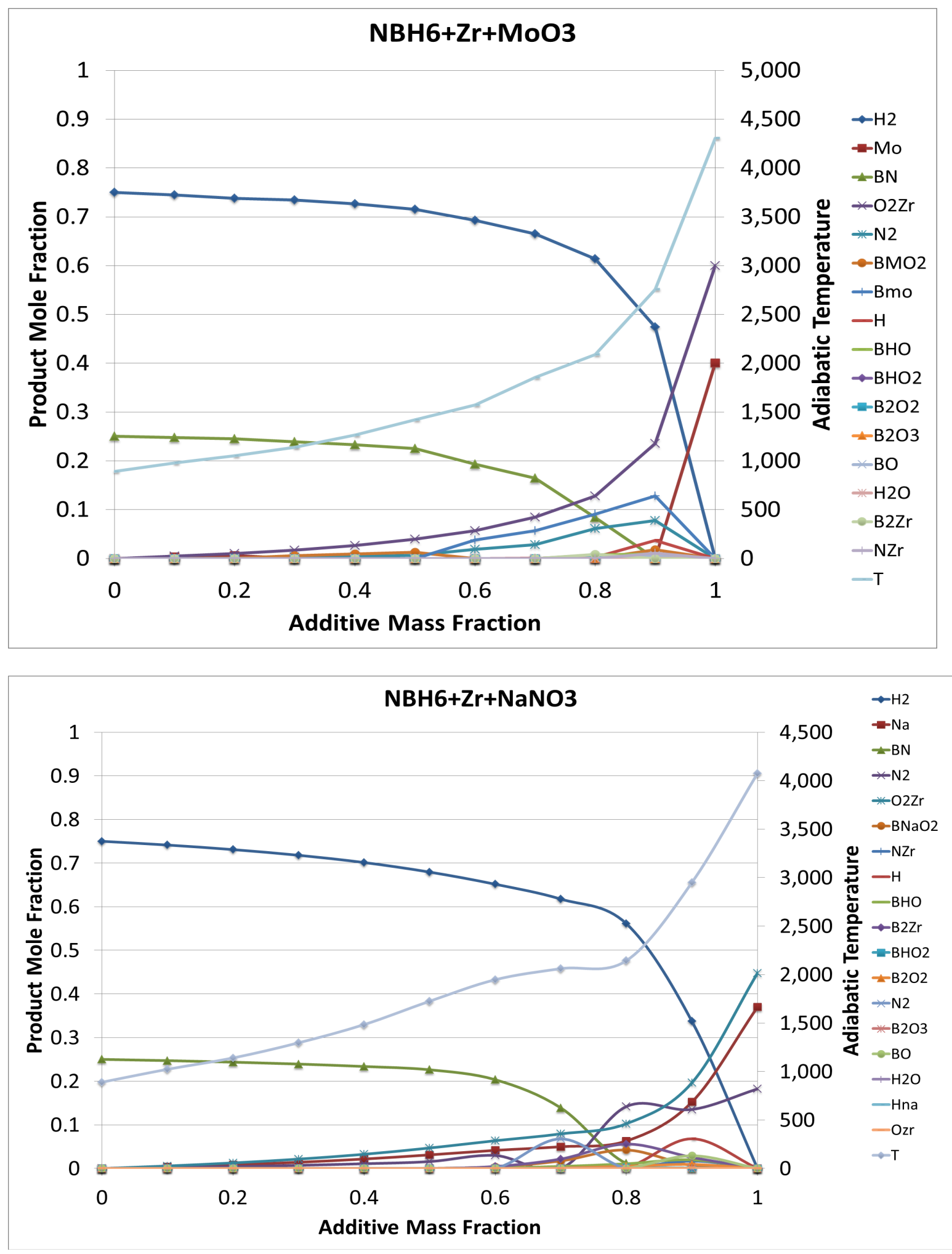

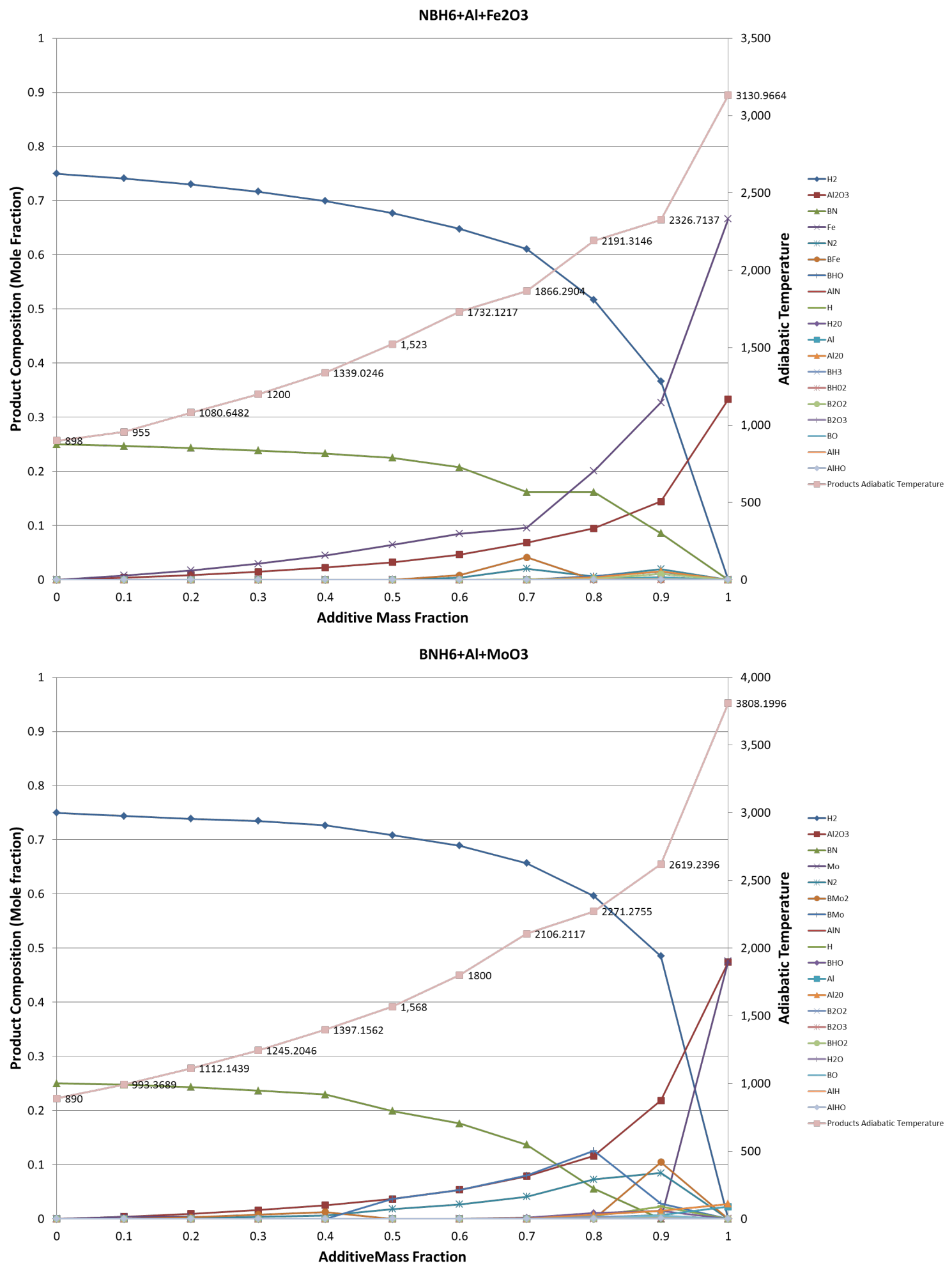
NBH6+Al+Bi2O3
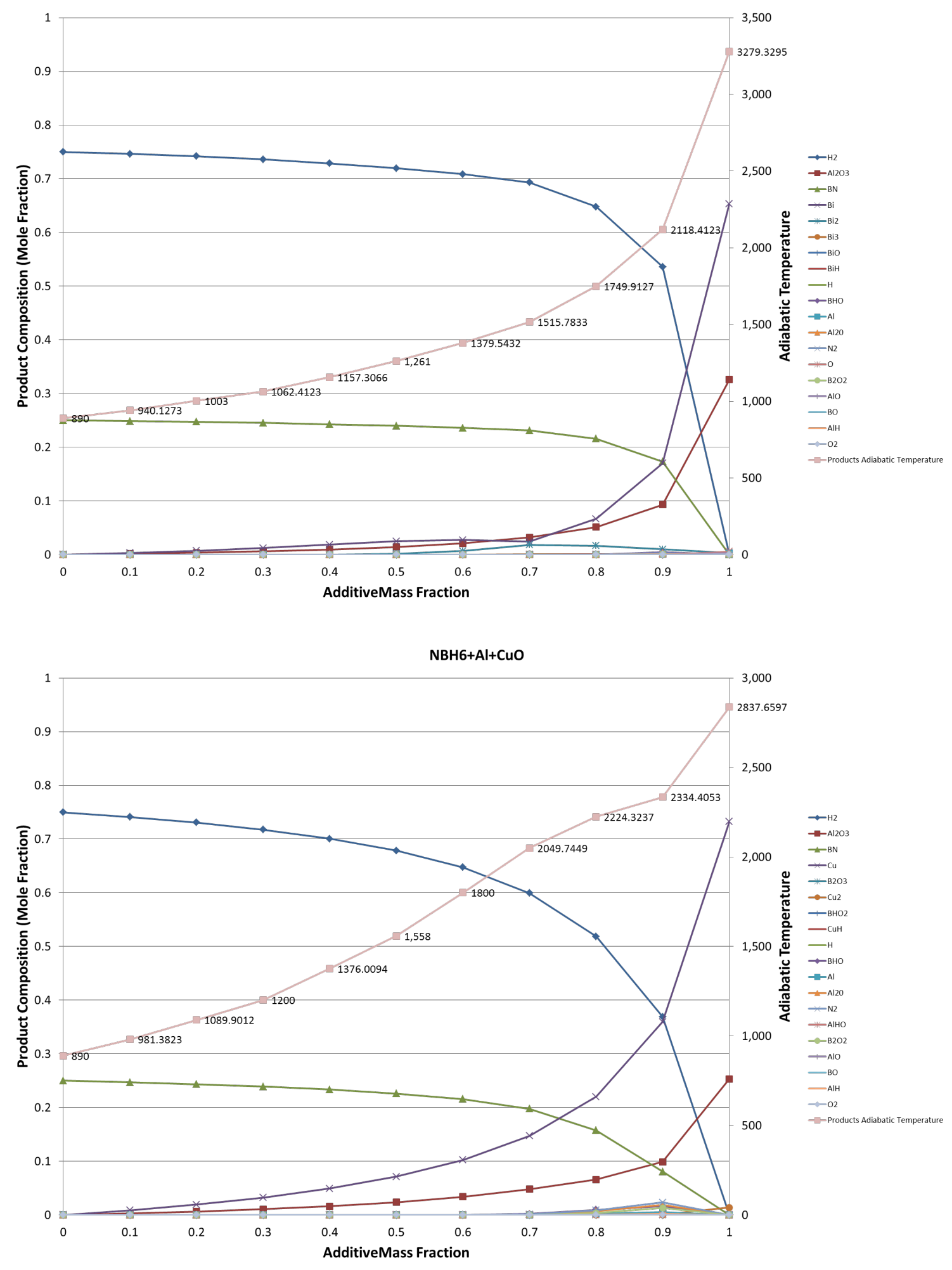
NBH6+Al+WO3
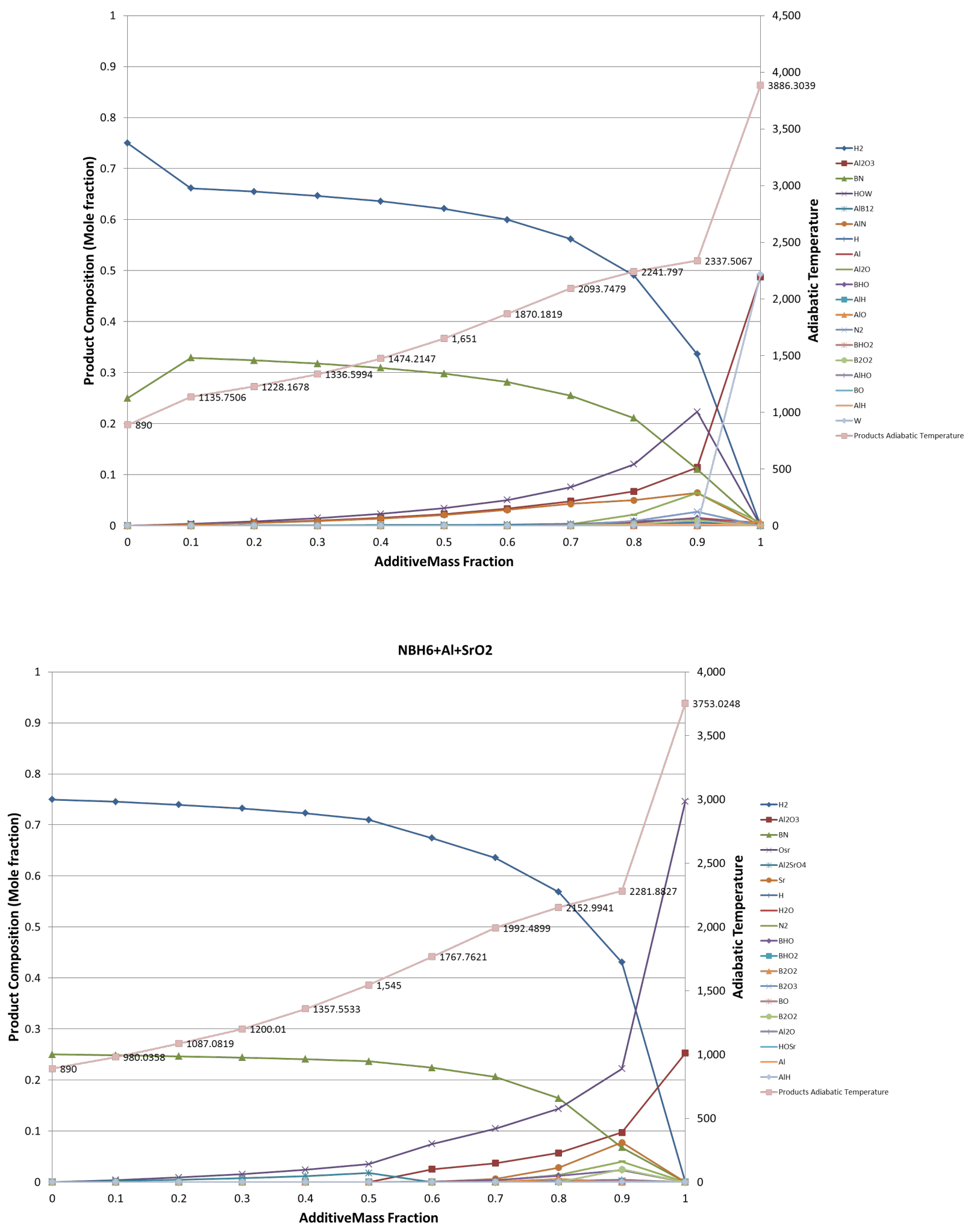
NBH6+Al+NaNO3

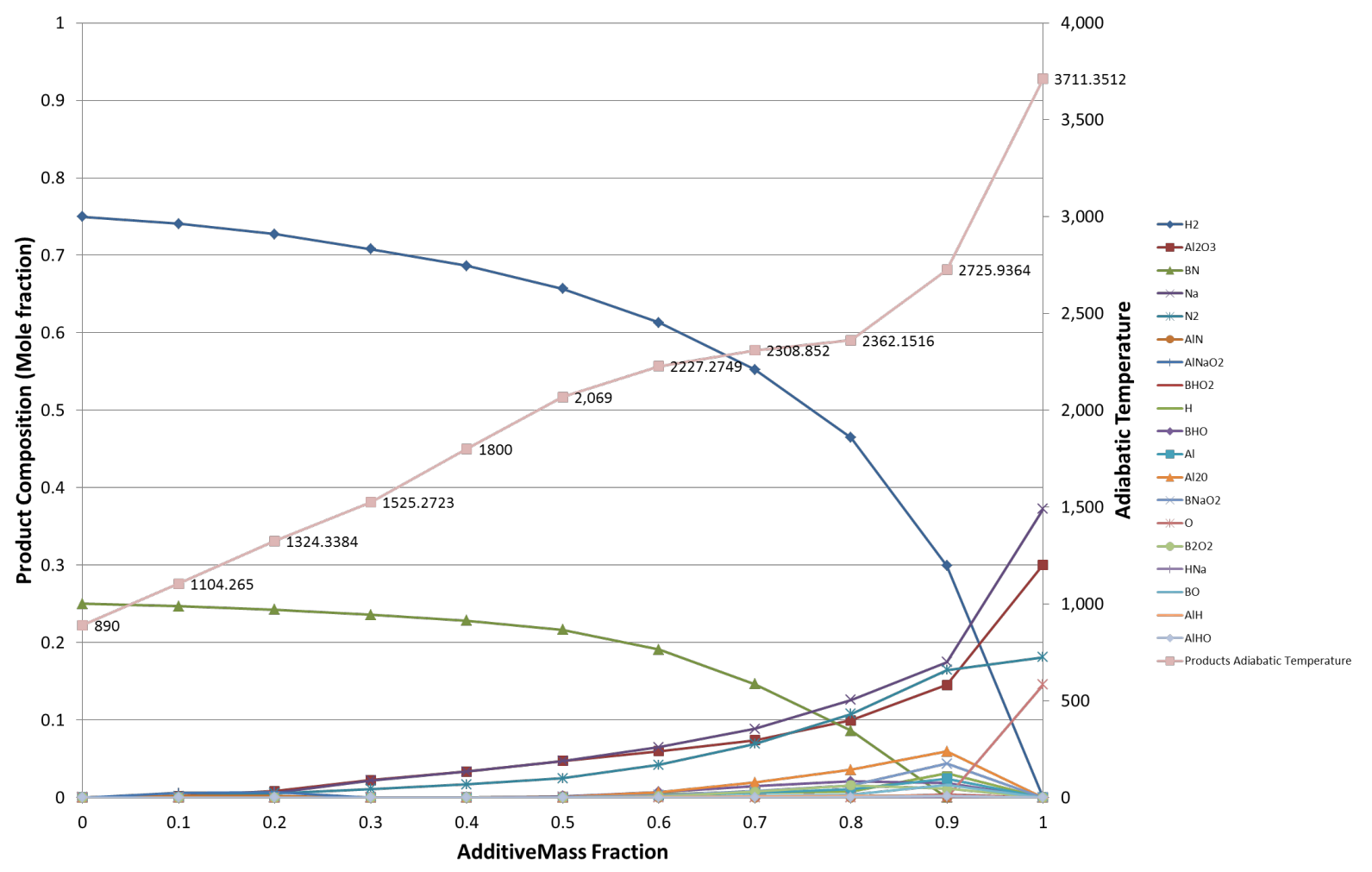




\section{Vita}

Daniel Rodriguez was born in El Paso, TX in 1988. He did his basic education in Cd. Juarez, Mexico. Then he pursued a college education at the University of Texas at El Paso, in August 2007. Daniel's first internship was at the Lawrence Livermore National Laboratory (LLNL) where he wrote in conjunction with Dr. Evgeny Shafirovich, Marco Machado, and Jose Luis Mena a report titled "A review of Underground Coal Gasification Field Tests Sponsored by the U.S Department of Energy." In addition, some improvements to an algorithm named UCG-MEEE were accomplished during this internship. In May 2012, Daniel received his B.S. degree in Mechanical Engineering. In summer 2012, Daniel pursued his M.S degree at UTEP and became a member of Dr. Shafirovich's research team, where he worked for a Department of Defense sponsored project on gas generators. Daniel has attended several conferences such as the $51^{\text {st }}$ AIAA Aerospace Sciences Meeting and the 2014 Spring Technical Meeting of the Central States Section of the Combustion Institute and presented his current research project. He also co-authored a paper titled "Nanocomposite and Mechanically Alloyed Reactive Materials as Energetic Additives in Chemical Oxygen Generators," which is currently in press in Combustion and Flame journal. Daniel passed the FE exam and is currently an Engineer in training.

Permanent address: 4111 Westcity ct apt \# 69

El Paso, TX 79902

This thesis/dissertation was typed by Daniel Rodriguez. 